\title{
37. PALEOMAGNETIC RESULTS, MIDDLE AMERICA TRENCH OFF MEXICO DEEP SEA DRILLING PROJECT LEG 66 $^{1}$
}

\author{
Nobuaki Niitsuma, Institute of Geosciences, Shizuoka University, 422 Shizuoka, Japan
}

\section{INTRODUCTION}

This chapter describes the results of a shipboard and shore-based paleomagnetic study of sediments and basement rocks recovered from the outer rise, lower and upper continental slope, Middle America Trench off Mexico (Fig. 1) during Leg 66 of the International Phase of Ocean Drilling of the Deep Sea Drilling Project. The purpose of examining sedimentary sequences is to obtain reliable paleomagnetic data, to establish the magnetostratigraphy of the drilled sediments, and to determine bedding dips and fault planes. Dating sedimentary sequences by means of magnetostratigraphy provides data about the sedimentation rate and the accretionary process along the trench and in the forearc area. Determining the position of geologic structures according to orientation of sedimentary layers and faults provides fundamental information for a reconstruction of the tectonic evolution of this area. I compare magnetic properties of basement rocks with opaque mineral composition of the rocks and ocean magnetic anomalies.

\section{METHODS}

\section{Paleomagnetic Techniques}

Remanent magnetization of sediment and rock samples was measured with a Digico balanced fluxgate rock magnetometer, calibrated frequently with a shipboard standard. Sensitivity of the magnetometer is inversely proportional to temperature; the negative gradient was $1 \% / 1^{\circ} \mathrm{C}$ for a standard sample $10^{-3}$ to $10^{-4} \mathrm{emu} / \mathrm{cc}$ in intensity. For samples $10^{-6} \mathrm{emu} / \mathrm{cc}$, there was a negative correlation between sensitivity and temperature, but the linear relationship was disturbed by a fluctuation in sensitivity of a factor of 2 . For the samples of less intensity than $10^{-7} \mathrm{emu} / \mathrm{cc}$, there were fluctuations of sensitivity beyond one order of magnitude or more in a linear relationship. Perhaps this fluctuation is one of the causes of the wide range in noise level $(1 \times$ $10^{-7}$ to $1 \times 10^{-9} \mathrm{emu} / \mathrm{cc}$ ). Error in direction of remanent magnetization is less than $4^{\circ}$.

I used a Schonstedt A.C. geophysical specimen demagnetizer (Model GSD-1) for alternating field (AF) demagnetization of the samples. With this single axis system demagnetizer, every sample was demagnetized three times, around three orthogonal axes.

A Bison magnetic susceptibility system (Model 3101) was used to measure initial sample susceptibility. Susceptibility was corrected for sample length.

The samples were thermomagnetically analyzed at the Institute of Geosciences, Shizuoka University, with a modified Hirone-type automatic thermomagnetic balance, which records changes in saturation magnetization $(J s)$ and weight of sample with temperature $(T)$ changes. Samples were chips of rock weighing 100 to $400 \mathrm{mg}$. A field of 5000 Oe was applied during the heating and cooling cycles, but every $5 \mathrm{~min}$. the magnetic field was reduced to zero for $30 \mathrm{~s}$ to weigh the sample. The heating and cooling rate was $500^{\circ} \mathrm{C} / \mathrm{hr}$., and the sample was heated in a vacuum of $10^{-4}$ torr.

\footnotetext{
${ }^{1}$ Initial Reports of the Deep Sea Drilling Project, Volume 66.
}

\author{
Sampling Procedure
}

Paleomagnetic samples were taken from unconsolidated and semiconsolidated sediments in the upper parts of the cores by inserting plastic tubes $2.5 \mathrm{~cm}$ across and $2.2 \mathrm{~cm}$ long into the split sections. The direction of the split planes were determined by continuous marks on the 9.5-meter plastic liners. In more lithified materials at deeper levels, cylindrical samples of diameter $2.5 \mathrm{~cm}$ were taken from the split core sections with a diamond corer ("minicore drill"). An orientation was marked with an arrow in the uphole direction on every sample before it was removed from the split core section. When we encountered the inclined bedding, we measured the inclination of bedding plane carefully against the split plane.

In soft, soupy sediments of the upper 20 meters of holes, it was difficult to find original sedimentary structures. From 20 to 80 meters the cored sediments were disturbed along the core liner with marginal laminations concave downward. Below sub-bottom depths of 50 to 200 meters, sediments are broken into pieces several centimeters long which were twisted during drilling rotation. I collected 531 oriented sediment samples selectively from less disturbed parts of cores, especially in the lower part of cores. I took 15 samples of basement rocks, 8 of which were oriented, with a "minicore drill," except for metamorphic rock in Hole 489A for which I used a diamond saw.

\section{REMANENT MAGNETIZATION OF SEDIMENTS}

\section{Stability Test of Sediments by AF Demagnetization}

The first step in a paleomagnetic study is to eliminate overprinted remanent magnetization from natural remanent magnetization. There are two possible overprinted components in sediment samples: chemical remanent magnetization of goethite and a soft component of remanent magnetization (Niitsuma, 1977). The chemical overprint is caused by precipitation of goethite in an oxidizing atmosphere after deposition of sediments. In this study we can ignore chemical overprint, because the samples were stored in nonoxidizing seawater.

Sediments acquire the soft component of remanent magnetization, consisting of viscous and isothermal remanent magnetization, after deposition mostly in the present magnetic field, even in the course of drilling and sample treatment. The amount and property of the soft component are attributed to type and grain size of magnetic minerals. Because AF demagnetization is effective for analyzing the soft component in remanent magnetization, it is also a check for reliability of remanent magnetization in the paleomagnetic investigation.

As pilot samples from each site, 20 sediment samples were demagnetized in an alternating field increased stepwise. These samples were classified into seven types according to the reaction of remanent magnetization during demagnetization (Figs. 2, 18, and Table 1). Applied AF was 50,100,150,200, and 250 Oe.

Type A. This type is characteristic of samples from the outer rise at Site 487. The sediments consist of hemi- 


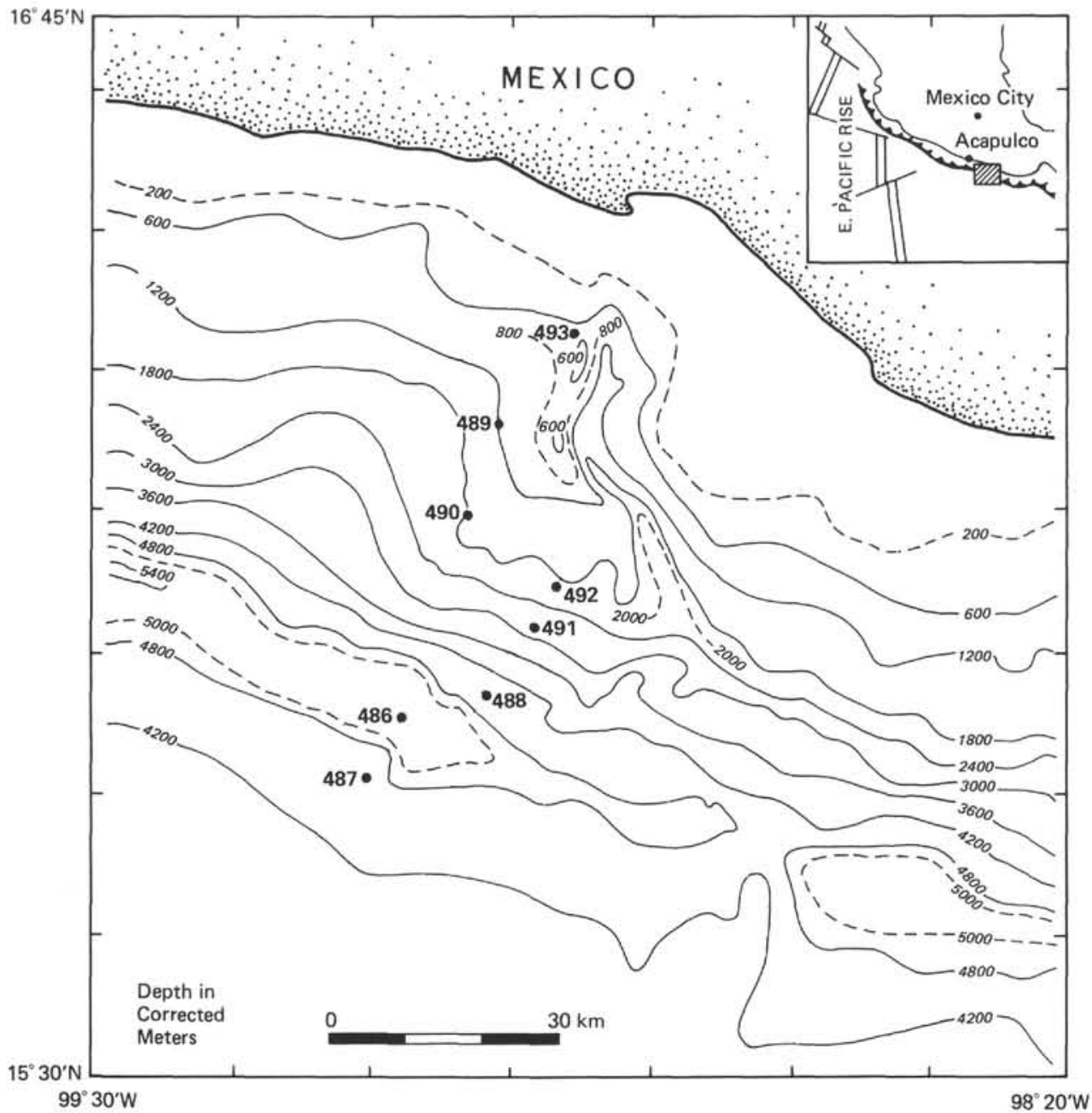

Figure 1. Location of Leg 66 sites.

pelagic mud and brown pelagic clay. Change in direction by $\mathrm{AF}$ demagnetization is larger than $20^{\circ}$ between 50 and $100 \mathrm{Oe}$, which is plotted at $75 \mathrm{Oe}$ on the horizontal coordinate in the lower graph of Figure 2, and less than $7^{\circ}$ above $100 \mathrm{Oe}$, the direction becoming stable. Intensity decreases by less than one order by 50 and $100 \mathrm{Oe} \mathrm{AF}$ demagnetization but does not change above 100 Oe. Magnetization of Type A samples is reliable for paleomagnetism after 100 - or 150 -Oe AF demagnetization.

Type $T$. This type characterizes samples from the lower slope, Sites 488, 491, and 492. Samples of this type consist of muddy silt and muddy siltstone and are from sandy intervals which probably originated in turbidity currents along the Middle America Trench. Change in direction of remanent magnetization was less than $14^{\circ}$ through all steps of AF demagnetization. Intensity does not change except in Hole 488 (280.32 m sub-bottom), where sample intensity increases at 150 and $200 \mathrm{Oe}$. Intensity of samples ranges from $2 \times 10^{-7}$ to $5 \times 10^{-5} \mathrm{emu} / \mathrm{cc}$. Because the samples of Type T have stable magnetization, they provide reliable paleomagnetism data.

Type $P$. Samples of this type occurred in the upper part of the lower slope at Site 492. Direction of mag- netization changes between $10^{\circ}$ and $40^{\circ}$. A characteristic minimum value in direction of change occurs at 100 - and 150-Oe AF demagnetization. Intensity decrease is within a factor of 3 . Pyrite grains and pyrite nodules occur in the sediments including horizons of the present samples. The characteristic high peak in direction change at $200 \mathrm{Oe}$ also occurred in pyrite-rich metamorphic rock from a subdepth of 318.06 meters at Hole 489A. This type of magnetization is probably valid for paleomagnetism after 100 - or $150-\mathrm{Oe}$ AF demagnetization.

Type $G$. This type occurs in sediments from the upper part of the lower slope and the lower part of the upper slope at Sites 490 and 492 . Direction change attains a minimum value at $100 \mathrm{Oe}$ and increases suddenly at 150-Oe AF demagnetization. Changes in intensity of remanent magnetization range within a factor of 2 . Muddy silty and muddy siltstone of this type contain glauconitic sand grains.

Type $S$. This type occurs in muddy siltstone and mudstone samples from the upper slope at Sites 490 and 493. Intensity ranges from $1 \times 10^{-7}$ to $2 \times 10^{-6} \mathrm{emu} / \mathrm{cc}$ and decreases monotonously in AF demagnetization steps. The direction of remanent magnetization is relatively stable and changes less than $20^{\circ}$ through all steps. At 

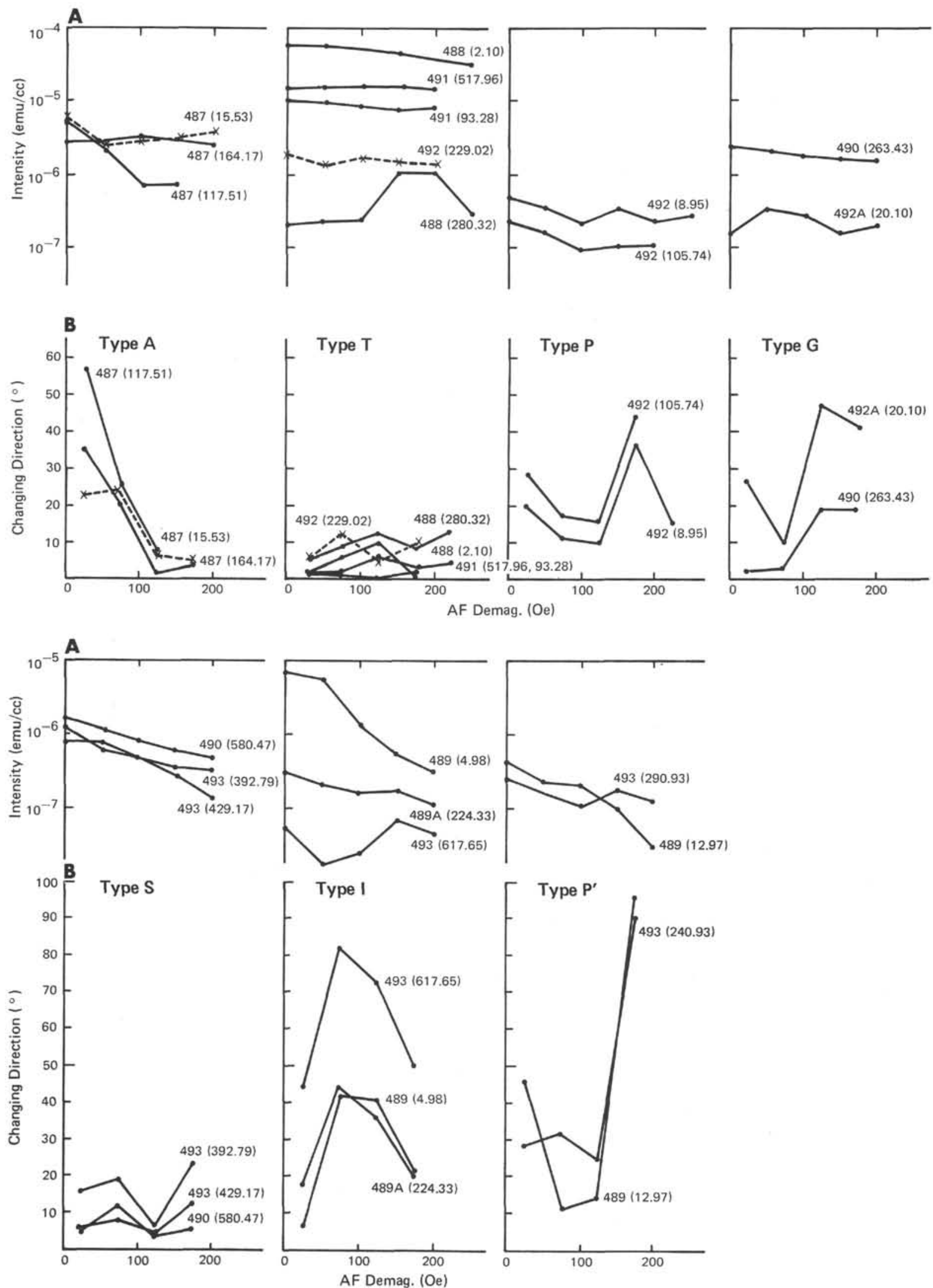

Figure 2. Reaction of remanent magnetization of sediment samples during stepwise AF demagnetization. A. Changes in intensity of remanent magnetization in logarithmic scale. B. Changes in direction of remanent magnetization with each AF demagnetization step. (Numbers in parentheses are meters sub-bottom.) 
Table 1. Remanent magnetization of selected sediment samples after stepwise AF demagnetization.

\begin{tabular}{|c|c|c|c|c|c|}
\hline Hole & Core & Section & $\begin{array}{c}\text { Interval } \\
(\mathrm{cm})\end{array}$ & $\begin{array}{l}\text { Sub-bottom } \\
\text { Depth } \\
\text { (m) }\end{array}$ & $\begin{array}{c}\mathrm{AF} \\
\text { Demag. } \\
\text { Field (Oe) }\end{array}$ \\
\hline 487 & 3 & 4 & $52.0-54.0$ & 15.53 & 0 \\
\hline & & & & & 50 \\
\hline & & & & & 100 \\
\hline & & & & & 150 \\
\hline & & & & & 200 \\
\hline & 14 & 2 & $100.0-102.0$ & 117.51 & 0 \\
\hline & & & & & 50 \\
\hline & & & & & 100 \\
\hline & & & & & 150 \\
\hline & 19 & 2 & $16.0-18.0$ & 164.17 & 0 \\
\hline & & & & & 50 \\
\hline & & & & & 100 \\
\hline & & & & & 150 \\
\hline & & & & & 200 \\
\hline 488 & 2 & 1 & $109.0-111.0$ & 2.10 & 0 \\
\hline & & & & & 50 \\
\hline & & & & & 100 \\
\hline & & & & & 150 \\
\hline & & & & & 200 \\
\hline & & & & & 250 \\
\hline & 31 & 3 & $131.0-133.0$ & 280.32 & 0 \\
\hline & & & & & 50 \\
\hline & & & & & 100 \\
\hline & & & & & 150 \\
\hline & & & & & 200 \\
\hline & & & & & 250 \\
\hline 489 & 1 & 4 & $47.0-49.0$ & 4.98 & 0 \\
\hline & & & & & 50 \\
\hline & & & & & 100 \\
\hline & & & & & 150 \\
\hline & & & & & 200 \\
\hline & 2 & 5 & $96.0-98.0$ & 12.97 & 0 \\
\hline & & & & & 50 \\
\hline & & & & & 100 \\
\hline & & & & & 150 \\
\hline & & & & & 200 \\
\hline $489 \mathrm{~A}$ & 23 & 5 & $132.0-134.0$ & 224.33 & 0 \\
\hline & & & & & 50 \\
\hline & & & & & 100 \\
\hline & & & & & 150 \\
\hline & & & & & 200 \\
\hline 490 & 1 & 4 & $95.0-97.0$ & 5.46 & 0 \\
\hline & & & & & 50 \\
\hline & & & & & 100 \\
\hline & & & & & 150 \\
\hline & & & & & 200 \\
\hline & 28 & 5 & $142.0-144.0$ & 263.43 & 0 \\
\hline & & & & & 50 \\
\hline & & & & & 100 \\
\hline & & & & & 150 \\
\hline & & & & & 200 \\
\hline & 64 & t & $146.0-148.0$ & 580.47 & 0 \\
\hline & & & & & 50 \\
\hline & & & & & 100 \\
\hline & & & & & 150 \\
\hline & & & & & 200 \\
\hline 491 & 10 & 5 & $127.0-129.0$ & 93.28 & 0 \\
\hline & & & & & 50 \\
\hline & & & & & 100 \\
\hline & & & & & 150 \\
\hline & & & & & 200 \\
\hline & 57 & 3 & $145.0-147.0$ & 517.96 & 0 \\
\hline & & & & & 50 \\
\hline & & & & & 100 \\
\hline & & & & & 150 \\
\hline & & & & & 200 \\
\hline 492 & 2 & 4 & $94.0-96.0$ & 8.95 & 0 \\
\hline & & & & & 50 \\
\hline & & & & & 100 \\
\hline & & & & & 150 \\
\hline & & & & & 200 \\
\hline & & & & & 250 \\
\hline & 12 & 5 & $123.0-125.0$ & 105.74 & 0 \\
\hline & & & & & 50 \\
\hline & & & & & 100 \\
\hline & & & & & 150 \\
\hline & & & & & 200 \\
\hline & 25 & 5 & $101.0-103.0$ & 229.02 & 0 \\
\hline & & & & & 50 \\
\hline & & & & & 100 \\
\hline & & & & & 150 \\
\hline & & & & & 200 \\
\hline $492 \mathrm{~A}$ & 4 & 2 & $9.0-11.0$ & 20.10 & 0 \\
\hline & & & & & 50 \\
\hline & & & & & 100 \\
\hline & & & & & 150 \\
\hline & & & & & 200 \\
\hline & 6 & 1 & $68.0-70.0$ & 28.69 & 0 \\
\hline & & & & & 50 \\
\hline & & & & & 100 \\
\hline & & & & & 150 \\
\hline & & & & & 200 \\
\hline
\end{tabular}


Table 1. (Continued).

\begin{tabular}{|c|c|c|c|c|c|c|c|c|c|}
\hline Hole & Core & Section & $\begin{array}{l}\text { Interval } \\
(\mathrm{cm})\end{array}$ & $\begin{array}{l}\text { Sub-bottom } \\
\text { Depth } \\
\text { (m) }\end{array}$ & $\begin{array}{c}\text { AF } \\
\text { Demag. } \\
\text { Field (Oe) }\end{array}$ & $\begin{array}{c}\text { Relative } \\
\text { Declination }\end{array}$ & Inclination & $\begin{array}{c}\text { Intensity } \\
\left(\times 10^{-6} \mathrm{emu} / \mathrm{cc}\right)\end{array}$ & Remarks \\
\hline \multirow[t]{20}{*}{493} & \multirow[t]{5}{*}{14} & \multirow[t]{5}{*}{5} & \multirow[t]{5}{*}{$92.0-94.0$} & \multirow[t]{5}{*}{240.93} & 0 & 17.1 & 74.1 & 0.255 & \multirow[t]{5}{*}{ Type S } \\
\hline & & & & & so & 47.0 & 49.4 & 0.169 & \\
\hline & & & & & 100 & 8.7 & 34.7 & 0.107 & \\
\hline & & & & & 150 & 347.2 & 19.6 & 0.179 & \\
\hline & & & & & 200 & 55.7 & -46.6 & 0.126 & \\
\hline & \multirow[t]{5}{*}{30} & \multirow[t]{5}{*}{5} & \multirow{5}{*}{$78.0-80.0$} & \multirow{5}{*}{392.79} & 0 & 78.8 & 69.2 & 1.241 & \multirow[t]{5}{*}{ Type S } \\
\hline & & & & & 50 & 67.0 & 54.4 & 0.621 & \\
\hline & & & & & 100 & 93.9 & 69.1 & 0.466 & \\
\hline & & & & & 150 & 110.4 & 66.9 & 0.374 & \\
\hline & & & & & 200 & 146.5 & 51.6 & 0.327 & \\
\hline & \multirow[t]{5}{*}{34} & \multirow[t]{5}{*}{4} & \multirow[t]{5}{*}{$66.0-68.0$} & \multirow[t]{5}{*}{429.17} & 0 & 251.6 & 46.6 & 0.837 & \multirow[t]{5}{*}{ Type S } \\
\hline & & & & & so & 252.2 & 41.6 & 0.775 & \\
\hline & & & & & 100 & 253.4 & 49.4 & 0.491 & \\
\hline & & & & & 150 & 249.0 & 46.0 & 0.281 & \\
\hline & & & & & 200 & 236.8 & 55.6 & 0.134 & \\
\hline & \multirow[t]{5}{*}{54} & \multirow[t]{5}{*}{3} & \multirow[t]{5}{*}{$64.0-66.0$} & \multirow[t]{5}{*}{617.65} & 0 & 154.4 & 60.4 & 0.055 & \multirow[t]{5}{*}{ Type I } \\
\hline & & & & & 50 & 117.4 & 24.1 & 0.017 & \\
\hline & & & & & 100 & 257.5 & 68.9 & 0.025 & \\
\hline & & & & & 150 & 137.5 & 29.4 & 0.070 & \\
\hline & & & & & 200 & 148.2 & -19.6 & 0.047 & \\
\hline
\end{tabular}

150 Oe the direction change is minimum-less than $7^{\circ}$. The remanent magnetization after 150-Oe AF demagnetization represents reliable paleomagnetic data.

Type $I$. This type occurs in muddy silt and muddy siltstone samples from the upper slope at Sites 489 and 493. Change in direction reaches a peak of more than $40^{\circ}$ at 100 and $150 \mathrm{Oe}$. Intensity ranges from $2 \times 10^{-8}$ to $7 \times 10^{-6} \mathrm{emu} / \mathrm{cc}$. This type of direction change is also found in ilmenite-rich plutonic rock from Site 493. For the paleomagnetic study, 150-Oe AF demagnetization is necessary to this type.

Type $P^{\prime}$. This type occurs in mud samples from the upper slope at Sites 489 and 493. Direction change in AF demagnetization is more than $40^{\circ}$; the minimum change occurs at 100 and $150 \mathrm{Oe}$. At $200 \mathrm{Oe}$ the amount of direction change is more than $90^{\circ}$. The reaction of remanent magnetization to AF demagnetization is similar to Type $\mathrm{P}$ but is twice the amount of direction change for Type $P$.

Remanent magnetization of samples from the lower slope and outer rise is generally stable and reliable. Some samples from the upper slope have less reliable remanent magnetization. Most of the soft component of remanent magnetization was eliminated effectively by $150-\mathrm{Oe}$ AF demagnetization. In routine measurement of remanent magnetization, all paleomagnetic samples were measured after 150-Oe AF demagnetization. Because the types of reaction of remanent magnetization correlate well with magnetic mineral composition and sedimentary facies, they are useful for determining the origin of the sediments. The contrast in AF demagnetization between lower and upper slopes indicates different origins for the sediments.

\section{Normal-Reverse Test}

Inquiry into the reliability of remanent magnetization of sediments is possible also by normal-reverse, folding, slumping, conglomerate, and other tests. The normalreverse test is applied to the sediment section accumulated during a period of geomagnetic polarity reversal or reversals. If the magnetic sequence includes both normal and reversed directions, the remanent magnetization is probably reliable.
Because with cored sediments we cannot determine the rotation angle of sediments around the drilling axis, inclination only is the basis of geomagnetic polarity determination. We cannot detect directly the effect of drilling disturbance on the remanent magnetization. A single core drilled at Site 488 comprises two positive intervals and one negative interval in inclination of remanent magnetization. In the upper two intervals, even though downward concave laminations along core tube margins indicate drilling disturbance, the sediments themselves did not appear to have been rotated. Figure 3 and Table 8 show the magnetic measurement of samples from these three intervals. Among them, changes in inclination to the opposite hemisphere are accompanied by those in declination of about $180^{\circ}$, which indicates that the sediment core recorded reversals of geomagnetic field and that the drilling disturbance did not affect the remanent magnetization and the inclination.

In the lower interval the sediment core is broken into pieces several centimeters thick which were rotated with respect to one another. In this interval the inclination changes gradually with the increase of subdepth from negative to positive and then to negative, though the apparent declination of samples was scattered (Fig. 4 and Table 8). Because the remanent magnetization of separated pieces was not affected by drilling disturbance, the inclination can be used to determine magnetic polarity.

In the upper part of Hole 492, Core 1, change in inclination accompanied that in declination of about $180^{\circ}$ (Fig. 5 and Table 12), indicating reliability of the remanent magnetization.

\section{Inclination Analysis}

In this study, only the inclination of remanent magnetization is essential, because drilling rotated the samples. Because the bedding plane dips up to $74^{\circ}$ in the Leg 66 area, the term inclination is used for the inclination after bedding correction.

Figure 6 is a histogram of the inclination of 541 sediment samples from the Leg 66 sites after AF demagnetization at $150 \mathrm{Oe}$. The histogram has bimodal distribution with peaks at positive and negative inclination 


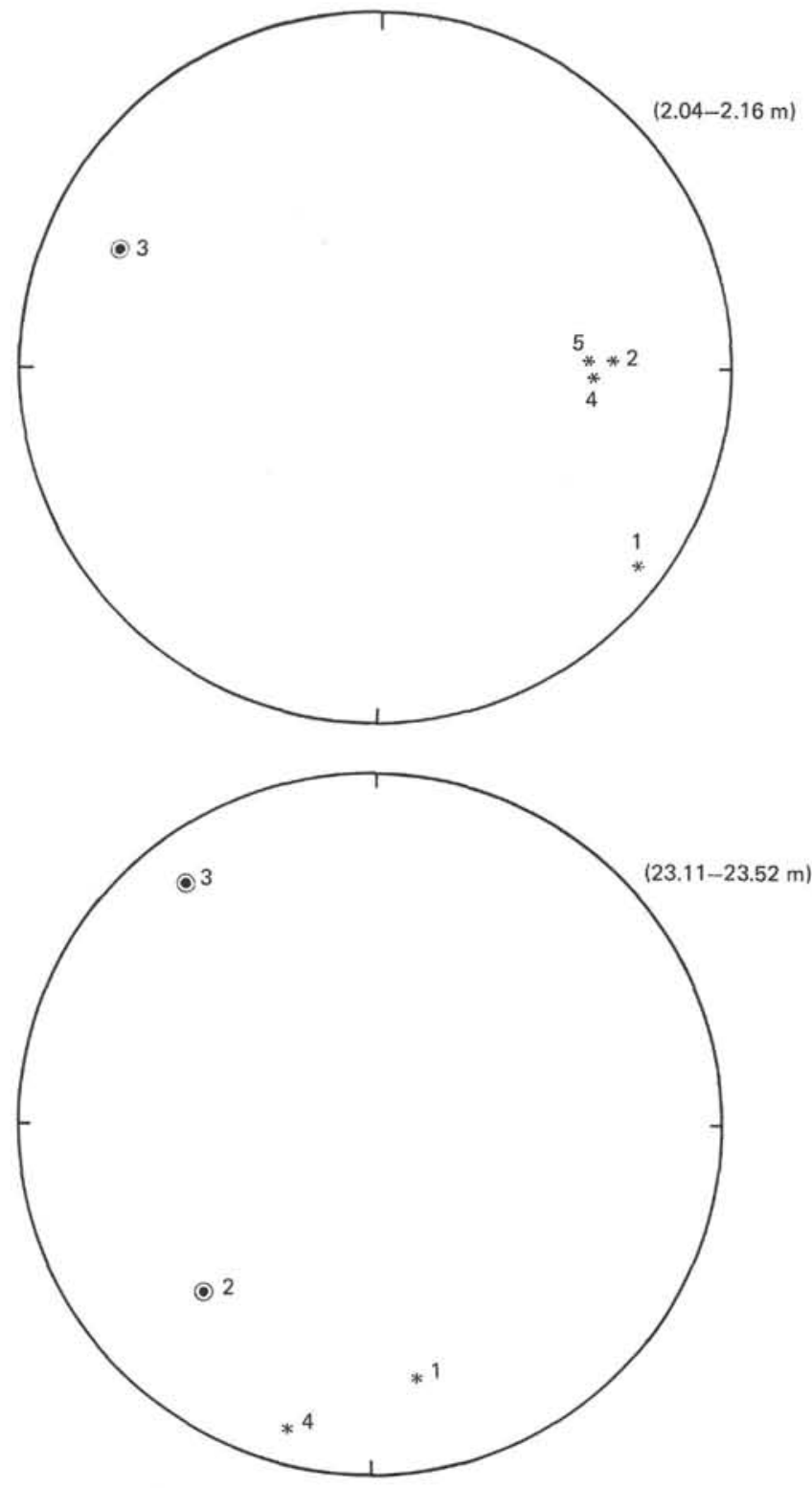

Figure 3. Normal-reverse test of upper part of Site 488 sediments. Inclination and relative declination are projected on stereo net. $(\bullet=$ upper hemisphere, $*=$ lower hemisphere. Sample horizons are numbered from shallowest to deepest.)

and a gentle trough in the low inclination range between the two peaks.

Four factors control the inclination measurement: magnetic field direction during deposition, error in magnetization of sediments, overprint of remanent magnetization, and magnetometer noise. Magnetic field direction is related to latitude of the site, magnetic dipole position, and the nondipole component of the geomagnetic field. If the poles of the geomagnetic dipole locate on the earth's rotation axis (theoretical axial geocentric dipole), inclination should be $29.8^{\circ}$ in the Leg 66 area at latitude $16^{\circ} \mathrm{N}$. On the basis of the present pole position of the geomagnetic field $\left(78.6^{\circ} \mathrm{N}, 69.8^{\circ} \mathrm{W}\right)$, the inclination is estimated as $44^{\circ}$. The actual inclination value is $40^{\circ}$, which is affected partly by the nondipole moment

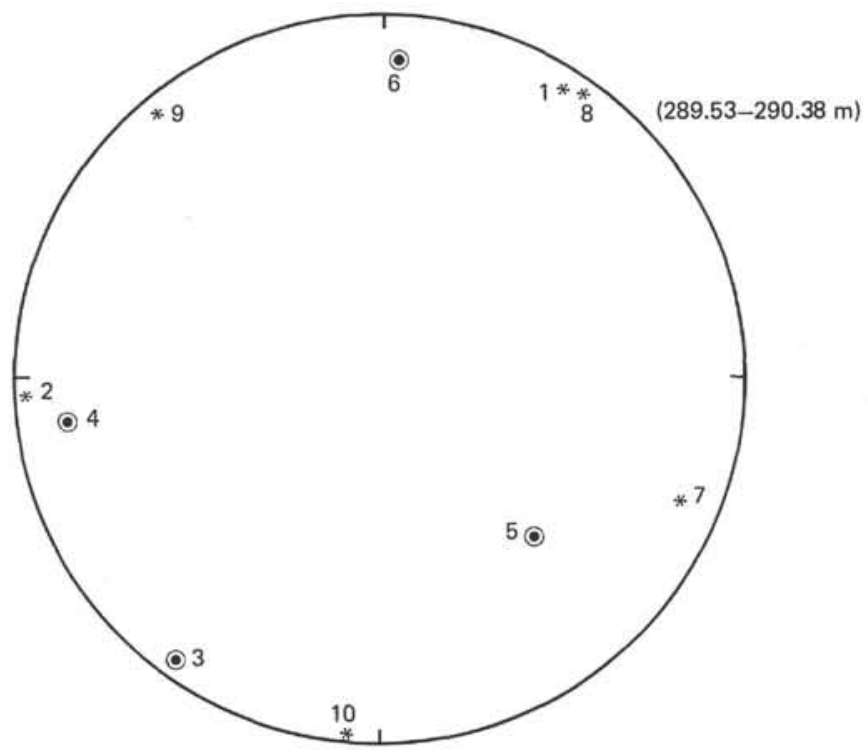

Figure 4. Normal-reverse test of lower part of Site 488 sediments. No systematic relation exists between inclination and declination. (Symbols as in Fig. 3.)

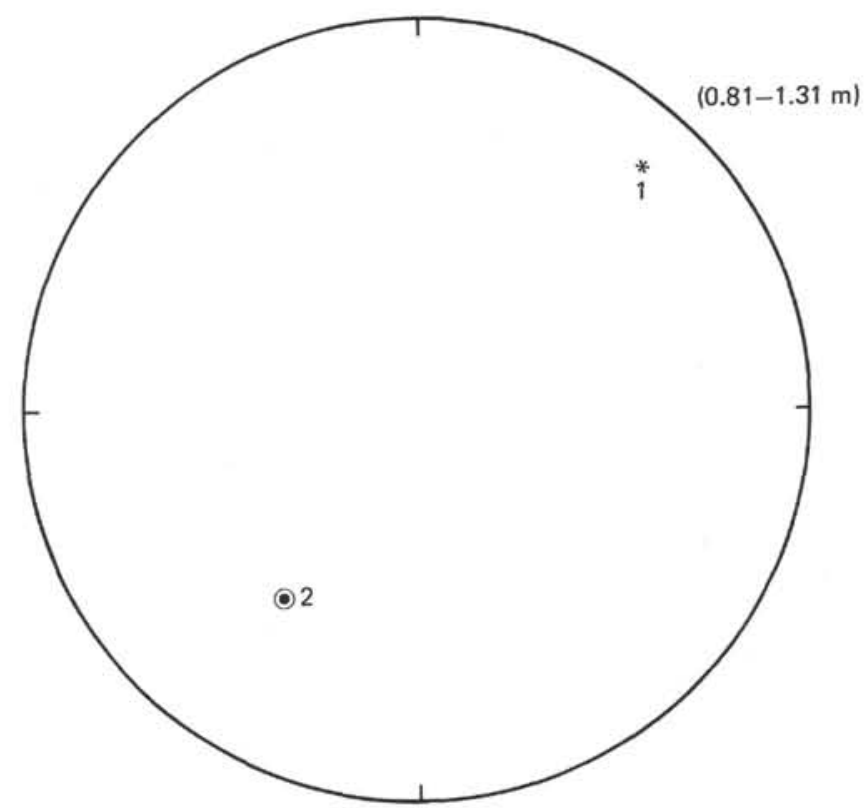

Figure 5. Normal-reverse test of upper part of Site 492 sediments. (Symbols as in Fig. 3.)

of the geomagnetic field. Considering these components of the geomagnetic field, we can estimate that the inclination value has a dispersion within a range of $15^{\circ}$ from $30^{\circ}$ in this area.

Error in magnetization is likely in a random direction, and the inclination measurement includes a value randomly scattered by the error, especially in the case of sediments poor in magnetic minerals. Overprint of remanent magnetization correlates with the direction of magnetic field in which samples have been preserved after initial magnetization. If the overprint due to the 


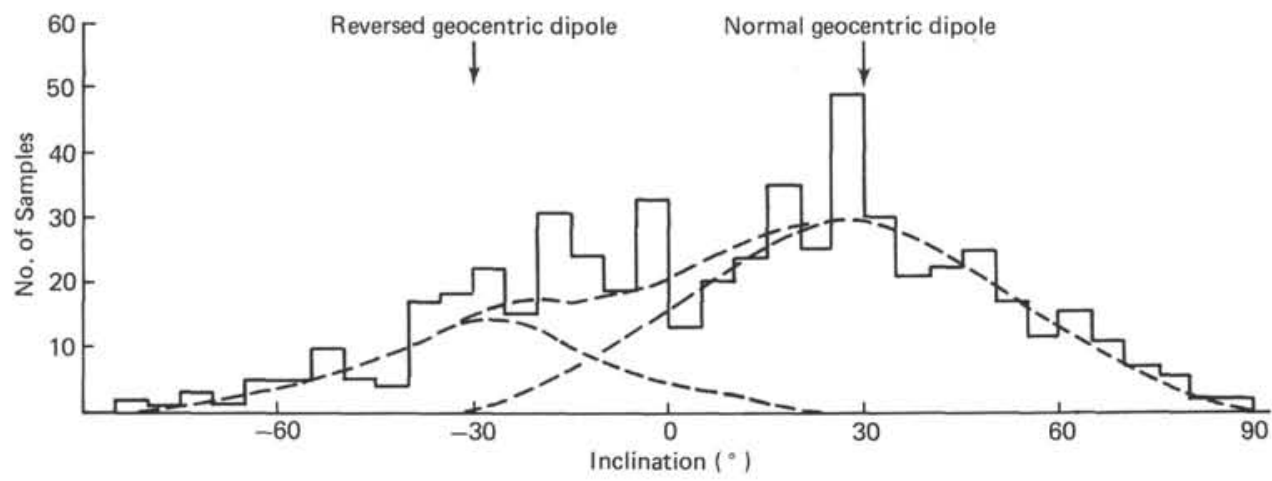

Figure 6. Histogram of inclination of sediment samples. Broken lines are best-fit normal distributions for the inclination data.

present magnetic field is dominant, the inclination should be positive. We can estimate the amount and character of the overprinted component by a demagnetization test. The overprint can be largely eliminated by $\mathrm{AF}$ demagnetization at $150 \mathrm{Oe}$. Magnetometer noise causes the inclination measurement to scatter, and the amount of dispersion should relate directly to the intensity of remanent magnetization in the sample.

In further analysis of inclination, I will use the following simple model. A certain average direction of magnetic field attributable to geocentric dipole and nondipole fields has lasted for one polarity interval-that is, long enough for accumulating sediments to acquire the remanent magnetization-then polarity reversed and the field direction lasted as long as before; finally, the event repeated itself in the same order. Throughout this process other factors randomly affected the inclination of remanent magnetization of the sediments. These factors comprise those dependent on and independent of magnetization intensity. Magnetic noise during measurement and magnetization error in sediments with fewer magnetic minerals are dependent on intensity. In my model, the frequency of inclination values has a bimodal distribution with maximum values at negative and positive inclinations corresponding to normal and reversed polarities, respectively; each maximum represents that of normal distribution of frequency of the corresponding polarity. At low latitude, as in the present area, the two normal distributions overlap, and a combination occurs in the frequency of inclination between the two modes-probably in low inclination intervals.

Inclinations of remanent magnetization in Leg 66 samples satisfy the aforementioned model. The average inclination value is $27.6^{\circ}$, calculated from cumulative frequency distribution of samples with various absolute inclination. This value agrees well with the theoretical inclination of $29.8^{\circ}$, and the average inclination of geomagnetic field in this area can be explained by the presence of geocentric dipole field during accumulation of the sediments.

From the frequency distribution of the inclination value corresponding to various intensities of remanent magnetization, we can estimate the relative importance of two random factors. Dispersion by randomness can be represented as standard deviation calculated from frequency distribution corresponding to absolute inclinations larger than $30^{\circ}$ (Table 2). There is no systematic change to be found in the standard deviation within the range of $10^{-8}$ to $10^{-5} \mathrm{emu} / \mathrm{cc}$ for remanent magnetization intensity. This fact indicates that the factor dependent on intensity is relatively small and should be of the order of $10^{-8} \mathrm{emu} / \mathrm{cc}$ in intensity. Probably most dispersion (at least $70 \%$, or $15^{\circ}$ in inclination) is the result of past changes in the geomagnetic field.

Using the average value and dispersion, we can calculate a frequency distribution of inclination in the interval from $-30^{\circ}$ to $30^{\circ}$. Distribution agrees well with the actual data (Fig. 6).

The standard deviation $\left(23.6^{\circ}\right.$ for positive and $21.0^{\circ}$ for negative inclination peaks) provides an estimate of the reliability of polarity determined by inclination. If we determine the polarity using only the sign of inclination-normal polarity from positive inclination and reversed polarity from negative inclination-the reliability of the determination is $87.9 \%$ for normal polarity and $90.5 \%$ for reversed polarity.

\section{MAGNETIC PROPERTIES OF BASEMENT ROCKS}

Reaction of remanent magnetization to AF demagnetization, changes in saturation magnetization $(J S)$ with temperature $(T)$, and magnetic properties of opaque minerals were examined in three ocean basalt, four metamorphic, and five plutonic rock samples from Holes 487, 489A, and 493, respectively.

Table 2. Standard deviation $(\sigma)$ of inclination values for positive and negative modes of samples with different intensity ranges of remanent magnetizations, calculated for inclinations in absolute ranges larger than $30^{\circ}$.

\begin{tabular}{lcc}
\hline $\begin{array}{c}\text { Intensity Range } \\
\text { of Samples }\end{array}$ & $\begin{array}{c}\text { Positive Mode } \\
\sigma(N)\end{array}$ & $\begin{array}{c}\text { Negative Mode } \\
\sigma(N)\end{array}$ \\
\hline $10^{-4}-10^{-5} \mathrm{emu} / \mathrm{cc}$ & $20.2(21)$ & $-(2)$ \\
$10^{-5}-10^{-6}$ & $24.3(37)$ & $12.0(19)$ \\
$10^{-6}-10^{-7}$ & $24.1(73)$ & $21.7(28)$ \\
$10^{-7}-10^{-8}$ & $24.7(33)$ & $24.8(19)$ \\
$10^{-8}-10^{-9}$ & $23.5(7)$ & $-(3)$ \\
$\quad$ Total & $23.6(171)$ & $21.0(71)$ \\
\hline
\end{tabular}




\section{Ocean Basalts}

Three samples were taken from the largest pieces of basalt recovered in Core 20 (Pieces 2, 13, 17) in Hole 487. Piece 2 was the only one large enough to have avoided drilling rotation. The intensity of magnetization is strong: Average and standard deviation are $10^{-2.43 \pm 0.10} \mathrm{emu} / \mathrm{cc}$. Magnetization is also relatively hard, so that the direction of magnetization changed less than $5^{\circ}$ by AF demagnetization. The intensity of remanent magnetization of the basalts decreases monotonously in stepwise AF demagnetization (Table 3 and Fig. 8). A ratio of intensity after AF demagnetization at 400 Oe against natural remanent magnetization evaluates the decrease by AF demagnetization. A higher ratio means a harder remanent magnetization. Among the three pieces, \#13 has the highest ratio $(0.75)$ and \#17 the lowest $(0.42)$ (Table 4).

Under the reflective microscope, opaque minerals in the basalt are of two kinds and are in the shape of magnetite. One is skeletal and the other cubic in shape (Plate 1, Figs. 1 and 4). The skeletal shape is similar to the shape of fish debris. The magnetite grains in the basalt have an almost skeletal shape, up to $30 \mu \mathrm{m}$ long and 2 $\mu \mathrm{m}$ wide, and there is intense maghemitization in all grains. In large, cubic magnetite grains, it appears along the rim. In the three samples, magnetite grains are smallest in Piece $13(<7 \mu \mathrm{m})$ and largest in Piece 17 (up to $30 \mu \mathrm{m}$ ) (Plate 1, Figs. 2 and 3). The difference in size of magnetite in the basalts agrees with that in decrease of remanent magnetization by AF demagnetization, the smaller size corresponding to the higher ratio of $J_{400} /$ NRM. This relation can be explained by the fact that the remanent magnetization of large grain with magnetic multidomain structure is easily demagnetized by AF demagnetization.

$J s-T$ curves of the three basalt samples are irreversible (Fig. 7). The magnetization $J s$ decreases with increasing temperature $(T)$ to a minimum value at a temperature of $355^{\circ}$ to $360^{\circ} \mathrm{C}\left(T_{c 1}\right)$, increases for a time, then decreases by further heating until magnetization is finally lost at temperatures of $570^{\circ}$ to $580^{\circ} \mathrm{C}\left(T_{c 2}\right)$. During the heating from $T_{c 2}$ to $650^{\circ}$ to $750^{\circ} \mathrm{C}$, no changes occurred in $J s$. In the cooling cycle $J s$ started to increase at a lower temperature $\left(T_{c 3}\right)$ than $T_{c 2}$. In this case $T_{c 2}$ corresponds to the breakdown temperature of titanomaghemite and $T_{c 3}$ to the Curie temperature of low-Ti spinel. The first decrease in magnetization $J s$ in the heating cycle $\left(T_{c 1}\right)$ corresponds to the Curie temperature of original titanomagnetite and the minimum magnetization is caused by titanomaghemite. The peak at higher temperature can be explained as titanomaghemite undergoing a two-phase inversion to low-Ti spinel plus hemoilmenite. The $J_{s}$ after cooling to room temperature $\left(J_{h o}\right)$ is several times larger than original magnetization $\left(J_{o}\right)$. The higher value of the ratio $J_{h o} / J_{o}$ means more intense titanomaghemitization of titanomagnetite grains. Among the samples, the ratio of Piece 13 was the highest and that of Piece 17 the lowest (Table 4). The higher ratio corresponds to the finer grain size of titanomagnetite. This relation between ratio and grain size indicates that the titanomagnetite has been oxidized from the surface of grains inside and altered to titanomaghemite, because the finer grains have a relatively larger surface area.

Ulvospinel content in original titanomagnetite is estimated as $35 \mathrm{~mol} . \%$ at the Curie temperature $\left(T_{c 1}\right)$, using the relation of Akimoto (1962). The content of ulvospinel in the titanomagnetite is consistent with the results of electron microprobe analysis of the present samples-31-39 mol.\% (Arai, this volume). An ulvospinel content of $35 \%$ is remarkably smaller than the $62 \pm 4 \%$, of average and standard deviation of ulvospinel in submarine basalts reviewed by Johnson (1979).

The inclination of the largest piece of basalt is -28.8 $\pm 0.2^{\circ}$, which agrees fairly well with the inclination of reversed axial geocentric dipole $\left(-29.6^{\circ}\right)$ in the latitude of this site $\left(15.9^{\circ} \mathrm{N}\right)$. Site 487 is on the northeastern margin of a positive anomaly crest with an amplitude of $50 n T$ (Shipley et al., 1980). Although the data on the marine magnetic anomaly and the direction of remanent magnetization of oceanic basement in this area are insufficient to discuss the source of anomaly, the magnetic intensity of basalt is strong enough to make an anomaly.

\section{Metamorphic Rocks}

We took five metamorphic rock samples from Cores 33 and 34 in Hole 489A in the upper slope. The metamorphic rocks are schist with biotite-hornblende-quartz, garnet-muscovite-quartz, and biotite-muscovite-quartz associations and muscovite-chlorite-bearing quartzite. Average and standard deviation of natural remanent magnetization intensity of the metamorphic rocks is $10^{-6.9 \pm 0.5} \mathrm{emu} / \mathrm{cc}$. Behavior of remanent magnetization to stepwise AF demagnetization is shown in Figure 8 and listed in Table 3 . Three of the samples evidence different behaviors from each other. The sample from 309.21 meters subdepth has small changes in direction at 150 - and 250-Oe AF demagnetization and almost constant intensity. The sample from 309.61 meters subdepth changes up to $40^{\circ}$ in direction at 100 and 150 $\mathrm{Oe}$-characteristic behavior for Type I magnetization of sediments mentioned earlier-and has gradually increasing intensity. The sample from 318.06 meters subdepth changes direction by more than $120^{\circ}$ at 200 $\mathrm{Oe}$-characteristic behavior for Type $\mathrm{P}$ magnetization of sediments - and has increasing intensity from a minimum value at the 150 -Oe step.

Under the reflective microscope, we saw very small amounts of opaque mineral in the metamorphic rocks. These minerals are associated with mafic minerals. They are predominantly oxide minerals and crack-filling pyrite, though pyrrhotite and chalcopyrite are occasionally present. The oxide minerals are lath-shaped ilmenite and rutile (Table 5). The oxide mineral lath is 30 to 100 $\mu \mathrm{m}$ long and a 20 to $30 \mu \mathrm{m}$ across (Plate 1, Fig. 5).

The $J s-T$ curve of the metamorphic rocks gave no information owing to their low magnetic mineral content.

The weak remanent magnetization of the metamorphic rock in Hole 489A is inconsistent with the magnetic 
Table 3. Remanent magnetization of basement rocks after stepwise AF demagnetization.

\begin{tabular}{|c|c|c|c|c|c|c|c|c|c|c|}
\hline Hole & Core & Section & Interval (cm) & $\begin{array}{l}\text { Sub-bottom } \\
\text { Depth } \\
\text { (m) }\end{array}$ & $\begin{array}{l}\text { AF Demag. } \\
\text { Field (Oe) }\end{array}$ & $\begin{array}{c}\text { Relative } \\
\text { Declination }\end{array}$ & Inclination & $\begin{array}{c}\text { Intensity } \\
\left(\times 10^{-6} \mathrm{emu} / \mathrm{cc}\right)\end{array}$ & $\begin{array}{l}\text { Susceptibility } \\
\left(\times 10^{-6} \mathrm{cgs}\right)\end{array}$ & Remarks \\
\hline \multirow[t]{17}{*}{487} & 20 & 1 & $9.0-11.0$ & 172.10 & 0 & 85.7 & -28.7 & 2870.0 & 196 & Basalt \\
\hline & & & & & 50 & 85.1 & -28.5 & 2830.0 & & \\
\hline & & & & & 100 & 85.1 & -28.8 & 2670.0 & & \\
\hline & & & & & 200 & 85.9 & -28.7 & 2480.0 & & \\
\hline & & & & & 300 & 86.2 & -28.9 & 2230.0 & & \\
\hline & & & & & 400 & 84.5 & -29.0 & 1950.0 & & \\
\hline & & & & & 500 & 84.5 & -28.9 & 1670.0 & & \\
\hline & & & & & 600 & 84.2 & -29.2 & 1420.0 & & \\
\hline & 20 & 1 & $93.0-95.0$ & 172.94 & 0 & 288.7 & -10.4 & 4170.0 & 324 & \\
\hline & & & & & 200 & 288.7 & -11.8 & 3820.0 & & \\
\hline & & & & & 400 & 289.4 & -15.1 & 3130.0 & & \\
\hline & & & & & 600 & 290.3 & -14.9 & 2320.0 & & \\
\hline & 20 & 1 & $118.0-120.0$ & 173.19 & 0 & 52.3 & 6.3 & 4350.0 & 182 & \\
\hline & & & & & 100 & 52.8 & 7.0 & 3720.0 & & \\
\hline & & & & & 200 & 53.1 & 7.3 & 3090.0 & & \\
\hline & & & & & 400 & 54.1 & 7.4 & 1840.0 & & \\
\hline & & & & & 600 & 54.5 & 6.7 & 1090.0 & & \\
\hline \multirow[t]{20}{*}{489} & 33 & 1 & $20.0-22.0$ & 309.21 & 0 & 251.7 & -39.0 & 0.211 & & Metamorphic \\
\hline & & & & & 50 & 207.7 & -39.5 & 0.197 & & rock \\
\hline & & & & & 100 & 179.1 & -32.5 & 0.194 & & \\
\hline & & & & & 150 & 174.3 & -19.9 & 0.249 & & \\
\hline & & & & & 200 & 147.0 & -7.1 & 0.223 & & \\
\hline & & & & & 250 & 145.1 & -16.6 & 0.199 & & \\
\hline & 33 & 1 & $28.0-30.0$ & 309.29 & 0 & 171.2 & -55.8 & 0.451 & & \\
\hline & 33 & 1 & $60.0-62.0$ & 309.61 & 0 & 173.5 & 56.6 & 0.136 & & \\
\hline & & & & & 50 & 171.4 & 43.1 & 0.167 & & \\
\hline & & & & & 100 & 199.9 & 79.6 & 0.206 & & \\
\hline & & & & & 150 & 151.8 & 43.4 & 0.274 & & \\
\hline & & & & & 200 & 163.3 & 65.2 & 0.290 & & \\
\hline & & & & & 250 & 152.3 & 64.1 & 0.282 & & \\
\hline & 34 & 1 & $5.0-7.0$ & 318.06 & 0 & 266.2 & -24.8 & 0.169 & & \\
\hline & & & & & 50 & 276.6 & -0.4 & 0.148 & & \\
\hline & & & & & 100 & 257.7 & -7.7 & 0.134 & & \\
\hline & & & & & 150 & 229.0 & -37.0 & 0.065 & & \\
\hline & & & & & 200 & 322.8 & 55.2 & 0.408 & & \\
\hline & & & & & 250 & 348.0 & 22.7 & 0.252 & & \\
\hline & 34 & 1 & $50.0-52.0$ & 318.51 & 0 & 347.4 & 66.5 & 0.023 & & \\
\hline \multirow[t]{17}{*}{493} & 58 & 1 & $52.0-54.0$ & 652.53 & 0 & 206.5 & 67.6 & 79.416 & & Plutonic \\
\hline & & & & & 50 & 172.7 & 16.8 & 51.081 & & rock \\
\hline & & & & & 100 & 281.7 & 60.9 & 22.933 & & \\
\hline & & & & & 150 & 135.7 & 9.4 & 35.367 & & \\
\hline & & & & & 200 & 150.2 & -7.3 & 45.463 & & \\
\hline & & & & & 300 & 246.6 & 23.8 & 38.143 & & \\
\hline & & & & & 400 & 55.9 & 13.5 & 38.231 & & \\
\hline & 58 & 1 & $59.0-61.0$ & 652.60 & 0 & 216.3 & 65.1 & 82.742 & 122 & \\
\hline & 58 & 1 & $73.0-75.0$ & 652.74 & 0 & 50.5 & 50.2 & 2.247 & 64 & \\
\hline & & & & & 50 & 57.6 & 43.3 & 1.855 & & \\
\hline & & & & & 100 & 67.5 & 8.9 & 1.366 & & \\
\hline & & & & & 150 & 350.6 & 20.2 & 0.996 & & \\
\hline & & & & & 200 & 0.2 & 0.3 & 1.061 & & \\
\hline & 59 & 1 & $137.0-139.0$ & 657.88 & 0 & 258.5 & 68.2 & 18.680 & 54 & \\
\hline & 59 & 2 & $74.0-76.0$ & 658.75 & 0 & 174.7 & 64.9 & 455.667 & 168 & \\
\hline & 60 & 1 & $79.0-81.0$ & 662.80 & 0 & 148.2 & 57.5 & 6.354 & 52 & \\
\hline & 60 & 2 & $39.0-41.0$ & 663.40 & 0 & 142.2 & 72.4 & 1.774 & 68 & \\
\hline
\end{tabular}

anomaly of amplitude of $150 \mathrm{nT}$ observed by Shipley et al. (1980).

Table 4. Magnetic properties of ocean basalt, Hole 487, outer rise.

\begin{tabular}{cccccccc}
\hline $\begin{array}{c}\text { Core/ } \\
\text { Section/Piece }\end{array}$ & $\begin{array}{c}\text { Sub-bottom } \\
\text { Depth } \\
(\mathrm{m})\end{array}$ & $\begin{array}{c}T_{c 1} \\
\left({ }^{\circ} \mathrm{C}\right)\end{array}$ & $\begin{array}{c}T_{c 2} \\
\left({ }^{\circ} \mathrm{C}\right)\end{array}$ & $\begin{array}{c}T_{c 3} \\
\left({ }^{\circ} \mathrm{C}\right)\end{array}$ & $J_{h o} / J_{O}$ & $\begin{array}{c}J_{400} \text { Oe/ } \\
J_{N R M}\end{array}$ & $\begin{array}{c}\text { Grain Size of } \\
\text { Magnetite } \\
(\mu \mathrm{m})\end{array}$ \\
\hline $20-12$ & 172.10 & 360 & 565 & 545 & 4.69 & 0.68 & $5-10$ \\
$20-113$ & 172.94 & 355 & 570 & 545 & 4.79 & 0.75 & $2-10$ \\
$20-117$ & 173.19 & 355 & 570 & 532 & 2.53 & 0.43 & $4-20$ \\
\hline
\end{tabular}

\section{Plutonic Rocks}

The plutonic rocks recovered from Site 493 on the upper slope are diorite, of which seven oriented samples were used in this study. Intensity of natural remanent magnetization is widely scattered, average and standard deviation being $10^{-4.7 \pm 0.9} \mathrm{emu} / \mathrm{cc}$. Susceptibility is 


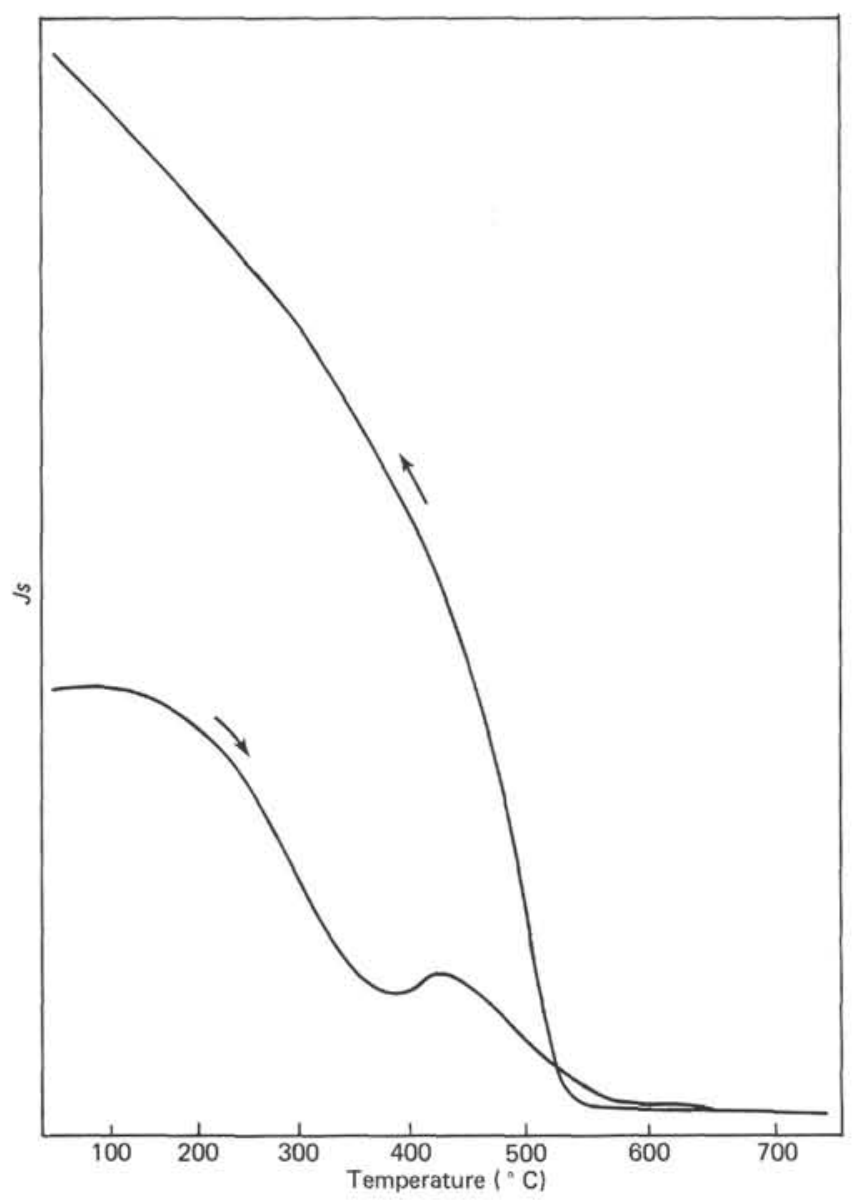

Figure 7. Saturation magnetization $(J S)$-temperature curves of ocean basalt, Section 487-20-1, Piece 17 (173.19 m sub-bottom).

$10^{-4.1 \pm 0.2} \mathrm{cgs}$. Inclination of natural remanent magnetization is $63.7 \pm 5^{\circ}$, which is remarkably steep compared with that of axial dipole $\left(29.8^{\circ}\right)$. Remanent magnetization during AF demagnetization is unstable. Two samples from 652.7 and 653.0 meters subdepth were examined by stepwise AF demagnetization (Table 3). Both behave similarly: more than $70^{\circ}$ change in direction of remanent magnetization at $150 \mathrm{Oe}$ and generally decreasing intensity (Fig. 8). This behavior is similar to Type I for sediments.

Under the reflective microscope, the plutonic rocks were seen to contain predominantly ilmenite as oxide mineral, pyrite, pyrrhotite, and occasionally chalcopyrite as a sulfide mineral (Table 6). The opaque minerals are generally granular and range from 10 to $500 \mu \mathrm{m}$. Among the sulfide minerals, pyrite content is higher than pyrrhotite. There is twinned pyrrhotite, $200 \mu \mathrm{m}$ across, in the sample from 658.75 meters subdepth, which has the strongest intensity of natural remanent magnetization among the plutonic rocks drilled. The composition of the opaque minerals indicates that the plutonic rock belongs to the "ilmenite series" of plutonic rocks (Ishihara, 1977), which are exposed on the circum-Pacific coasts.

$J S-T$ curves of the plutonic rocks are irreversible. $J S$ decreases gradually as temperature increases. At $520^{\circ}$ to $560^{\circ} \mathrm{C}$ the sample weight decreases and remains constant up to $700^{\circ} \mathrm{C}$. At temperature higher than $700^{\circ} \mathrm{C}$, sample weight decreases gradually with increase of temperature. In the cooling cycle from $870^{\circ} \mathrm{C}$, Js appears at the Curie temperature of $770^{\circ} \mathrm{C}$ and $J s$ increases with cooling. $J S$ at room temperature is larger than before heating (Fig. 9). Increased $J S$ after heating means that magnetic material was produced during heating. The Curie temperature of the new material is $770^{\circ} \mathrm{C}$, which is the same as metallic iron; therefore the new material is probably metallic iron produced by the reduction of iron sulfide, pyrite, pyrrhotite, and chalcopyrite. The $J_{S}-T$ curve of the sample from 658.75 meters subdepth is also irreversible. This sample has a Curie temperature of $320^{\circ} \mathrm{C}$ in the heating cycle and $270^{\circ} \mathrm{C}$ in the cooling cycle after heating to $600^{\circ} \mathrm{C}$. The $J s$ at room temperature after heating is smaller than before (Fig. 9). The change in Curie temperature and $J s$ can be explained by a decrease in sulfur content in the pyrrhotite during heating. In this sample there is a decrease in weight at $540^{\circ} \mathrm{C}$, as in the other plutonic samples, which is explained by decomposition of sulfide minerals.

It is difficult to identify these plutonic rocks as the source of the 150-nT marine magnetic anomaly in the upper slope area (Shipley et al., 1980), because the strongest intensity of the remanent magnetization in the plutonic rock is $10^{-3.34} \mathrm{emu} / \mathrm{cc}$, one order weaker than the intensity of ocean basalt at Site 487 . Steep positive inclination of natural remanent magnetization is probably caused by an induced magnetic field in the drilling core tube, judging from the direction of remanent magnetization and the unstable soft nature of remanent magnetization.

\section{MAGNETOSTRATIGRAPHY}

Magnetostratigraphy was established for the sedimentary sequences in the outer rise (Site 486), lower slope (Sites 488, 491, and 492), and upper slope (Sites 490,489 , and 493). The magnetic polarity was based mainly on the inclination of remanent magnetization after bedding correction, declination of nonrotated cores, and relative declination to dip of bedding plane, if data were available.

In the sequences of the upper slope, tectonic breaks due to faulting occur at a subdepth of 420 meters at Site 490 , and sedimentary breaks occur at 5 to 7 meters at Site 489 and at 360 meters at Site 493 , which is related to an unconformity. The tectonic break is suggested by the existence of many minor faults with slickensides and by the increased dips of bedding planes around the faults, soupy crashed sediments, and remarkably low recovery rate. The sedimentary breaks are identified by changes in color, hardness, and fossil content. The fossil data indicate ranges of hiatus in age from late early Miocene to Pleistocene at Site 489 and from late early Miocene to early late Miocene at Site 493 .

Magnetostratigraphic correlation was based principally on the normal-reversed polarity sequence but was supplemented with nannoplankton and radiolarian fossil data (Stradner, this volume; McMillen, this volume). The units of magnetostratigraphic correlation are 

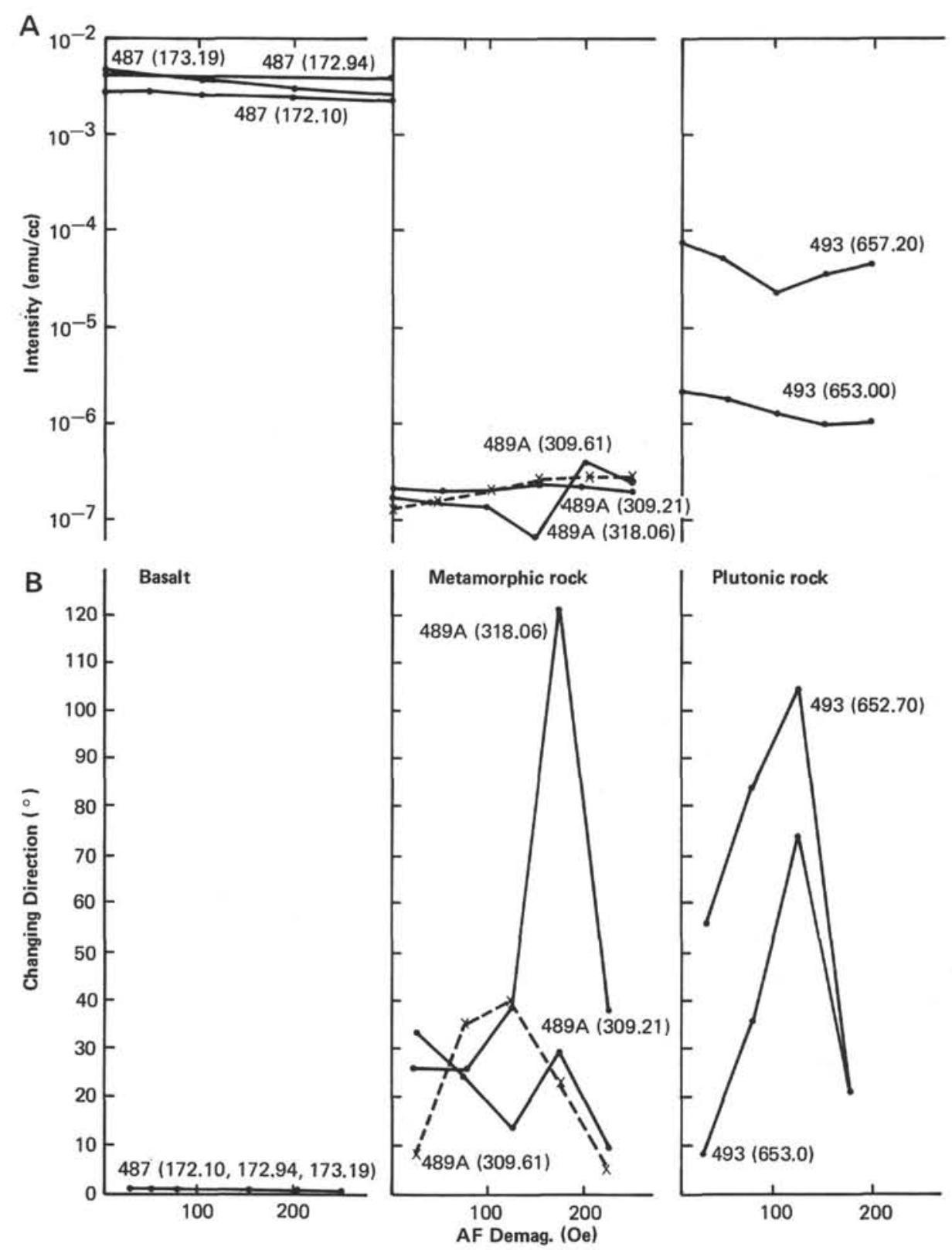

Figure 8. Reaction of remanent magnetization of basement rocks during stepwise AF demagnetization. A. Changes in intensity of remanent magnetization in a logarithmic scale. B. Changes in direction of remanent magnetization in degree with each AF demagnetization step. (Numbers in parentheses are meters sub-bottom.)

Table 5. Reflective minerals and magnetic properties in metamorphic rocks, Hole 489A, upper slope.

\begin{tabular}{|c|c|c|c|}
\hline Core/Section & $\begin{array}{l}\text { Sub-bottom } \\
\text { Depth } \\
\text { (m) }\end{array}$ & Reflective Mineral (size) & Remarks \\
\hline $33-1,21 \mathrm{~cm}$ & 309.21 & Il, Rt $(20 \mu \mathrm{m})>$ Py & Reflective mineral rare \\
\hline $33-1,29 \mathrm{~cm}$ & 309.29 & II, Rt $(10-30,100)$ & \\
\hline $33-1,61 \mathrm{~cm}$ & 309.61 & $\mathrm{Il}(40)>\operatorname{Py}(100) \geq \mathrm{Rt}(20)$ & Type 1 \\
\hline $34-1,6 \mathrm{~cm}$ & 318.06 & $\operatorname{Rt}(30), \operatorname{Py}(50-100)>\mathrm{Il}, \mathrm{Po}, \mathrm{Cp}$ & Type P \\
\hline
\end{tabular}

Note: $\mathrm{ll}=$ ilmenite, $\mathrm{Rt}=$ rutile, $\mathrm{Py}=$ pyrite, $\mathrm{Po}=$ pyrrhotite, $\mathrm{Cp}=$ chalcopyrite.

numbered starting with the youngest (Epochs 1 through 4 corresponding to the Brunhes, Matuyama, Gauss, and Gilbert polarity epochs and Epoch 5 below the Gilbert). The magnetostratigraphic columns and results of mea- surement are shown in Figures $10-17$ and listed in Tables 7-13. Magnetostratigraphic correlation between the sites and comparison with a standard magnetostratigraphic scale (Ryan et al., 1974) are shown in Figure 18, together with the horizons of the pilot samples examined by stepwise AF demagnetization and their types.

\section{Outer Rise}

Hole 487. Remanent magnetization of samples from Hole 487 shows a relatively strong average intensity $\left(10^{-5.35} \pm 0.43 \mathrm{emu} / \mathrm{cc}\right)$ after 150 -Oe AF demagnetization (Fig. 10). The magnetization is stable and all pilot samples belong to Type A (Fig. 18). The upper half of the sequence can be correlated with Brunhes Normal Polar- 
Table 6. Reflective minerals in plutonic rocks at Site 493, upper slope.

\begin{tabular}{|c|c|c|c|}
\hline Core/Section/Piece & $\begin{array}{l}\text { Sub-bottom } \\
\text { Depth } \\
\text { (m) }\end{array}$ & Reflective Mineral $(\mu \mathrm{m})$ & Remarks \\
\hline $58-15$ & 652.70 & $\mathrm{II}(500)>\mathrm{Py}(20-100)>\mathrm{Po}(10-50)>\mathrm{Cp}(10)$ & \\
\hline $59-29$ & 658.75 & II $>\mathrm{Po}>\mathrm{Py}>\mathrm{Cp}_{\mathrm{p}}$ & Granular, $20-500 \mu \mathrm{m}$ \\
\hline $60-13$ & 662.90 & $\mathrm{Il}>\mathrm{Py}, \mathrm{Po}>\mathrm{Cp}$ & Granular, $10-80 \mu \mathrm{m}$ \\
\hline $60-24$ & 663.40 & $\mathrm{II}(10-50)>\mathrm{Py}(10-150)>\mathrm{Po}(10)>\mathrm{Cp}$ & \\
\hline
\end{tabular}

Note: $\mathrm{Il}=$ ilmenite, $\mathrm{Py}=$ pyrite, $\mathrm{Po}=$ pyrrhotite, $\mathrm{Cp}=$ chalcopyrite.
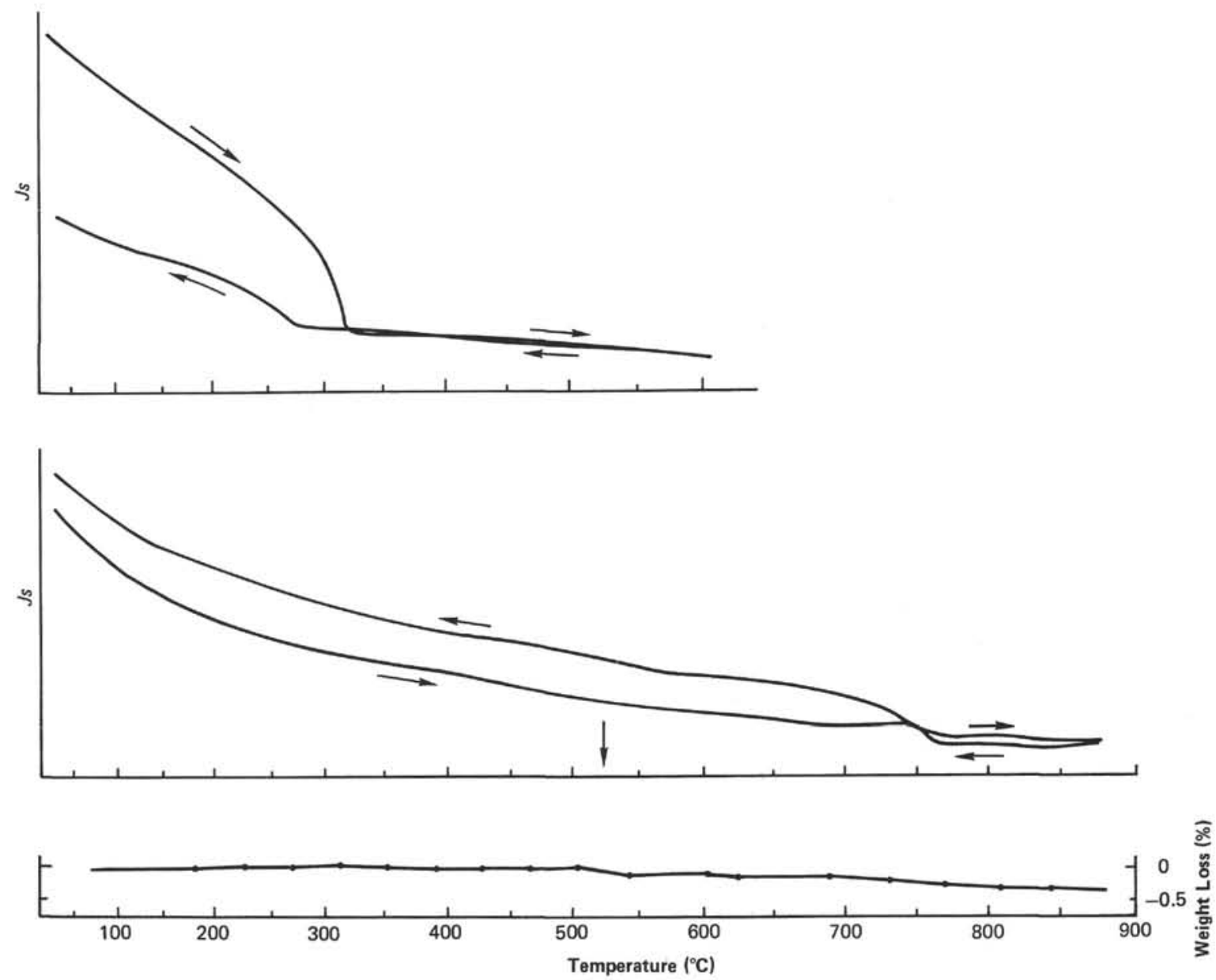

Figure 9. Saturation magnetization ( $J s)$-temperature curves of plutonic rocks, Site 493, upper slope. (Top): Section 493-59-2, Piece 9 (658.75 m sub-bottom); (bottom): Section 493-60-1, Piece 3 (662.90 m sub-bottom).

ity Epoch and the lower half with the Matuyama Epoch through Epoch 10. The magnetostratigraphic correlation indicates a large increase in the rate of sedimentation in the last $0.69 \mathrm{~m} . \mathrm{y}$.

\section{Lower Slope}

Hole 488. The average intensity of remanent magnetization is $10^{-5.27 \pm 0.64} \mathrm{emu} / \mathrm{cc}$ after 150 -Oe AF demagnetization (Fig. 11). The magnetization is stable and belongs to Type $T$. The magnetostratigraphic sequence is correlated with the Brunhes Epoch and the later part of the Matuyama Epoch, including Jaramillo Event. Short events at three horizons in the later part of the Brunhes Epoch and two horizons in late Matuyama Epoch are recognizable not only by inclination but by declination as well. Such short events have been reported in Lake Biwa sediments (late Brunhes Epoch) (Yaskawa et al., 1973).

Hole 491 . The average intensity is $10^{-5.8 \pm 0.7} \mathrm{emu} / \mathrm{cc}$ after 150-Oe demagnetization (Fig. 14). The magnetization of the samples belongs to Type $\mathrm{T}$, which has stable remanence direction. The magnetostratigraphic sequence is correlated with Epochs 1 through 4 . Above 76 meters subdepth, intensity is remarkably low, $\left(10^{-6.7 \pm 0.7} \mathrm{emu} /\right.$ cc) and the rate of sedimentation is also low.

Hole 492. The average intensity is $10^{-6.6 \pm 0.6} \mathrm{emu} / \mathrm{cc}$. This intensity is the same as in the upper part of Hole 491. The intensity of the lowest part, below 228 meters subdepth, is $10^{-5.7 \pm 0.7} \mathrm{emu} / \mathrm{cc}$, the same as at Site 488 . The remanence of the upper part of the sediments at this site belongs to Type $\mathrm{P}$ and of the lower part to Type $\mathrm{T}$. Because the sediments have been brecciated tectonically, 


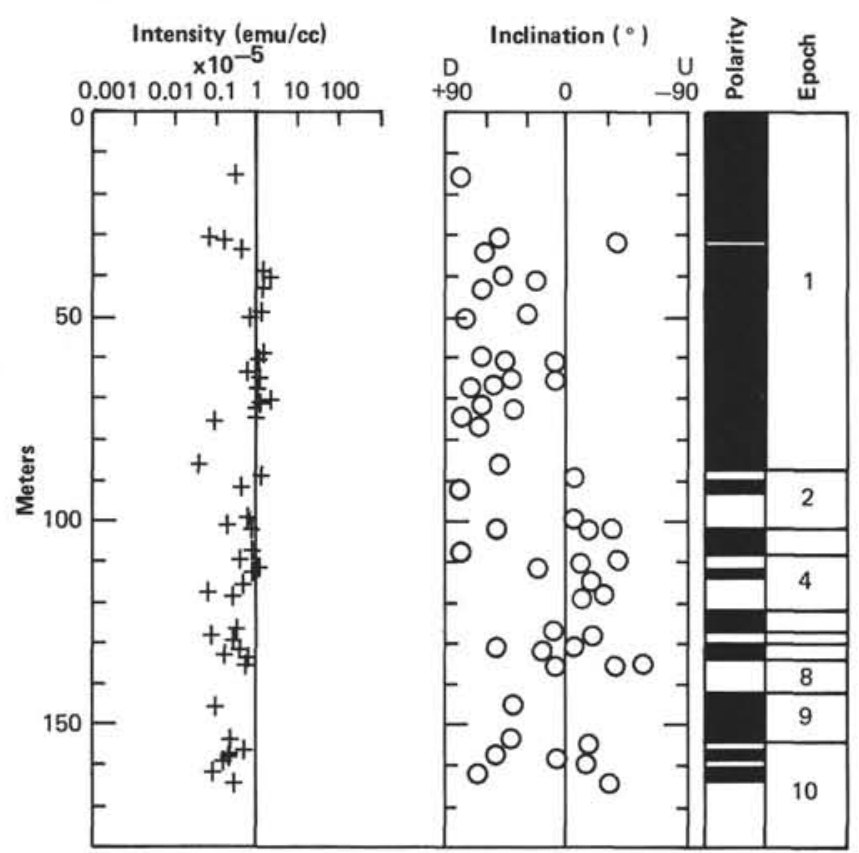

Figure 10. Magnetostratigraphy, Hole 487, outer rise.

no paleomagnetic sample was collected in the intervals from 125 to 155 meters or from 190 to 210 meters. The magnetostratigraphic sequence is correlated with Epochs 1 through 9.

Hole $492 \mathrm{~A}$. The average intensity is $10^{-6.5 \pm 0.3}$ $\mathrm{emu} / \mathrm{cc}$ (Fig. 16). The sediments contain glauconite. The remanence is Type G. Normal polarity dominates the magnetostratigraphic sequence, of which correlation with Site 492 is difficult, because the upper parts of the sequences in Holes 492 and $492 \mathrm{~A}$ may have hiatuses, and sediment accumulation not have been uniform.

\section{Upper Slope}

Hole 490. The average intensity of remanent magnetization is $10^{-6.6 \pm 0.9} \mathrm{emu} / \mathrm{cc}$ (Fig. 13). Type of remanence is $\mathrm{S}$ and $\mathrm{G}$. The magnetostratigraphic sequence is correlated with Epochs 1 to 5 and indicates a uniform rate of sedimentation. A normal fault exists in the middle of Epoch 4 (= Gilbert Reversed Polarity Epoch). The correlation indicates that the missing interval ranges from 3.7 to $4.6 \mathrm{Ma}$ (Events a through $\mathrm{c}_{2}$ ).

Hole 489. The average intensity of remanent magnetization is $10^{-7.2 \pm 0.8} \mathrm{emu} / \mathrm{cc}$, which is one to two orders lower than that of the other lower slope sites (Fig. 12). The magnetization is Types I and P. There is an unconformity in the uppermost part of the sequence, and the magnetostratigraphic sequence below the unconformity correlates with Epochs 17 through 21.

Hole 493. The average intensity is $10^{-6.8 \pm 0.5} \mathrm{emu} / \mathrm{cc}$ (Fig. 17). The samples from the upper 360 meters were demagnetized twice in an alternating field of opposite directions at 150 Oe to examine stability. The results are shown in Table 13 and Figure 17. Type of remanence is $\mathrm{S}$ and $\mathrm{I}$. The sedimentary sequence is divided into twoupper and lower-by unconformity. The upper magnetostratigraphic sequence is correlated with Epochs 1

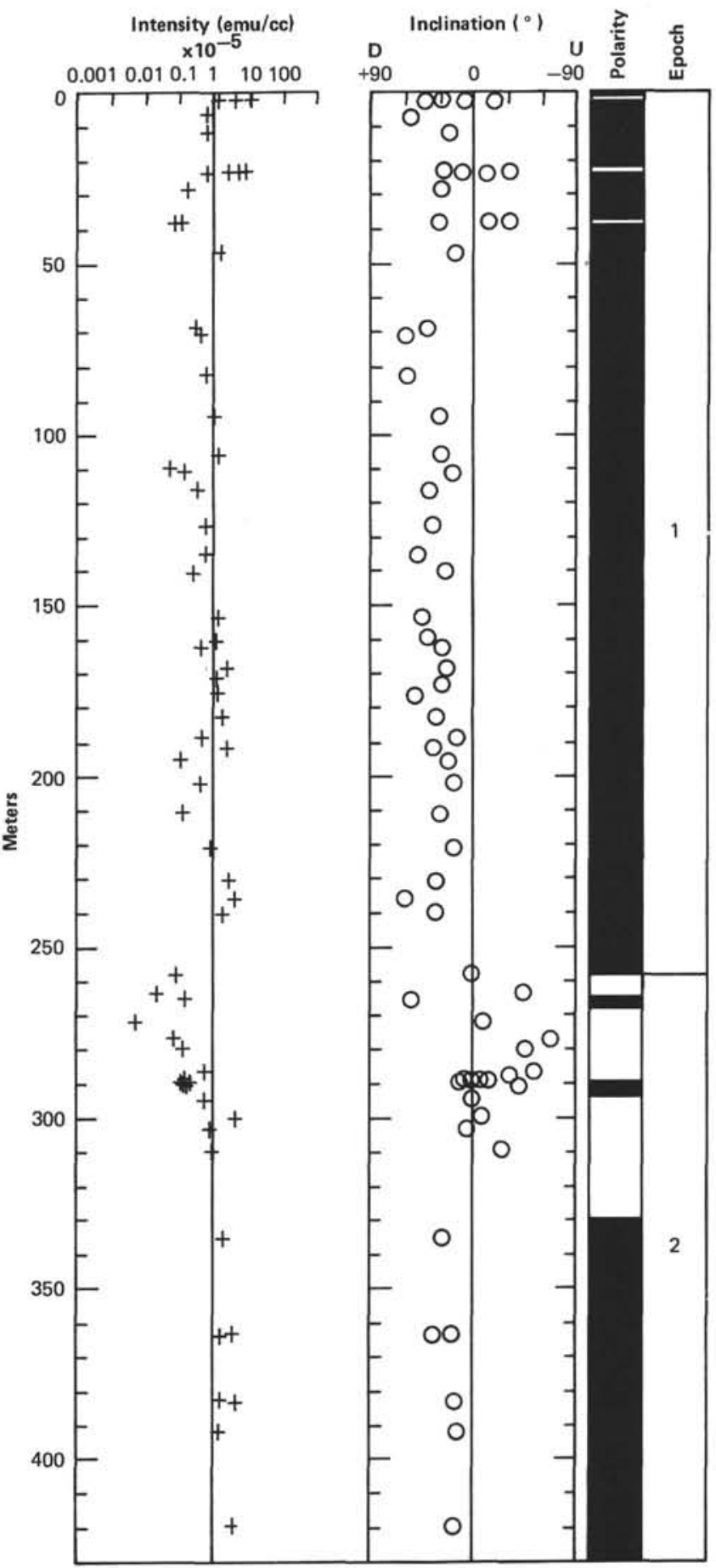

Figure 11. Magnetostratigraphy, Hole 488 , lower slope.

through 8 and the lower sequence with Epochs 16 and 17. The hiatus represented by the unconformity extends from 8.5 to $18.0 \mathrm{Ma}$. Very little intensity difference is observed between the lower section of lower Miocene and the upper section of the upper Miocene to Pleistocene. This indicates that sediments with a similar magnetic mineral content have been supplied to the present area in the early Miocene and late Miocene to Pleistocene, probably from the same source area. The absolute inclination in the lower section $\left(42.9 \pm 20.7^{\circ}\right)$ is signifi- 


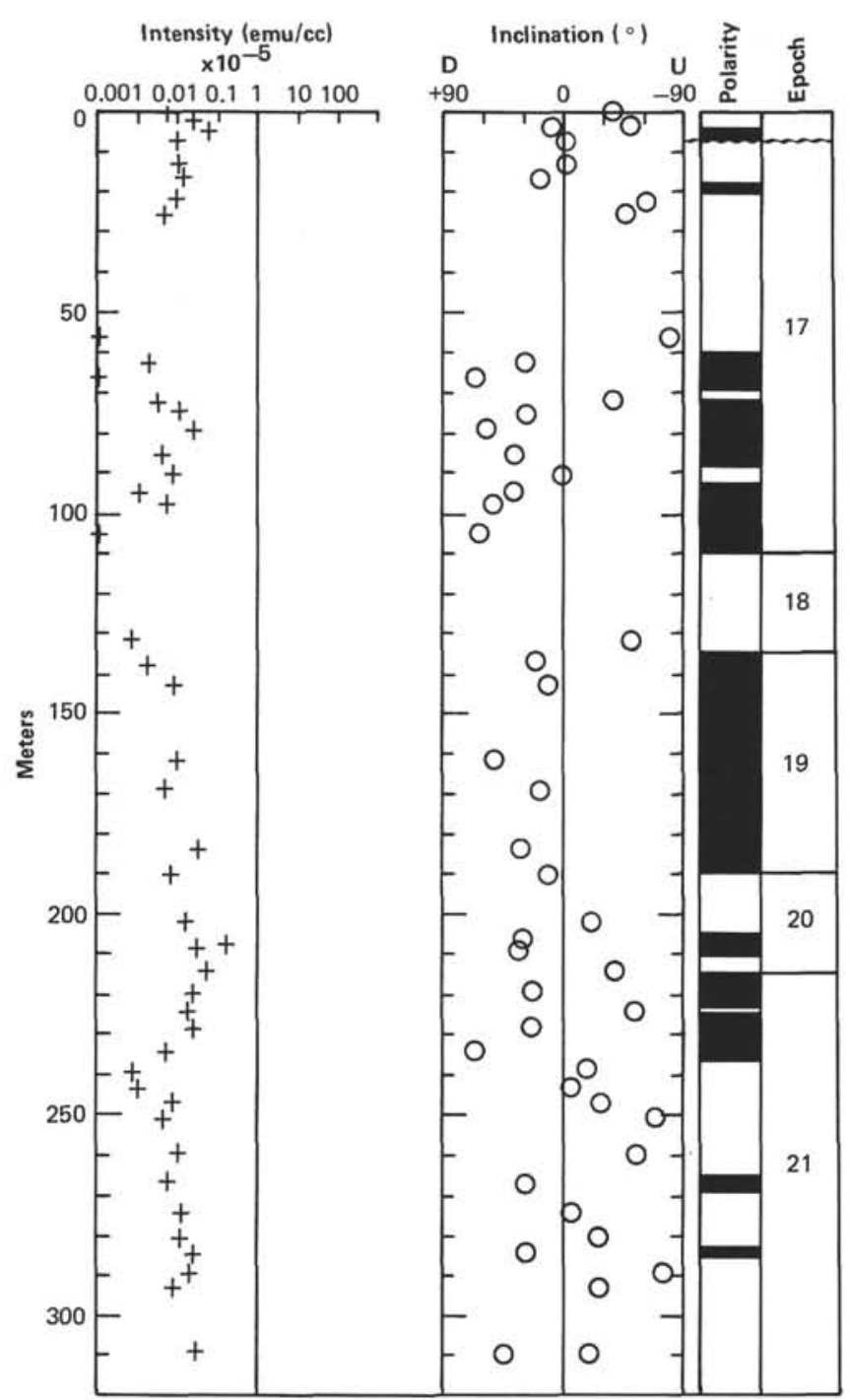

Figure 12. Magnetostratigraphy, Holes 489 and 489A, upper slope.

cantly larger than in the upper section $\left(27.5 \pm 21.2^{\circ}\right)$, which agrees with the present geocentric axial dipole value. If the higher inclination is adopted, paleolatitude is calculated as $25.0^{\circ}$ on the assumption that the average inclination represents a geocentric axial dipole during the early Miocene.

The intensity of remanent magnetization of the upper slope sediments is uniformly weak, and the sediments show reactions to AF demagnetization different from those of the lower slope and outer rise sediments. Thus the origin of the upper slope sediments may be different from that of the lower slope and outer rise sediments. The weak intensity and types of reaction to AF demagnetization are similar to the intensity and reactions of plutonic and metamorphic rocks from continental basement.

The most conspicuous characteristic of the sediment accumulation rate in the upper slope area is an unconformity in the middle Miocene (Fig. 18). The age of the sedimentary break ranges from the late early Miocene $(16.5 \mathrm{Ma})$ to the middle late Miocene $(8.5 \mathrm{Ma})$.

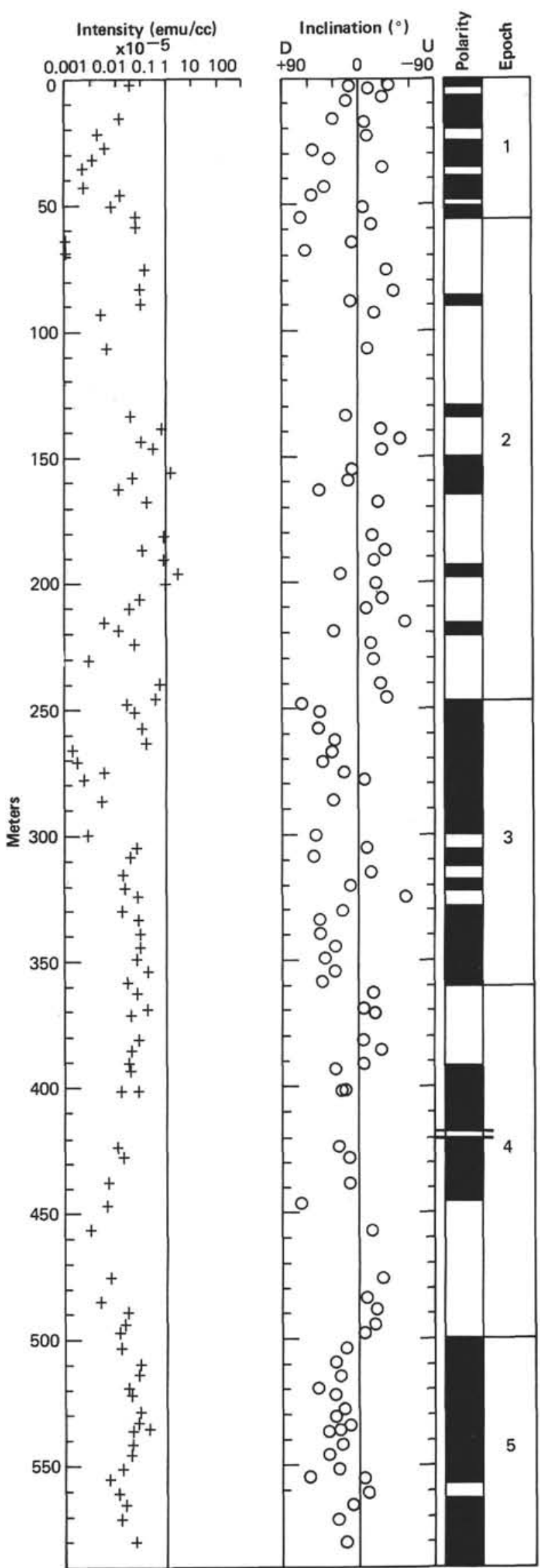

Figure 13. Magnetostratigraphy, Hole 490, upper slope. 


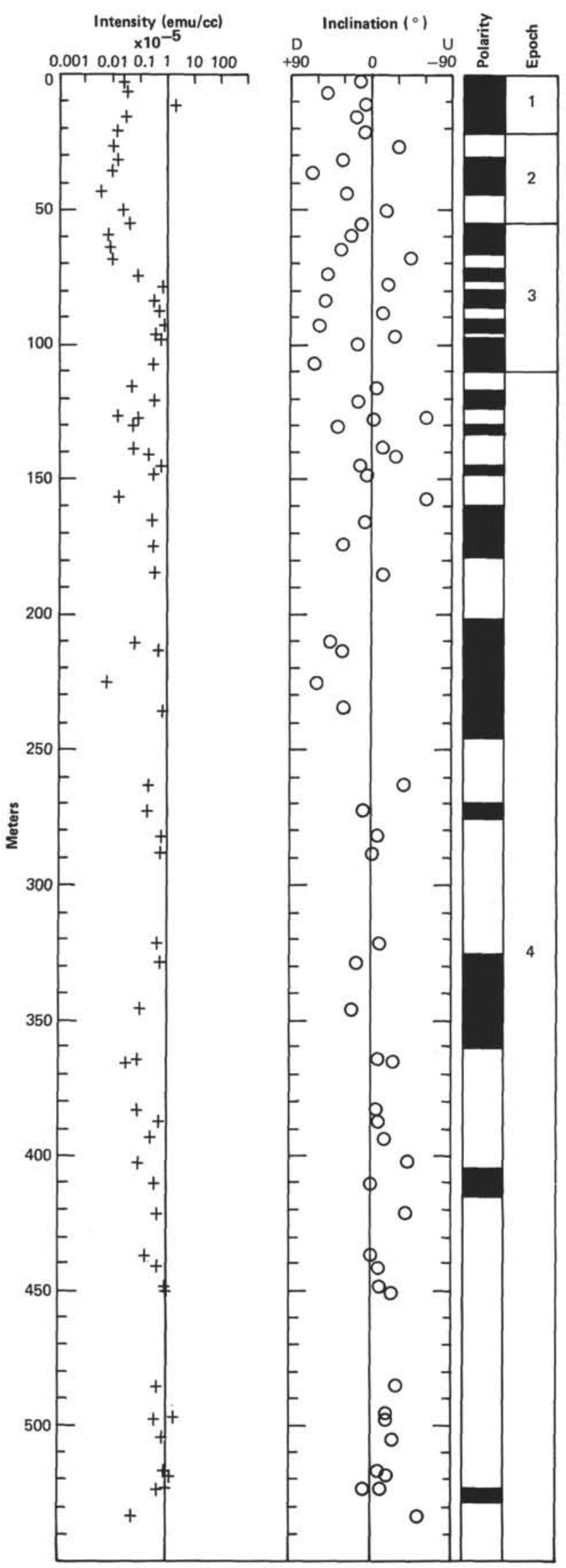

Figure 14. Magnetostratigraphy, Hole 491, lower slope.

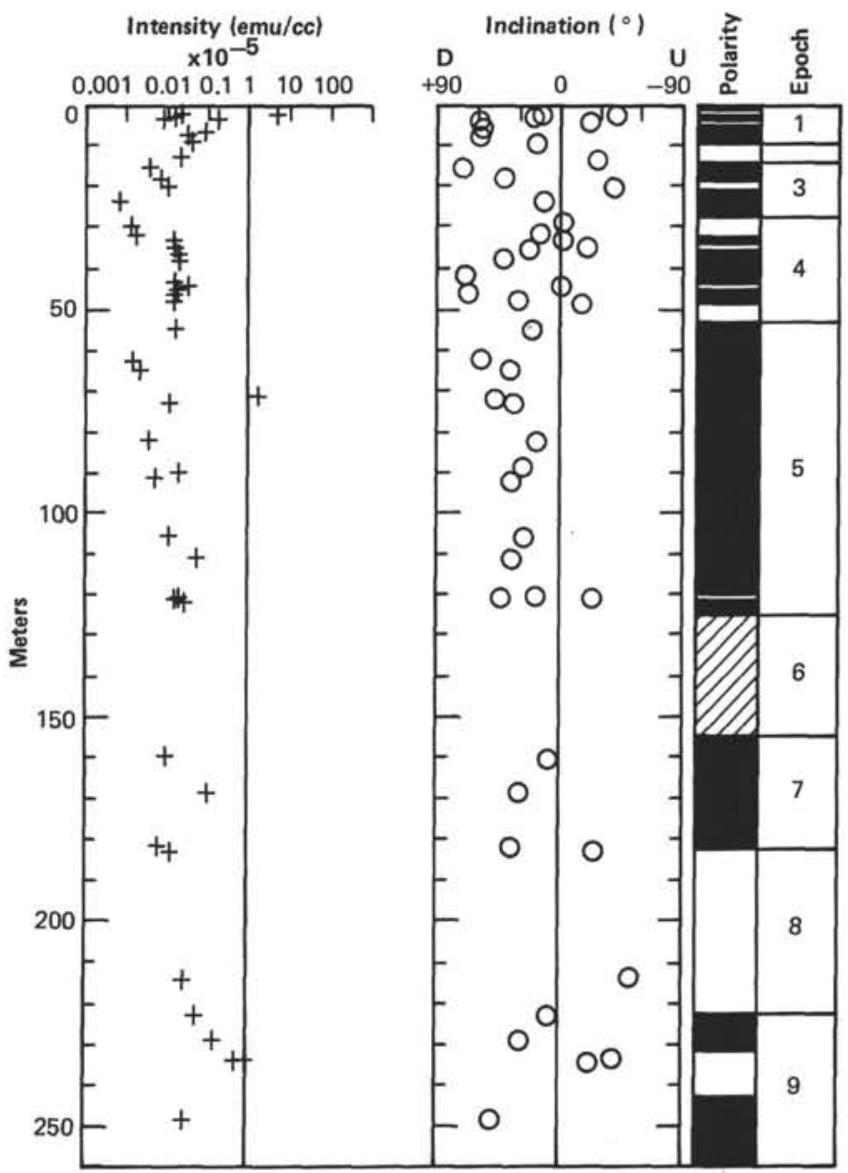

Figure 15. Magnetostratigraphy, Hole 492, lower slope.

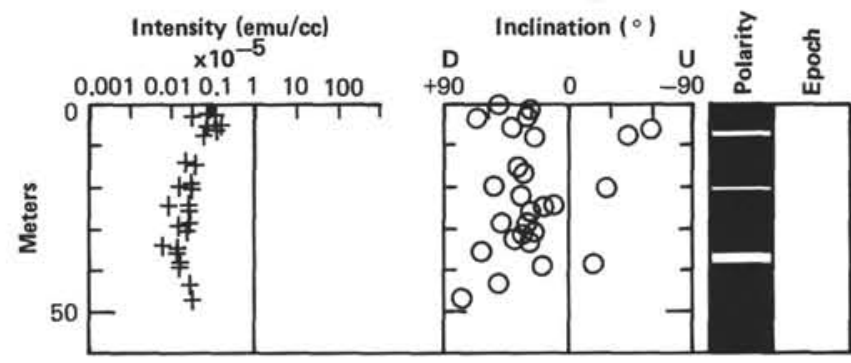

Figure 16. Magnetostratigraphy, Hole 492A, lower slope.

\section{SEDIMENT ACCUMULATION ON THE LOWER SLOPE AND OUTER RISE DURING THE LAST 0.69 M.Y.}

\section{Rate of Sedimentation}

There exists a clear relationship between rate of sedimentation and the distance of sites from the Middle America Trench (Fig. 19): the rate (paleomagnetically determined) of sedimentation during the last 0.69 m.y. (Brunhes Normal Polarity Epoch) in the lower slope area, Sites 488, 491, and 492, clearly decreases as distance from the trench increases (see also Shepard and McMillen, this volume). 


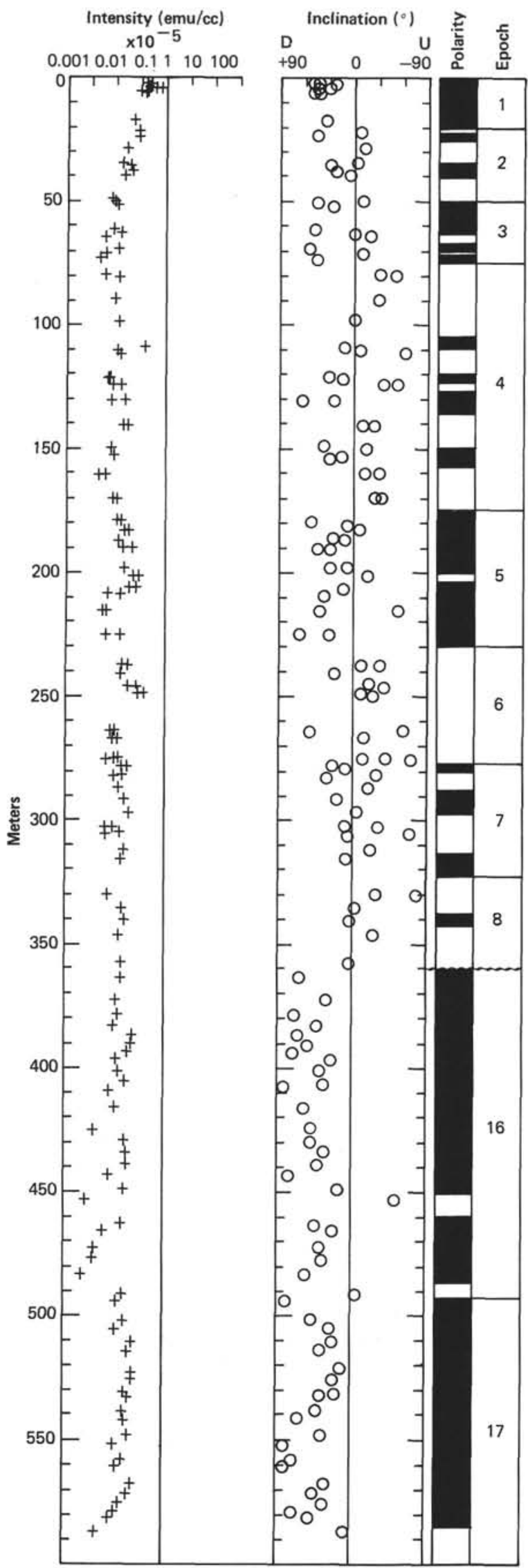

Figure 17. Magnetostratigraphy, Holes 493, 493A, and 493B, upper slope.

\begin{tabular}{ccc}
\hline Site & $\begin{array}{c}\text { Distance from } \\
\text { the Trench } \\
(\mathrm{km})\end{array}$ & $\begin{array}{c}\text { Sedimentation Rate } \\
\text { during Last 0.69 m.y. } \\
(\mathrm{m} / \mathrm{m} . \mathrm{y} .)\end{array}$ \\
\hline 488 & 6.6 & 374 \\
491 & 16.7 & 31.9 \\
492 & 22.8 & 14.8 \\
\hline
\end{tabular}

Figure 19 shows that the rate of sedimentation in the lower slope area decreases exponentially with an increase in distance from the trench. The relation can be expressed by the following equation:

$$
r=R e^{-k_{s} D},
$$

where $r$ is rate of sedimentation in $\mathrm{m} / \mathrm{m}$.y. at a given site at a distance of $D(\mathrm{~km})$ from the trench axis, $R$ is a rate of sedimentation along the trench axis in $\mathrm{m} / \mathrm{m} . \mathrm{y}$., and $k_{s}$ is a constant. Using the data of the three sites, we obtain 0.21 as the value of $k_{s}$. This value means that the rate of sedimentation in the lower slope decreases one order of magnitude every $11.2 \mathrm{~km}$ of distance from the trench axis and the rate of sedimentation along the trench axis may be $1353 \mathrm{~m} / \mathrm{m} . \mathrm{y}$.

We have to treat Site 487 in a somewhat different manner, because it is at the east end of the Cocos Plate. There is an interesting change in rate of sedimentation in the sequence at Site 487 . The rate of sedimentation at $6.9 \mathrm{~m} / \mathrm{m}$.y. was almost constant before $0.89 \mathrm{Ma}$. Since then the rate increased rapidly to more than $127 \mathrm{~m} / \mathrm{m}$.y. This increase is probably related to the change in the relative location of Site 487 with respect to the Middle America Trench, the change being due to ocean floor spreading and subduction. I analyzed this increased rate, using the rate of Cocos Plate motion against that of the North American Plate and assuming that sedimentation rate decreases exponentially with increase in distance from the trench axis. Given these assumptions, the rate of sedimentation can be expressed by the following equation:

$$
r=R e^{-k_{a} D},
$$

where $r(\mathrm{~m} / \mathrm{m} . \mathrm{y}$.$) is rate of sedimentation at given point$ at a distance $D(\mathrm{~km})$ from the trench axis, $R(\mathrm{~m} / \mathrm{m}$.y.) is a rate of sedimentation at the trench axis, and $k_{a}$ is a constant.

Assuming the convergence rate of the Cocos and North American plates to be $69 \mathrm{~km} / \mathrm{m}$.y. (Minster and Jordan, 1978), the distance of the Site 487 from the trench axis can be calculated by the following equation:

$$
D=D_{p}+69 \times t,
$$

where $D(\mathrm{~km})$ is a distance from the trench axis at $t \mathrm{Ma}$, and $D_{p}(\mathrm{~km})$ is present distance of the site from the trench axis. Using Equations (2) and (3), we can obtain an equation for changing rate of sedimentation with time:

$$
r=R e^{-k_{a}(D p+69 t)} .
$$


Table 7. Paleomagnetic results at Site 487 , outer rise.

\begin{tabular}{|c|c|c|c|c|c|c|c|c|}
\hline Hole & Core & Section & Interval $(\mathrm{cm})$ & $\begin{array}{l}\text { Sub-bottom } \\
\text { Depth } \\
\text { (m) }\end{array}$ & $\begin{array}{l}\text { AF Demag. } \\
\text { Field (Oe) }\end{array}$ & $\begin{array}{c}\text { Relative } \\
\text { Declination }\end{array}$ & Inclination & $\begin{array}{c}\text { Intensity } \\
\left(\times 10^{-6} \mathrm{emu} / \mathrm{cc}\right)\end{array}$ \\
\hline \multirow[t]{57}{*}{487} & 3 & 4 & $52.0-54.0$ & 15.53 & 0 & 59.2 & 67.4 & 5.81 \\
\hline & 3 & 4 & $52.0-54,0$ & 15.53 & 150 & 56.9 & 78.6 & 3.24 \\
\hline & 5 & 1 & $132.0-134.0$ & 30.83 & 0 & 252.5 & 31.7 & 0.87 \\
\hline & 5 & 1 & $132.0-134.0$ & 30.83 & 150 & 248.8 & 50.8 & 0.75 \\
\hline & 5 & 2 & $65.0-67.0$ & 31.66 & 0 & 86.3 & -29.1 & 1.75 \\
\hline & 5 & 2 & $65.0-67.0$ & 31.66 & 150 & 84.5 & -37.0 & 1.54 \\
\hline & 5 & 3 & $90.0-92.0$ & 33.41 & 0 & 90.9 & 66.9 & 4.35 \\
\hline & 5 & 3 & $90.0-92.0$ & 33.41 & 150 & 76.6 & 60.2 & 3.72 \\
\hline & 6 & 1 & $60.0-62.0$ & 39.61 & 150 & 336.6 & 46.5 & 12.73 \\
\hline & 6 & 2 & $60.0-62.0$ & 41.11 & 150 & 244.3 & 24.0 & 16.99 \\
\hline & 6 & 3 & $99.0-101.0$ & 43.00 & 150 & 141.4 & 62.3 & 13.36 \\
\hline & 7 & 1 & $25.0-27.0$ & 48.76 & 150 & 217.0 & 27.9 & 13.07 \\
\hline & 7 & i & $135.0-137.0$ & 49.86 & 150 & 338.5 & 74.2 & 6.90 \\
\hline & 8 & i & $100.0-102.0$ & 59.01 & 150 & 150.6 & 62.5 & 13.32 \\
\hline & 8 & 2 & $135.0-137.0$ & 60.86 & 150 & 15.9 & 45.7 & 9.23 \\
\hline & 8 & 3 & $46.0-48.0$ & 61.47 & 150 & 158.3 & 7.5 & 11.70 \\
\hline & 8 & 4 & $125.0-127.0$ & 63.76 & 150 & 245.8 & 7.2 & 6.28 \\
\hline & 8 & 5 & $88.0-90.0$ & 64.89 & 150 & 215.4 & 41.5 & 10.76 \\
\hline & 8 & 6 & $84.0-86.0$ & 66.35 & 150 & 262.1 & 51.0 & 12.98 \\
\hline & 9 & 1 & $30.0-32.0$ & 67.81 & 150 & 128.4 & 67.5 & 10.82 \\
\hline & 9 & 2 & $135.0-137.0$ & 70.36 & 150 & 241.2 & 64.7 & 20.63 \\
\hline & 9 & 3 & $53.0-55.0$ & 71.04 & 150 & 170.0 & 64.9 & 11.36 \\
\hline & 9 & 4 & $32.0-34.0$ & 72.33 & 150 & 4.0 & 38.4 & 9.83 \\
\hline & 9 & 5 & $118.0-120.0$ & 74.69 & 150 & 292.0 & 73.6 & 9.72 \\
\hline & 9 & 6 & $82.0-84.0$ & 75.83 & 150 & 59.7 & 67.2 & 0.95 \\
\hline & 10 & 7 & $9.0-11.0$ & 86.10 & 150 & 158.1 & 48.5 & 0.38 \\
\hline & iI & 2 & $98.0-100.0$ & 88.99 & 150 & 25.1 & -4.7 & 12.56 \\
\hline & 11 & 4 & $81.0-83.0$ & 91.82 & 150 & 134.9 & 78.0 & 4.59 \\
\hline & 12 & 3 & $76.0-78.0$ & 99.77 & 150 & 175.0 & -5.1 & 6.01 \\
\hline & 12 & 4 & $31.0-33.0$ & 100.82 & 150 & 329.7 & -13.9 & 1.89 \\
\hline & 12 & 4 & $92.0-94.0$ & 101.43 & 150 & 210.9 & -34.1 & 9.24 \\
\hline & 12 & 5 & $41.0-43.0$ & 102.42 & 150 & 325.3 & 49.0 & 7.48 \\
\hline & 13 & 2 & $65.0-67.0$ & 107.66 & 150 & 2.4 & 76.4 & 8.77 \\
\hline & 13 & 3 & $80.0-82.0$ & 109.31 & 150 & 192.6 & -38.1 & 4.10 \\
\hline & 13 & 4 & $90.0-92.0$ & 110.91 & 150 & 115.6 & -10.7 & 12.24 \\
\hline & 13 & 5 & $33.0-35.0$ & 111.84 & 150 & 10.3 & 19.7 & 9.59 \\
\hline & 14 & $i$ & $61.0-63.0$ & 115.62 & 150 & 251.4 & -16.9 & 4.81 \\
\hline & 14 & 2 & $100.0-102.0$ & 117.51 & 0 & 116.4 & 35.3 & 5.39 \\
\hline & 14 & 2 & $100.0-102.0$ & 117.51 & 150 & 166.3 & -26.5 & 0.73 \\
\hline & 14 & 3 & $42.0-44.0$ & 118.43 & 150 & 200.6 & -14.3 & 2.83 \\
\hline & is & 2 & $74.0-76.0$ & 126.75 & 150 & 51.4 & 8.8 & 3.19 \\
\hline & 15 & 3 & $67.0-69.0$ & 128.18 & 150 & 48.7 & -18.8 & 0.73 \\
\hline & 15 & 4 & $57.0-59.0$ & 129.58 & 150 & 33.2 & -3.0 & 2.62 \\
\hline & is & 5 & $46.0-48.0$ & 130.97 & 150 & 211.1 & 51.0 & 3.81 \\
\hline & is & 6 & $41.0-43.0$ & 132.42 & 150 & 219.5 & 11.4 & 1.63 \\
\hline & 15 & 7 & $26.0-28.0$ & 133.77 & 150 & 301.2 & 3.5 & 6.75 \\
\hline & 16 & 1 & $47.0-49.0$ & 134.48 & 150 & 33.9 & -57.8 & 8.81 \\
\hline & 16 & 2 & $66.0-68.0$ & 136.17 & 150 & 201.5 & -37.6 & 6.14 \\
\hline & 17 & 2 & $30.0-32.0$ & 145.31 & 150 & 5.5 & 36.9 & 1.14 \\
\hline & 18 & $i$ & $68.0-70.0$ & 153.69 & 150 & 256.3 & 39.8 & 2.48 \\
\hline & 18 & 2 & $131.0-133.0$ & 155.82 & 150 & 71.2 & -16.9 & 5.30 \\
\hline & 18 & 3 & $73.0-75.0$ & 156.74 & 150 & 286.6 & 50.1 & 2.42 \\
\hline & 18 & 4 & $69.0-71.0$ & 158.20 & 150 & 204.6 & 4.0 & 2.31 \\
\hline & 18 & 5 & $20.0-22.0$ & 159.21 & 150 & 260.0 & -15.2 & 1.52 \\
\hline & 18 & 6 & $128.0-130.0$ & 161.79 & 150 & 63.4 & 63.6 & 0.95 \\
\hline & 19 & 2 & $16.0-18.0$ & 164.17 & 0 & 132.2 & -0.1 & 2.83 \\
\hline & 19 & 2 & $16.0-18.0$ & 164.17 & 150 & 181.2 & -32.3 & 2.94 \\
\hline
\end{tabular}

Integrating Equation (4) obtains the thickness of sediments that have accumulated at a given site during a time interval from $T_{1}$ to $T_{2}$ as follows:

$$
H=\int_{T_{1}}^{T_{2}} r d t=\int_{T_{1}}^{T_{2}} R e^{-k_{a}\left(D_{p}+69 t\right)} d t
$$

and

$$
H=\frac{R}{69 k_{a} e^{k_{a} D p}}\left[-e^{-69 k_{a} t}\right]_{T_{1}}^{T_{2}} .
$$

By using magnetostratigraphic data from Site 487, which include the Brunhes/Matuyama boundary of 0.69 Ma at 87.5 meters subdepth and the upper limit of the Jaramillo Event of $0.89 \mathrm{Ma}$ at 90 meters subdepth, we obtain the value of $k_{a}: 0.065$. This means the rate of sedimentation decreases one order of magnitude for every $35 \mathrm{~km}$.

If we assume a conformable relationship between rates of sedimentation and the distance from the trench on both the ocean and land sides, a maximum rate and position of sediment accumulation is predicted by the equations. The maximum rate occurs $2 \mathrm{~km}$ landward of the topographic trench axis (Fig. 19). Using this maximum rate $(900 \mathrm{~m} / \mathrm{m} . y$.$) , we can write the sediment ac-$ cumulation rate equation at a site with a distance $D \mathrm{~km}$ from the maximum rate position, as follows (ocean side):

$$
r_{o}=900 e^{-0.065 D}
$$

and (land side)

$$
r_{s}=900 e^{-0.21 D} .
$$

Figure 19 shows the relation between the submarine topography and calculated rates of sediment accumulation. In this figure it is noteworthy that the constantrate line of $10 \mathrm{~m} / \mathrm{m}$.y. passes over the sub-bottom depression formed by the Middle America Trench. The constant-rate line connects the outer limit of the gentle upper slope and the inner limit of the flat outer rise at a water depth of 3450 to 3500 meters. This distribution of constant-rate lines means that the sands and fine sediments from turbidity currents are accumulating within 
Table 8. Paleomagnetic results and bedding orientations at Site 488 , lower slope.

\begin{tabular}{|c|c|c|c|c|c|c|c|c|c|c|}
\hline Hole & Core & Section & Interval $(\mathrm{cm})$ & $\begin{array}{l}\text { Sub-bottom } \\
\text { Depth } \\
\text { (m) }\end{array}$ & $\begin{array}{l}\text { AF Demag. } \\
\text { Field (Oe) }\end{array}$ & $\begin{array}{c}\text { Relative } \\
\text { Declination }\end{array}$ & Inclination & $\begin{array}{c}\text { Intensity } \\
\left(\times 10^{-6} \mathrm{emu} / \mathrm{cc}\right)\end{array}$ & $\begin{array}{l}\text { Bedding Or } \\
\text { Strike }\end{array}$ & $\begin{array}{l}\text { ientation } \\
\text { Dip }\end{array}$ \\
\hline \multirow[t]{72}{*}{488} & 2 & 1 & $103.0-105.5$ & 2.04 & 150 & 126.8 & 5.5 & 111.41 & & \\
\hline & 2 & 1 & $106.0-108.0$ & 2.07 & 150 & 88.1 & 31.9 & 10.40 & & \\
\hline & 2 & 1 & $109.0-111.0$ & 2.10 & 150 & 294.0 & -18.6 & 43.95 & & \\
\hline & 2 & 1 & $112.0-114.5$ & 2.13 & 150 & 91.4 & 37.8 & 11.70 & & \\
\hline & 2 & 1 & $114.5-117.5$ & 2.16 & 150 & 87.6 & 38.7 & 13.52 & & \\
\hline & 2 & 4 & $131.0-133.0$ & 6.82 & 150 & 149.3 & 55.1 & 6.75 & & \\
\hline & 3 & 1 & $106.0-108.0$ & 11.57 & 150 & 224.1 & 20.4 & 6.79 & & \\
\hline & 4 & 3 & $10.0-12.5$ & 23.11 & 150 & 169.6 & 26.2 & 24.50 & & \\
\hline & 4 & 3 & $13.0-15.0$ & 23.14 & 150 & 225.0 & -31.6 & 84.97 & & \\
\hline & 4 & 3 & $15.0-17.0$ & 23.16 & 150 & 322.7 & -10.6 & 50.34 & & \\
\hline & 4 & 3 & $51.0-53.0$ & 23.52 & 150 & 195.2 & 9.3 & 6.16 & & \\
\hline & 4 & 6 & $74.0-76.0$ & 28.25 & 150 & 122.4 & 28.7 & 1.61 & & \\
\hline & 5 & 6 & $60.0-62.0$ & 37.61 & 150 & 289.6 & 30.6 & 1.07 & & \\
\hline & 5 & 6 & $68.0-70.0$ & 37.69 & 150 & 207.3 & -31.8 & 0.74 & & \\
\hline & 5 & 6 & $77.0-79.0$ & 37.78 & 150 & 219.6 & -12.6 & 1.13 & & \\
\hline & 6 & 6 & $27.0-29.0$ & 46.78 & 150 & 251.9 & 16.0 & 15.37 & & \\
\hline & 9 & 1 & $93.0-96.0$ & 68.45 & 150 & 284.3 & 42.9 & 3.15 & & \\
\hline & 9 & 3 & $27.0-29.0$ & 70.78 & 150 & 309.3 & 60.2 & 3.83 & & \\
\hline & 10 & 4 & $93.0-95.0$ & 82.44 & 150 & 132.9 & 59.0 & 5.95 & & \\
\hline & 11 & 6 & $57.0-59.0$ & 94.58 & 150 & 280.6 & 30.4 & 9.12 & & \\
\hline & 13 & 1 & $45.0-47.0$ & 105.96 & 150 & 123.6 & 27.7 & 13.51 & & \\
\hline & 13 & 3 & $135.0-137.0$ & 109.86 & 150 & 352.1 & 85.6 & 0.51 & & \\
\hline & 13 & 4 & $68.0-70.0$ & 110.69 & 150 & 68.2 & 19.1 & 1.36 & & \\
\hline & 14 & 1 & $130.0-132.0$ & 116.31 & 150 & 46.2 & 37.5 & 3.37 & & \\
\hline & 15 & 2 & $20.0-22.0$ & 126.21 & 150 & 138.1 & 35.9 & 5.37 & & \\
\hline & 16 & 1 & $102.0-104.0$ & 135.03 & 150 & 318.0 & 48.9 & 5.49 & & \\
\hline & 16 & 5 & $6.0-8.0$ & 140.07 & 150 & 204.8 & 24.0 & 2.79 & & \\
\hline & 18 & 1 & $59.0-61.0$ & 153.60 & 150 & 74.6 & 44.3 & 13.11 & & \\
\hline & 18 & 5 & $69.0-71.0$ & 159.70 & 150 & 153.8 & 38.6 & 10.95 & & \\
\hline & 19 & 1 & $13.0-15.0$ & 162.64 & 150 & 97.0 & 29.3 & 4.54 & & \\
\hline & 19 & 5 & $21.0-23.0$ & 168.72 & 150 & 204.8 & 26.4 & 24.12 & & \\
\hline & 20 & 1 & $41.0-43.0$ & 172.42 & 150 & 124.2 & 28.3 & 12.11 & & \\
\hline & 20 & 3 & $131.0-133.0$ & 176.32 & 150 & 76.6 & 50.4 & 12.16 & & \\
\hline & 21 & 1 & $129.0-131.0$ & 182.80 & 150 & 16.3 & 31.1 & 19.16 & & \\
\hline & 21 & 5 & $128.0-130.0$ & 188.79 & 150 & 79.3 & 15.2 & 4.77 & & \\
\hline & 22 & 1 & $112.0-114.0$ & 192.13 & 150 & 12.8 & 31.1 & 25.27 & & \\
\hline & 22 & 3 & $129.0-131.0$ & 195.30 & 150 & 191.8 & 23.2 & 1.00 & & \\
\hline & 23 & 1 & $137.0-139.0$ & 201.88 & 150 & 240.4 & 16.9 & 4.36 & & \\
\hline & 24 & 1 & $66.0-68.0$ & 210.67 & 150 & 298.7 & 28.0 & 1.14 & & \\
\hline & 25 & 1 & $118.0-120.0$ & 220.69 & 150 & 22.6 & 16.8 & 8.95 & & \\
\hline & 26 & 1 & $134.0-136.0$ & 230.35 & 150 & 259.3 & 30.8 & 31.29 & & \\
\hline & 26 & 5 & $78.0-80.0$ & 235.79 & 150 & 332.3 & 58.8 & 41.02 & & \\
\hline & 27 & 1 & $135.0-137.0$ & 239.86 & 150 & 267.7 & 33.6 & 17.87 & & \\
\hline & 29 & 1 & $27.0-29.0$ & 257.78 & 150 & 141.9 & 1.0 & 0.72 & & \\
\hline & 29 & 5 & $9.0-11.0$ & 263.60 & 150 & 164.7 & -44.0 & 0.24 & & \\
\hline & 30 & 1 & $122.0-124.0$ & 265.73 & 150 & 112.2 & 54.9 & 1.43 & & \\
\hline & 30 & 5 & $135.0-137.0$ & 271.86 & 150 & 59.7 & -9.6 & 0.05 & & \\
\hline & 31 & 1 & $98.0-100.0$ & 276.99 & 150 & 177.0 & -68.0 & 0.82 & & \\
\hline & 31 & 3 & $131.0-132.0$ & 280.32 & 150 & 227.2 & -46.4 & 1.14 & & \\
\hline & 32 & 1 & $134.0-136.0$ & 286.35 & 150 & 345.1 & -53.1 & 5.18 & & \\
\hline & 32 & 3 & $99.0-101.0$ & 289.00 & 150 & 176.0 & -33.5 & 1.59 & & \\
\hline & 32 & 4 & $2.0-4.0$ & 289.53 & 150 & 31.8 & 6.0 & 1.68 & & \\
\hline & 32 & 4 & $4.0-6.0$ & 289.55 & 150 & 267.0 & 3.0 & 1.68 & & \\
\hline & 32 & 4 & $7.0-9.0$ & 289.58 & 150 & 215.4 & -4.7 & 2.31 & & \\
\hline & 32 & 4 & $10.0-12.0$ & 289.61 & 150 & 261.5 & -14.0 & 1.72 & & \\
\hline & 32 & 4 & $13.0-15.0$ & 289.64 & 150 & 135.9 & -39.7 & 1.69 & & \\
\hline & 32 & 4 & $16.0-18.0$ & 289.67 & 150 & 2.5 & -10.3 & 1.19 & & \\
\hline & 32 & 4 & $30.0-32.0$ & 289.81 & 150 & 112.2 & 12.5 & 1.54 & & \\
\hline & 32 & 4 & $49.0-51.0$ & 290.00 & 150 & 34.6 & 4.1 & 1.82 & & \\
\hline & 32 & 4 & $63.0-65.0$ & 290.14 & 150 & 320.1 & 4.6 & 1.51 & & \\
\hline & 32 & 4 & $87.0-89.0$ & 290.38 & 150 & 185.0 & 1.4 & 1.89 & & \\
\hline & 33 & 1 & $80.0-82.0$ & 294.81 & 150 & 29.8 & -0.8 & 5.53 & & \\
\hline & 33 & 5 & $24.0-26.0$ & 300.25 & 150 & 265.8 & -6.9 & 47.50 & & \\
\hline & 34 & 1 & $55.0-57.0$ & 303.56 & 150 & 314.5 & 1.7 & 8.73 & & \\
\hline & 34 & 5 & $45.0-47.0$ & 309.46 & 150 & 283.1 & -26.3 & 9.35 & & \\
\hline & 37 & 2 & $23.0-25.0$ & 335.24 & 150 & 342.3 & 26.2 & 18.96 & & \\
\hline & 40 & 2 & $1.0-3.0$ & 363.52 & 150 & 95.2 & 20.2 & 36.62 & & \\
\hline & 40 & 2 & $21.0-23.0$ & 363.72 & 150 & 166.7 & 33.5 & 15.96 & & \\
\hline & 42 & 2 & $15.0-17.0$ & 382.66 & 150 & 207.3 & 16.0 & 14.65 & N $27 \mathrm{~W}$ & $20 \mathrm{E}$ \\
\hline & 42 & 2 & $54.0-56.0$ & 383.05 & 150 & 200.0 & 14.5 & 47.44 & $20 \mathrm{~W}$ & $20 \mathrm{E}$ \\
\hline & 43 & 1 & $137.0-139.0$ & 391.88 & 150 & 20.2 & 13.4 & 12.70 & $20 \mathrm{~W}$ & $35 \mathrm{E}$ \\
\hline & 45 & 7 & $55.0-57.0$ & 419.06 & 150 & 78.3 & 17.4 & 37.50 & & \\
\hline
\end{tabular}


Table 9. Paleomagnetic results, Site 489, upper slope.

\begin{tabular}{|c|c|c|c|c|c|c|c|c|}
\hline Hole & Core & Section & Interval $(\mathrm{cm})$ & $\begin{array}{l}\text { Sub-bottom } \\
\text { Depth } \\
\text { (m) }\end{array}$ & $\begin{array}{l}\text { AF Demag. } \\
\text { Field (Oe) }\end{array}$ & $\begin{array}{c}\text { Relative } \\
\text { Declination }\end{array}$ & Inclination & $\begin{array}{c}\text { Intensity } \\
\left(\times 10^{-6} \mathrm{emu} / \mathrm{cc}\right)\end{array}$ \\
\hline \multirow[t]{7}{*}{489} & 1 & 2 & $119.0-121.0$ & 2.70 & 150 & 197.9 & -46.6 & 0.270 \\
\hline & 1 & 4 & $47.0-49.0$ & 4.98 & 150 & 5.8 & 6.5 & 0.560 \\
\hline & 2 & 1 & $134.0-136.0$ & 7.35 & 150 & 15.0 & -0.8 & 0.100 \\
\hline & 2 & 5 & $96.0-98.0$ & 12.97 & 150 & 22.1 & -2.7 & 0.100 \\
\hline & 3 & 1 & $114.0-116.0$ & 16.65 & 150 & 133.9 & 17.0 & 0.140 \\
\hline & 3 & 5 & $51.0-53.0$ & 22.02 & 150 & 204.6 & -62.3 & 0.090 \\
\hline & 4 & 1 & $73.0-75.0$ & 25.74 & 150 & 226.3 & -47.8 & 0.050 \\
\hline \multirow[t]{37}{*}{ 489A } & 4 & 1 & $59.0-61.0$ & 56.10 & 150 & 42.1 & -82.4 & 0.001 \\
\hline & 4 & 5 & $95.0-97.0$ & 62.46 & 150 & 349.3 & 27.3 & 0.020 \\
\hline & 5 & 1 & $138.0-140.0$ & 66.39 & 150 & 212.5 & 65.6 & 0.001 \\
\hline & 5 & 5 & $80.0-82.0$ & 71.81 & 150 & 85.1 & -37.2 & 0.035 \\
\hline & 6 & 1 & $67.0-69.0$ & 75.18 & 150 & 216.5 & 28.6 & 0.103 \\
\hline & 6 & 3 & $141.0-143.0$ & 78.92 & 150 & 277.2 & 56.6 & 0.248 \\
\hline & 7 & 1 & $131.0-133.0$ & 85.32 & 150 & 319.3 & 36.0 & 0.036 \\
\hline & 7 & 5 & $33.0-35.0$ & 90.34 & 150 & 354.1 & 0.3 & 0.082 \\
\hline & 8 & 1 & $129.0-131.0$ & 94.80 & 150 & 1.7 & 34.5 & 0.014 \\
\hline & 8 & 3 & $136.0-138.0$ & 97.87 & 150 & 250.6 & 51.6 & 0.067 \\
\hline & 9 & 2 & $92.0-94.0$ & 105.43 & 150 & 36.6 & 61.4 & 0.001 \\
\hline & II & 4 & $68.0-70.0$ & 137.19 & 150 & 159.8 & 21.2 & 0.017 \\
\hline & 12 & 1 & $3.0-5.0$ & 131.54 & 150 & 27.4 & -53.3 & 0.008 \\
\hline & 13 & 1 & $145.0-147.0$ & 142.46 & 150 & 47.1 & 10.6 & 0.082 \\
\hline & 15 & 1 & $119.0-121.0$ & 161.20 & 150 & 346.9 & 51.5 & 0.086 \\
\hline & 16 & 4 & $3.0-5.0$ & 169.04 & 150 & 350.9 & 16.8 & 0.046 \\
\hline & 19 & 1 & $55.0-57.0$ & 183.56 & 150 & 22.5 & 30.8 & 0.328 \\
\hline & 20 & 1 & $142.0-144.0$ & 189.93 & 150 & 354.4 & 9.1 & 0.069 \\
\hline & 21 & 3 & $96.0-98.0$ & 201.97 & 150 & 313.6 & -22.7 & 0.178 \\
\hline & 21 & 6 & $117.0-119.0$ & 206.68 & 150 & 5.9 & 28.1 & 1.556 \\
\hline & 21 & 1 & $108.0-110.0$ & 208.59 & 150 & 208.7 & 30.5 & 0.315 \\
\hline & 22 & 5 & $57.0-59.0$ & 214.08 & 150 & 41.2 & -39.1 & 0.533 \\
\hline & 23 & 2 & $109.0-111.0$ & 219.60 & 150 & 154.0 & 21.7 & 0.234 \\
\hline & 23 & 5 & $132.0-134.0$ & 224.33 & 150 & 139.5 & -54.4 & 0.177 \\
\hline & 24 & 2 & $38.0-40.0$ & 228.39 & 150 & 24.2 & 24.5 & 0.235 \\
\hline & 24 & 6 & $40.0-42.0$ & 234.41 & 150 & 298.0 & 65.3 & 0.054 \\
\hline & 25 & 2 & $139.0-141.0$ & 238.90 & 150 & 333.5 & -20.0 & 0.008 \\
\hline & 25 & 5 & $112.0-114.0$ & 243.13 & 150 & 5.0 & -6.0 & 0.011 \\
\hline & 26 & 1 & $124.0-126.0$ & 246.75 & 150 & 55.4 & -28.3 & 0.082 \\
\hline & 26 & 4 & $58.0-60.0$ & 250.59 & 150 & 176.8 & -71.3 & 0.048 \\
\hline & 27 & 3 & $130.0-132.0$ & 259.31 & 150 & 30.6 & -55.2 & 0.105 \\
\hline & 28 & 2 & $100.0-102.0$ & 266.51 & 150 & 88.6 & 27.5 & 0.059 \\
\hline & 29 & 1 & $138.0-140.0$ & 274.39 & 150 & 57.1 & -4.7 & 0.130 \\
\hline & 29 & 5 & $102.0-104.0$ & 280.03 & 150 & 33.6 & -28.0 & 0.128 \\
\hline & 30 & 2 & $82.0-84.0$ & 284.33 & 150 & 38.1 & 27.3 & 0.270 \\
\hline & 30 & 5 & $105.0-107.0$ & 289.06 & 150 & 250.9 & -77.4 & 0.196 \\
\hline & 31 & 2 & $80.0-82.0$ & 293.31 & 150 & 199.6 & -27.2 & 0.071 \\
\hline
\end{tabular}

the topographic depression along the Middle America Trench.

The total accumulation rate along the Middle America Trench can be calculated using Equations (7) and (8). The total volume of the sediments accumulated in the trench is represented by the area of the sediments in cross section, which can be calculated by integrating Equations (7) and (8).

$$
\begin{aligned}
S= & \int_{0}^{\infty} r_{o} d D+\int_{0}^{\infty} r_{s} d D=\int_{0}^{\infty} 0.9 e^{-0.065 D} d D \\
& +\int_{0}^{\infty} 0.9 e^{-0.21 D} d D \\
S= & {\left[-\frac{0.9 e^{-0.065 D}}{0.065}\right]_{0}^{\infty}+\left[-\frac{0.9 e^{-0.21 D}}{0.21}\right]_{0}^{\infty} } \\
S= & \frac{0.9}{0.065}+\frac{0.9}{0.21}=13.8+4.3=18.1,
\end{aligned}
$$

where $S$ is the area of sediments accumulated during 1 $\mathrm{m} . \mathrm{y}$. in $\mathrm{km}^{2}$ (on the cross section).

The porosity of accumulating sediments during last $0.69 \mathrm{~m} . \mathrm{y}$. (Shephard et al., this volume) are listed in the following table.

\begin{tabular}{cccr}
\hline Site & $\begin{array}{c}\text { Porosity of } \\
(\%)\end{array}$ & $\begin{array}{c}\text { Porosity of } \\
\text { Area Base } \\
(\%)\end{array}$ & $\begin{array}{c}\text { Thickness } \\
(\mathrm{m})\end{array}$ \\
\hline 492 & 66 & 51 & 9.5 \\
491 & 61 & 48 & 22.0 \\
488 & $\begin{array}{c}61 \\
\text { decrease } \\
\text { from 65 to } \\
45 \text { with } \\
\end{array}$ & $49-33$ & 258.0 \\
487 & $\begin{array}{c}\text { subdepth } \\
78\end{array}$ & 64 & 87.5 \\
\hline
\end{tabular}

The weighted average porosity is $47 \%$ for the accumulating sediments. Thus the total amount of accumulating sediments along the trench area without pore space is $9.6 \mathrm{~km}^{2} / \mathrm{m} . \mathrm{y}$. $(18.1 \times 0.53)$. As the area of sediment accretion under the lower slope is $106.9 \mathrm{~km}^{2}$ and the estimated porosity of area base is $23 \%$ (33\% of volume base), the sediment under the lower slope can be accreted for $8.6 \mathrm{~m} . y$., assuming accretion from the accumulation of sediment along the trench area. The calculated duration is consistent with the oldest age of cored sediments in the upper part of the lower slope at Site 492.

\section{Magnetization Boundary in Lower Slope and Outer Rise}

There is a noticeable variety in intensity of remanent magnetization of the sediments accumulated in the lower slope and outer rise areas during last 0.69 m.y.: 
Table 10. Paleomagnetic results and bedding orientation at Site 490, upper slope.

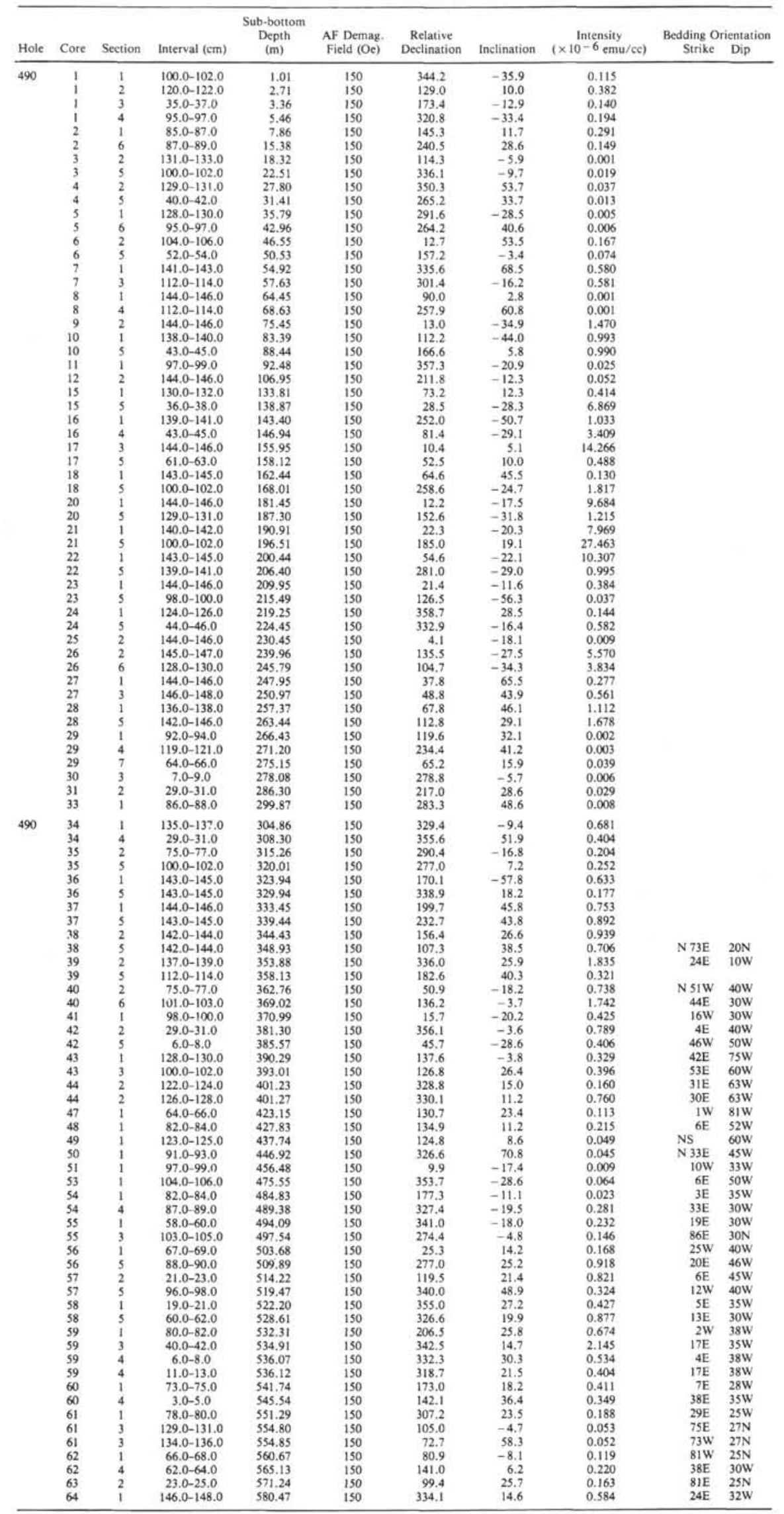


Table 11. Paleomagnetic results and bedding orientation at Site 491, lower slope.

\begin{tabular}{|c|c|c|c|c|c|c|c|c|c|c|c|}
\hline \multirow[b]{2}{*}{ Hole } & \multirow[b]{2}{*}{ Core } & \multirow[b]{2}{*}{ Section } & \multirow[b]{2}{*}{ Interval $(\mathrm{cm})$} & \multirow{2}{*}{$\begin{array}{l}\text { Sub-bottom } \\
\text { Depth } \\
\text { (m) }\end{array}$} & \multirow{2}{*}{$\begin{array}{l}\text { AF Demag. } \\
\text { Field (Oe) }\end{array}$} & \multirow{2}{*}{$\begin{array}{c}\text { Relative } \\
\text { Declination }\end{array}$} & \multirow[b]{2}{*}{ Inclination } & \multirow{2}{*}{$\begin{array}{c}\text { Intensity } \\
\left(\times 10^{-6} \mathrm{emu} / \mathrm{cc}\right)\end{array}$} & $\begin{array}{l}\text { Bedc } \\
\text { Orient }\end{array}$ & ing & \\
\hline & & & & & & & & & Strike & Dip & Remarks \\
\hline 491 & 1 & 2 & $140.0-142.0$ & 2.91 & 150 & 308.2 & 11.0 & 0.262 & & & \\
\hline & 1 & 5 & $82.0-84.0$ & 6.83 & 150 & 62.7 & 49.3 & 0.317 & & & \\
\hline & 2 & 1 & $140.0-142.0$ & 11.41 & 150 & 153.4 & 4.2 & 20.529 & & & \\
\hline & 2 & 4 & $113.0-115.0$ & 15.64 & 150 & 142.2 & 15.8 & 0.284 & & & \\
\hline & 3 & 1 & $144.0-146.0$ & 20.95 & 150 & 115.6 & 6.3 & 0.145 & & & \\
\hline & 3 & 5 & $129.0-131.0$ & 26.80 & 150 & 2.2 & -31.0 & 0.103 & & & \\
\hline & 4 & 2 & $115.0-117.0$ & 31.66 & 150 & 163.1 & 31.6 & 0.146 & & & \\
\hline & 4 & 5 & $106.0-108.0$ & 36.07 & 150 & 200.6 & 64.6 & 0.098 & & & \\
\hline & 5 & 4 & $42.0-44.0$ & 43.43 & 150 & 311.7 & 27.2 & 0.036 & & & \\
\hline & 6 & 2 & $38.0-40.0$ & 49.89 & 150 & 123.9 & -16.8 & 0.235 & & & \\
\hline & 6 & 5 & $136.0-138.0$ & 55.37 & 150 & 80.4 & 12.8 & 0.377 & & & \\
\hline & 7 & 1 & $137.0-139.0$ & 58.88 & 150 & 272.8 & 18.3 & 0.066 & & & \\
\hline & 7 & 5 & $113.0-115.0$ & 64.64 & 150 & 46.8 & 33.0 & 0.074 & & & \\
\hline & 8 & 1 & $137.0-139.0$ & 68.38 & 150 & 93.1 & -46.0 & 0.086 & & & \\
\hline & 8 & 5 & $113.0-115.0$ & 74.14 & 150 & 39.4 & 47.8 & 0.778 & & & \\
\hline & 9 & 1 & $133.0-135.0$ & 77.84 & 150 & 254.4 & -18.7 & 8.363 & & & \\
\hline & 9 & 5 & $134.0-136.0$ & 83.85 & 150 & 358.0 & 51.0 & 3.708 & & & \\
\hline & 10 & 2 & $66.0-68.0$ & 88.17 & 150 & 2.4 & -11.8 & 5.124 & & & \\
\hline & 10 & 5 & $127.0-129.0$ & 93.28 & 150 & 87.6 & 58.1 & 7.587 & & & \\
\hline & 11 & 1 & $126.0-128.0$ & 96.77 & 150 & 18.1 & -25.6 & 4.414 & & & \\
\hline & 11 & 3 & $115.0-117.0$ & 99.66 & 150 & 355.7 & 15.2 & 6.471 & & & \\
\hline & 13 & 2 & $25.0-27.0$ & 106.76 & 150 & 37.2 & 63.0 & 3.504 & N 53E & $24 \mathrm{~N}$ & \\
\hline & 14 & 1 & $133.0-135.0$ & 115.84 & 150 & 306.1 & -4.4 & 0.547 & $54 \mathrm{E}$ & $24 \mathrm{~N}$ & \\
\hline & 14 & 5 & $56.0-58.0$ & 121.07 & 150 & 43.2 & 13.9 & 3.267 & $43 W$ & $24 W$ & "A"' \\
\hline & 15 & 2 & $105.0-107.0$ & 126.56 & 150 & 158.3 & -61.6 & 0.148 & $22 \mathrm{E}$ & $26 \mathrm{~W}$ & "A" \\
\hline & 15 & 3 & $64.0-66.0$ & 127.65 & 150 & 95.5 & -2.9 & 0.805 & $84 \mathrm{E}$ & $32 W$ & \\
\hline & 15 & 5 & $20.0-22.0$ & 130.21 & 150 & 79.2 & 36.7 & 0.577 & $79 W$ & $27 \mathrm{~S}$ & "A" \\
\hline & 16 & 4 & $57.0-59.0$ & 138.58 & 150 & 65.1 & -14.0 & 0.618 & $65 W$ & $30 \mathrm{~N}$ & \\
\hline & 16 & 6 & $15.0-17.0$ & 141.16 & 150 & 257.0 & -27.5 & 2.364 & $82 \mathrm{E}$ & $30 \mathrm{~N}$ & \\
\hline & 17 & 2 & $60.0-62.0$ & 145.11 & 150 & 103.5 & 8.2 & 6.039 & $76 \mathrm{E}$ & $43 N$ & \\
\hline & 17 & 4 & $50.0-52.0$ & 148.01 & 150 & 83.7 & 1.7 & 3.140 & $84 W$ & $30 \mathrm{~N}$ & \\
\hline & 18 & 4 & $25.0-27.0$ & 157.26 & 150 & 342.2 & -62.0 & 0.195 & $85 \mathrm{~W}$ & $21 \mathrm{~N}$ & \\
\hline & 19 & 3 & $56.0-58.0$ & 165.57 & 150 & 116.1 & 3.8 & 3.203 & $40 W$ & $28 \mathrm{~W}$ & "B" \\
\hline & 20 & 2 & $121.0-123.0$ & 174.22 & 150 & 78.9 & 29.4 & 3.415 & & & \\
\hline & 21 & 3 & $90.0-92.0$ & 184.91 & 150 & 297.4 & -13.9 & 4.188 & & & \\
\hline & 25 & 1 & $85.0-87.0$ & 210.36 & 150 & 291.4 & 45.4 & 0.809 & N 64E & $62 \mathrm{~N}$ & \\
\hline & 25 & 3 & $73.0-75.0$ & 213.24 & 150 & 289.1 & 33.0 & 4.743 & $73 \mathrm{E}$ & $63 \mathrm{~N}$ & \\
\hline & 26 & 5 & $14.0-16.0$ & 225.15 & 150 & 92.2 & 60.6 & 0.061 & $88 \mathrm{E}$ & $58 \mathrm{~N}$ & \\
\hline & 27 & 5 & $96.0-98.0$ & 235.47 & 150 & 108.7 & 27.8 & 7.249 & $63 \mathrm{E}$ & $63 \mathrm{~N}$ & \\
\hline & 30 & 5 & $20.0-22.0$ & 263.21 & 150 & 183.3 & -38.0 & 2.050 & $3 W$ & $43 W$ & "C" \\
\hline & 31 & 5 & $22.0-24.0$ & 272.73 & 150 & 59.7 & 7.4 & 1.948 & $89 \mathrm{~W}$ & $30 \mathrm{~N}$ & \\
\hline & 32 & 5 & $28.0-30.0$ & 282.29 & 150 & 168.3 & -5.7 & 6.975 & $19 W$ & $25 \mathrm{~W}$ & "C"C", \\
\hline & 33 & 2 & $145.0-147.0$ & 288.46 & 150 & 97.4 & -1.0 & 8.554 & $87 \mathrm{E}$ & $25 \mathrm{~N}$ & \\
\hline & 36 & 5 & $136.0-138.0$ & 321.37 & 150 & 292.4 & -7.5 & 4.253 & $52 \mathrm{E}$ & $15 \mathrm{~N}$ & \\
\hline & 37 & 4 & $34.0-36.0$ & 328.35 & 150 & 92.7 & 15.6 & 5.939 & $87 \mathrm{E}$ & $30 \mathrm{~N}$ & \\
\hline & 39 & 3 & $4.0-6.0$ & 345.55 & 150 & 28.2 & 21.0 & 1.103 & $10 \mathrm{E}$ & $45 \mathrm{E}$ & "D" \\
\hline & 41 & 2 & $126.0-128.0$ & 364.27 & 150 & 38.1 & -7.4 & 0.806 & $38 \mathrm{~W}$ & $31 \mathrm{~N}$ & \\
\hline & 41 & 3 & $114.0-116.0$ & 365.65 & 150 & 236.8 & -24.7 & 0.290 & $33 W$ & $39 \mathrm{~N}$ & \\
\hline & 43 & 2 & $134.0-136.0$ & 383.35 & 150 & 69.6 & -4.2 & 0.931 & $65 \mathrm{~W}$ & $26 \mathrm{~N}$ & \\
\hline & 43 & 5 & $88.0-90.0$ & 387.39 & 150 & 8.4 & -9.4 & 4.793 & $15 \mathrm{~W}$ & $35 \mathrm{E}$ & \\
\hline & 44 & 3 & $27.0-29.0$ & 393.28 & 150 & 193.1 & -15.3 & 2.811 & $13 W$ & $28 \mathrm{E}$ & \\
\hline & 45 & 2 & $144.0-146.0$ & 402.45 & 150 & 357.5 & -41.6 & 0.906 & $3 \mathrm{E}$ & $24 W$ & "D", \\
\hline & 46 & 1 & $110.0-112.0$ & 410.11 & 150 & 172.6 & 1.0 & 4.007 & $40 \mathrm{E}$ & $28 \mathrm{~W}$ & \\
\hline & 47 & 3 & $11.0-13.0$ & 421.62 & 150 & 290.6 & -38.0 & 5.102 & $33 \mathrm{E}$ & $41 \mathrm{E}$ & "D" \\
\hline & 48 & 6 & $134.0-136.0$ & 436.85 & 150 & 227.4 & -1.0 & 1.649 & $82 \mathrm{E}$ & $20 \mathrm{~N}$ & \\
\hline & 49 & 3 & $60.0-62.0$ & 441.11 & 150 & 68.2 & -9.1 & 4.896 & $68 \mathrm{~W}$ & $20 \mathrm{~N}$ & \\
\hline & 50 & 2 & $18.0-20.0$ & 448.69 & 150 & 231.9 & -10.1 & 9.709 & $88 \mathrm{~W}$ & $21 \mathrm{~N}$ & \\
\hline & 50 & 2 & $132.0-134.0$ & 449.83 & 150 & 224.1 & -19.7 & 10.911 & $75 \mathrm{E}$ & $10 \mathrm{~N}$ & \\
\hline & 54 & 1 & $50.0-52.0$ & 485.51 & 150 & 247.2 & -27.4 & 4.051 & $22 W$ & $4 \mathrm{E}$ & \\
\hline & 55 & 2 & $15.0-17.0$ & 496.16 & 150 & 188.8 & -15.6 & 17.902 & $69 \mathrm{E}$ & $14 \mathrm{~N}$ & \\
\hline & 55 & 3 & $54.0-56.0$ & 498.05 & 150 & 358.2 & -17.1 & 3.190 & $69 \mathrm{E}$ & $8 \mathrm{~N}$ & \\
\hline & 56 & 1 & $73.0-75.0$ & 504.74 & 150 & 279.2 & -25.9 & 7.433 & $51 \mathrm{E}$ & $8 \mathrm{~N}$ & \\
\hline & 57 & 3 & $30.0-32.0$ & 516.81 & 150 & 140.8 & -5.2 & 8.194 & $55 \mathrm{~W}$ & $28 \mathrm{~N}$ & \\
\hline & 57 & 3 & $145.0-147.0$ & 517.96 & 150 & 6.6 & -12.4 & 15.327 & $10 \mathrm{~W}$ & $16 \mathrm{E}$ & \\
\hline & 58 & 1 & $12.0-14.0$ & 523.13 & 150 & 13.1 & -10.7 & 10.251 & $3 W$ & $19 \mathrm{E}$ & \\
\hline & 58 & 1 & $88.0-90.0$ & 523.89 & 150 & 257.3 & 5.7 & 4.453 & $42 W$ & $16 \mathrm{E}$ & \\
\hline & 59 & 1 & $56.0-58.0$ & 533.07 & 150 & 316.2 & -53.3 & 0.594 & $54 \mathrm{E}$ & $6 \mathrm{E}$ & \\
\hline
\end{tabular}


Table 12. Paleomagnetic results and bedding orientation, Site 492 , lower slope.

\begin{tabular}{|c|c|c|c|c|c|c|c|c|c|c|c|}
\hline \multirow[b]{2}{*}{ Hole } & \multirow[b]{2}{*}{ Core } & \multirow[b]{2}{*}{ Section } & & $\begin{array}{l}\text { Sub-bottom } \\
\text { Depth }\end{array}$ & AF Demag. & Relative & & Intensity & $\begin{array}{c}\text { Bed } \\
\text { Orien }\end{array}$ & $\begin{array}{l}\text { ling } \\
\text { ation }\end{array}$ & \\
\hline & & & Interval $(\mathrm{cm})$ & (m) & Field (Oe) & Declination & Inclination & $\left(\times 10^{-6} \mathrm{emu} / \mathrm{cc}\right)$ & Strike & Dip & Remarks \\
\hline 492 & 1 & 1 & $80.0-82.0$ & 0.81 & 150 & 42.7 & 15.7 & 0.250 & & & \\
\hline & 1 & 1 & $130.0-132.0$ & 1.31 & 150 & 215.1 & -39.8 & 43.926 & & & \\
\hline & 1 & 2 & $64.0-66.0$ & 2.15 & 150 & 228.1 & 19.4 & 0.155 & & & \\
\hline & 1 & 3 & $21.0-23.0$ & 3.22 & 150 & 22.0 & 59.2 & 0.084 & & & \\
\hline & 2 & 1 & $90.0-92.0$ & 4.41 & 150 & 158.3 & -22.1 & 1.425 & & & \\
\hline & 2 & 2 & $141.0-143.0$ & 6.42 & 150 & 270.3 & 57.3 & 0.764 & & & \\
\hline & 2 & 3 & $138.0-140.0$ & 7.89 & 150 & 139.3 & 59.1 & 0.264 & & & \\
\hline & 2 & 4 & $94.0-96.0$ & 8.95 & 150 & 115.1 & 16.6 & 0.367 & & & \\
\hline & 3 & 1 & $17.0-19.0$ & 13.18 & 150 & 265.7 & -27.2 & 0.222 & & & \\
\hline & 3 & 2 & $65.0-67.0$ & 15.16 & 150 & 273.6 & 71.6 & 0.034 & & & \\
\hline & 3 & 4 & $34.0-36.0$ & 17.85 & 150 & 4.4 & 41.4 & 0.064 & & & \\
\hline & 3 & 5 & $39.0-41.0$ & 19.40 & 150 & 122.4 & -38.8 & 0.088 & & & \\
\hline & 4 & 1 & $117.0-119.0$ & 23.68 & 150 & 212.0 & 10.6 & 0.007 & & & \\
\hline & 4 & 6 & $31.0-33.0$ & 30.32 & 150 & 125.2 & -2.7 & 0.013 & & & \\
\hline & 4 & 7 & $15.0-17.0$ & 31.66 & 150 & 106.2 & -3.1 & 0.015 & & & \\
\hline & 5 & 1 & $109.0-111.0$ & 33.10 & 150 & 355.4 & 16.0 & 0.152 & & & \\
\hline & 5 & 2 & $102.0-104.0$ & 34.53 & 150 & 61.2 & -20.1 & 0.151 & & & \\
\hline & 5 & 3 & $100.0-102.0$ & 36.01 & 150 & 69.1 & 20.4 & 0.177 & & & \\
\hline & 5 & 4 & $84.0-86.0$ & 37.35 & 150 & 183.1 & 41.2 & 0.183 & & & \\
\hline & 6 & 1 & $118.0-120.0$ & 42.69 & 150 & 28.3 & 70.2 & 0.181 & & & \\
\hline & 6 & 2 & $120.0-122.0$ & 44.21 & 150 & 325.0 & -1.3 & 0.347 & & & \\
\hline & 6 & 3 & $120.0-122.0$ & 45.71 & 150 & 283.1 & 67.2 & 0.148 & & & \\
\hline & 6 & 4 & $116.0-118.0$ & 47.17 & 150 & 125.0 & 29.9 & 0.229 & & & \\
\hline & 6 & 5 & $100.0-102.0$ & 48.51 & 150 & 205.3 & -16.4 & 0.149 & & & \\
\hline & 7 & 3 & $44.0-46.0$ & 54.45 & 150 & 3.7 & 18.9 & 0.165 & & & \\
\hline & 8 & 1 & $138.0-140.0$ & 61.89 & 150 & 301.2 & 56.4 & 0.013 & & & \\
\hline & 8 & 3 & $107.0-109.0$ & 64.58 & 150 & 236.3 & 36.8 & 0.021 & & & \\
\hline & 9 & 1 & $127.0-129.0$ & 71.28 & 150 & 192.9 & 44.7 & 15.308 & & & \\
\hline & 9 & 2 & $127.0-129.0$ & 72.78 & 150 & 248.7 & 36.2 & 0.109 & & & \\
\hline & 10 & 2 & $110.0-112.0$ & 82.11 & 150 & 312.2 & 15.9 & 0.039 & & & \\
\hline & 11 & 1 & $47.0-49.0$ & 89.48 & 150 & 317.4 & 28.8 & 0.185 & & & \\
\hline & 11 & 2 & $78.0-80.0$ & 91.29 & 150 & 332.9 & 31.6 & 0.052 & & & \\
\hline & 12 & 5 & $123.0-125.0$ & 105.74 & 150 & 230.2 & 25.9 & 0.110 & & & \\
\hline & 13 & 2 & $142.0-144.0$ & 110.93 & 150 & 353.7 & 31.3 & 0.518 & $\mathrm{~N} \quad 6 \mathrm{E}$ & $29 \mathrm{~W}$ & \\
\hline & 14 & 3 & $21.0-23.0$ & 120.72 & 150 & 103.8 & 40.7 & 0.151 & & & \\
\hline & 14 & 3 & $25.0-27.0$ & 120.76 & 150 & 143.7 & -24.6 & 0.183 & N $36 \mathrm{E}$ & $45 \mathrm{~W}$ & \\
\hline & 14 & 3 & $45.0-47.0$ & 120.96 & 150 & 365.2 & 15.2 & 0.263 & $4 \mathrm{E}$ & $31 \mathrm{~W}$ & \\
\hline & 18 & 4 & $27.0-29.0$ & 160.28 & 150 & 67.9 & 2.0 & 0.108 & $89 \mathrm{~W}$ & $14 \mathrm{~S}$ & \\
\hline & 19 & 3 & $69.0-71.0$ & 168.70 & 150 & 115.9 & 24.4 & 1.240 & $64 \mathrm{E}$ & $34 \mathrm{~S}$ & \\
\hline & 20 & 6 & $24.0-26.0$ & 182.25 & 150 & 301.4 & 34.3 & 0.071 & $59 \mathrm{E}$ & $44 \mathrm{~N}$ & \\
\hline & 20 & 6 & $85.0-87.0$ & 182.86 & 150 & 128.6 & -27.7 & 0.133 & NS & $39 \mathrm{E}$ & "E" \\
\hline & 24 & 2 & $16.0-18.0$ & 214.17 & 150 & 28.8 & -53.3 & 0.286 & $81 \mathrm{~W}$ & $74 \mathrm{~S}$ & \\
\hline & 25 & 1 & $100.0-102.0$ & 223.01 & 150 & 14.9 & 1.1 & 0.549 & $83 \mathrm{~W}$ & $43 \mathrm{~S}$ & \\
\hline & 25 & 5 & $101.0-103.0$ & 229.02 & 150 & 187.3 & 25.1 & 1.529 & $7 \mathrm{~W}$ & $42 \mathrm{E}$ & \\
\hline & 26 & 2 & $90.0-92.0$ & 233.91 & 150 & 157.8 & -38.3 & 5.552 & $22 \mathrm{E}$ & $35 \mathrm{~W}$ & \\
\hline & 26 & 2 & $131.0-133.0$ & 234.32 & 150 & 128.0 & -26.5 & 8.940 & $42 \mathrm{E}$ & $29 \mathrm{~W}$ & \\
\hline & 27 & 5 & $112.0-114.0$ & 248.13 & 150 & 355.1 & 46.5 & 0.288 & $5 \mathrm{E}$ & $38 \mathrm{~W}$ & \\
\hline $492 \mathrm{~A}$ & 1 & 1 & $20.0-22.0$ & 0.21 & 150 & 45.9 & 51.7 & 0.104 & & & \\
\hline & 1 & i & $69.0-71.0$ & 0.70 & 150 & 313.9 & 30.7 & 0.608 & & & \\
\hline & 1 & i & $130.0-132.0$ & 1.31 & 150 & 313.5 & 31.4 & 0.867 & & & \\
\hline & 1 & 2 & $11.0-13.0$ & 1.62 & 150 & 142.7 & 28.4 & 1.065 & & & \\
\hline & 1 & 2 & $90.0-92.0$ & 2.41 & 150 & 153.6 & 32.2 & 0.561 & & & \\
\hline & 1 & 3 & $12.0-14.0$ & 3.13 & 150 & 298.5 & 32.2 & 0.292 & & & \\
\hline & 1 & 3 & $77.0-79.0$ & 3.78 & 150 & 320.2 & 65.8 & 0.789 & & & \\
\hline & 2 & 1 & $106.0-108.0$ & 5.32 & 150 & 116.0 & 39.2 & 1.910 & & & \\
\hline & 2 & 2 & $30.0-32.0$ & 6.06 & 150 & 143.9 & -58.4 & 0.654 & & & \\
\hline & 2 & 2 & $97.0-99.0$ & 6.73 & 150 & 154.0 & -47.0 & 1.336 & & & \\
\hline & 2 & 3 & $57.0-59.0$ & 7.83 & 150 & 355.7 & 25.1 & 0.592 & & & \\
\hline & 3 & 1 & $45.0-47.0$ & 14.21 & 150 & 121.6 & 38.0 & 0.243 & & & \\
\hline & 3 & 1 & $114.0-116.0$ & 14.90 & 150 & 90.4 & 37.2 & 0.378 & & & \\
\hline & 3 & 2 & $27.0-29.0$ & 15.53 & 150 & 336.4 & 36.6 & 0.423 & & & \\
\hline & 4 & 1 & $75.0-77.0$ & 19.26 & 150 & 313.5 & 53.5 & 0.286 & & & \\
\hline & 4 & 2 & $9.0-11.0$ & 20.10 & 150 & 264.9 & -28.1 & 0.163 & & & \\
\hline & 4 & 2 & $71.0-73.0$ & 20.72 & 150 & 291.0 & 35.1 & 0.302 & & & \\
\hline & 5 & 1 & $56.0-58.0$ & 23.82 & 150 & 314.0 & 10.9 & 0.264 & & & \\
\hline & 5 & 1 & $124.0-126.0$ & 24.50 & 150 & 141.7 & 20.7 & 0.105 & & & \\
\hline & 5 & 2 & $46.0-48.0$ & 25.22 & 150 & 320.4 & 28.2 & 0.270 & & & \\
\hline & 6 & 1 & $68.0-70.0$ & 28.69 & 150 & 9.3 & 31.3 & 0.275 & & & \\
\hline & 6 & 1 & $144.0-146.0$ & 29.45 & 150 & 59.1 & 45.6 & 0.167 & & & \\
\hline & 6 & 2 & $44.0-46.0$ & 29.95 & 150 & 92.4 & 34.5 & 0.231 & & & \\
\hline & 6 & 2 & $131.0-133.0$ & 30.82 & 150 & 42.2 & 29.0 & 0.251 & & & \\
\hline & 7 & 1 & $51.0-53.0$ & 33.27 & 150 & 148.6 & 39.0 & 0.154 & & & \\
\hline & 7 & 1 & $117.0-119.0$ & 33.93 & 150 & 273.9 & 26.2 & 0.065 & & & \\
\hline & 7 & 2 & $51.0-53.0$ & 34.77 & 150 & 42.4 & 60.9 & 0.156 & & & \\
\hline & 8 & 1 & $30.0-32.0$ & 37.81 & 150 & 32.4 & -18.6 & 0.161 & & & \\
\hline & 8 & 1 & $112.0-114.0$ & 38.63 & 150 & 78.6 & 18.5 & 0.164 & & & \\
\hline & 9 & 1 & $72.0-74.0$ & 42.98 & 150 & 58.3 & 51.3 & 0.294 & & & \\
\hline & 10 & 1 & $18.0-20.0$ & 47.19 & 150 & 154.9 & 75.5 & 0.323 & & & \\
\hline
\end{tabular}


Table 13. Paleomagnetic results and bedding orientation, Site 493, upper slope.

\begin{tabular}{|c|c|c|c|c|c|c|c|c|c|c|c|}
\hline \multirow[b]{2}{*}{ Hole } & \multirow[b]{2}{*}{ Core } & \multirow[b]{2}{*}{ Section } & \multirow[b]{2}{*}{ Interval $(\mathrm{cm})$} & $\begin{array}{l}\text { Sub-bottom } \\
\text { Depth }\end{array}$ & AF Demag. & Relative & & Intensity & $\begin{array}{r}\text { Bedd } \\
\text { Orient }\end{array}$ & $\begin{array}{l}\text { ing } \\
\text { tion }\end{array}$ & \\
\hline & & & & (m) & Field $(\mathrm{Oe})$ & Declination & Inclination & $\left(\times 10^{-6} \mathrm{emu} / \mathrm{cc}\right)$ & Strike & Dip & Remarks \\
\hline 493 & 1 & 1 & $91.0-93.0$ & 0.92 & 150 & 45.7 & 40.1 & 1.508 & & & \\
\hline & 1 & 1 & $91.0-93.0$ & 0.92 & -150 & 44.9 & 43.8 & 2.493 & & & \\
\hline & 1 & 2 & $91.0-93.0$ & 2.42 & 150 & 226.0 & 26.2 & 1.755 & & & \\
\hline & 1 & 2 & $91.0-93.0$ & 2.42 & -150 & 236.6 & 24.1 & 3.098 & & & \\
\hline & 1 & 3 & $91.0-93.0$ & 3.92 & 150 & 162.5 & 28.9 & 1.865 & & & \\
\hline & 1 & 3 & $91.0-93.0$ & 3.92 & -150 & 162.4 & 29.5 & 3.581 & & & \\
\hline & 1 & 4 & $91.0-93.0$ & 5.42 & 150 & 231.5 & 41.5 & 0.803 & & & \\
\hline & i & 4 & $91.0-93.0$ & 5.42 & -150 & 241.9 & 49.7 & 1.688 & & & \\
\hline & 2 & 1 & $131.0-133.0$ & 121.32 & 150 & 125.8 & 14.4 & 0.053 & & & \\
\hline & 2 & $i$ & $131.0-133.0$ & 121.32 & -150 & 323.9 & 25.2 & 0.064 & & & \\
\hline & 2 & 3 & $126.0-128.0$ & 124.27 & 150 & 177.7 & -53.0 & 0.085 & & & \\
\hline & 2 & 3 & $126.0-128.0$ & 124.27 & -150 & 38.7 & -39.2 & 0.183 & & & \\
\hline & 3 & 1 & $120.0-122.0$ & 130.71 & 150 & 51.7 & 22.3 & 0.228 & & & \\
\hline & 3 & 1 & $120.0-122.0$ & 130.71 & -150 & 39.6 & 60.9 & 0.078 & & & \\
\hline & 4 & 2 & $41.0-43.0$ & 140.92 & 150 & 330.7 & -20.0 & 0.308 & & & \\
\hline & 4 & 2 & $41.0-43.0$ & 140.92 & -150 & 318.3 & -13.2 & 0.211 & & & \\
\hline & 5 & 2 & $30.0-32.0$ & 150.31 & 150 & 153.5 & -16.5 & 0.073 & & & \\
\hline & 5 & 2 & $30.0-32.0$ & 150.31 & -150 & 80.4 & 33.6 & 0.071 & & & \\
\hline & 5 & 4 & $30.0-32.0$ & 153.31 & 150 & 64.8 & 15.8 & 0.093 & & & \\
\hline & 5 & 4 & $30.0-32.0$ & 153.31 & -150 & 355.6 & 24.0 & 0.091 & & & \\
\hline & 6 & 2 & $90.0-92.0$ & 160.41 & 150 & 166.4 & -33.6 & 0.024 & & & \\
\hline & 6 & 2 & $90.0-92.0$ & 160.41 & $\begin{array}{l}-150 \\
-\end{array}$ & 316.8 & -16.1 & 0.051 & & & \\
\hline & 7 & 2 & $90.0-92.0$ & 169.91 & 150 & 354.2 & -35.1 & 0.078 & & & \\
\hline & 7 & 2 & $90.0-92.0$ & 169.91 & -150 & 314.3 & -30.7 & 0.127 & & & \\
\hline & 8 & 2 & $100.0-102.0$ & 179.51 & 150 & 216.2 & 86.1 & 0.131 & & & \\
\hline & 8 & 2 & $100.0-102.0$ & 179.51 & -150 & 312.4 & 48.6 & 0.193 & & & \\
\hline & 8 & 4 & $100.0-102.0$ & 182.51 & 150 & 214.1 & 2.4 & 0.368 & & & \\
\hline & 8 & 4 & $100.0-102.0$ & 182.51 & -150 & 215.6 & -5.2 & 0.264 & & & \\
\hline & 9 & 1 & $80.0-82.0$ & 187.31 & 150 & 1.4 & 20.6 & 0.145 & & & \\
\hline & 9 & 1 & $80.0-82.0$ & 187.31 & -150 & 26.2 & 12.0 & 0.147 & & & \\
\hline & 9 & 3 & $70.0-72.0$ & 190.21 & 150 & 19.6 & 37.2 & 0.516 & & & \\
\hline & 9 & 3 & $70.0-72.0$ & 190.21 & -150 & 44.9 & 27.4 & 0.228 & & & \\
\hline & 10 & 2 & $60.0-62.0$ & 198.11 & 150 & 295.1 & 4.4 & 0.236 & & & \\
\hline & 10 & 2 & $60.0-62.0$ & 198.11 & -150 & 321.9 & 25.3 & 0.233 & & & \\
\hline & 10 & 4 & $60.0-62.0$ & 201.11 & 150 & 229.5 & -17.9 & 1.015 & & & \\
\hline & 10 & 4 & $60.0-62.0$ & 201.11 & -150 & 231.4 & -19.4 & 0.580 & & & \\
\hline & 11 & 1 & $66.0-68.0$ & 206.17 & 150 & 298.5 & 11.0 & 0.686 & & & \\
\hline & 11 & $i$ & $66.0-68.0$ & 206.17 & -150 & 304.4 & 9.4 & 0.431 & & & \\
\hline & 11 & 3 & $66.0-68.0$ & 209.17 & 150 & 153.9 & 28.8 & 0.057 & & & \\
\hline & 11 & 3 & $66.0-68.0$ & 209.17 & -150 & 317.5 & 30.4 & 0.170 & & & \\
\hline & 12 & 1 & $39.0-41.0$ & 215.40 & 150 & 18.0 & 38.2 & 0.045 & & & \\
\hline & 12 & 1 & $39.0-41.0$ & 215.40 & -150 & 281.7 & -56.7 & 0.035 & & & \\
\hline & 13 & i & $87.0-89.0$ & 225.38 & 150 & 132.7 & 26.2 & 0.184 & & & \\
\hline & 13 & $i$ & $87.0-89.0$ & 225.38 & -150 & 72.3 & 63.9 & 0.049 & & & \\
\hline & 14 & 3 & $28.0-30.0$ & 237.29 & 150 & 255.5 & -12.6 & 0.221 & & & \\
\hline & 14 & 3 & $28.0-30.0$ & 237.29 & -150 & 261.7 & -35.2 & 0.323 & & & \\
\hline & 14 & 5 & $92.0-94.0$ & 240.93 & 150 & 347.2 & 19.6 & 0.179 & & & \\
\hline & 15 & 2 & $105.0-107.0$ & 246.06 & 150 & 332.2 & -20.5 & 0.662 & & & \\
\hline & 15 & 2 & $105.0-107.0$ & 246.06 & -150 & 333.5 & -38.1 & 0.325 & & & \\
\hline & 15 & 4 & $105.0-107.0$ & 249.06 & 150 & 221.2 & -15.1 & 1.488 & & & \\
\hline & 15 & 4 & $105.0-107.0$ & 249.06 & -150 & 231.4 & -21.0 & 0.821 & & & \\
\hline & 17 & 2 & $5.0-7.0$ & 264.06 & 150 & 238.6 & -63.3 & 0.097 & & & \\
\hline & 17 & 2 & $5.0-7.0$ & 264.06 & -150 & 21.3 & 50.0 & 0.073 & & & \\
\hline & 17 & 4 & $3.0-5.0$ & 267.04 & 150 & 223.7 & -16.2 & 0.141 & & & \\
\hline & 17 & 4 & $3.0-5.0$ & 267.04 & -150 & 266.2 & -13.8 & 0.080 & & & \\
\hline & 18 & 2 & $127.0-129.0$ & 274.78 & 150 & 147.6 & -41.9 & 0.119 & & & \\
\hline & 18 & 3 & $13.0-15.0$ & 275.14 & 150 & 153.2 & -72.4 & 0.047 & & & \\
\hline & 18 & 3 & $13.0-15.0$ & 275.14 & -150 & 188.0 & -14.0 & 0.097 & & & \\
\hline & 18 & 5 & $12.0-14.0$ & 278.13 & 150 & 271.2 & 10.6 & 0.366 & $\mathrm{~N} 1 \mathrm{~W}$ & 13E & "S" \\
\hline & 18 & 5 & $12.0-14.0$ & 278.13 & -150 & 274.9 & 21.1 & 0.182 & & & \\
\hline & 19 & 1 & $44.0-46.0$ & 281.95 & 150 & 128.0 & -29.6 & 0.086 & & & \\
\hline & 19 & $i$ & $44.0-46.0$ & 281.95 & -150 & 317.7 & 27.0 & 0.202 & & & \\
\hline & 19 & 4 & $66.0-68.0$ & 286.67 & 150 & 297.1 & -20.2 & 0.167 & N 19E & $42 \mathrm{~W}$ & "S" \\
\hline 493 & 20 & 1 & $63.0-65.0$ & 291.64 & 150 & 359.7 & 16.7 & 0.263 & & & \\
\hline & 20 & 5 & $5.0-7.0$ & 297.06 & 150 & 71.2 & -5.1 & 0.389 & & & \\
\hline & 21 & 2 & $76.0-78.0$ & 302.77 & 150 & 43.4 & -33.8 & 0.088 & & & \\
\hline & 21 & 2 & $76.0-78.0$ & 302.77 & -150 & 26.3 & 7.3 & 0.046 & & & \\
\hline & 21 & 4 & $13.0-15.0$ & 305.14 & 150 & 37.9 & -71.2 & 0.177 & & & \\
\hline & 21 & 4 & $13.0-15.0$ & 305.14 & -150 & 141.8 & 1.8 & 0.048 & & & \\
\hline & 22 & 2 & $41.0-43.0$ & 311.92 & 150 & 85.6 & -23.3 & 0.275 & & & \\
\hline & 22 & 4 & $97.0-99.0$ & 315.48 & 150 & 321.2 & 4.5 & 0.191 & & & \\
\hline & 24 & 1 & $123.0-125.0$ & 330.24 & 150 & 165.6 & -81.1 & 0.059 & & & \\
\hline & 24 & i & $123.0-125.0$ & 330.24 & -150 & 321.9 & -31.5 & 0.065 & & & \\
\hline & 24 & 5 & $50.0-52.0$ & 335.51 & 150 & 320.3 & -3.1 & 0.242 & & & \\
\hline & 25 & 2 & $2.0-4.0$ & 340.03 & 150 & 334.1 & -0.4 & 0.290 & & & \\
\hline & 25 & 6 & $16.0-18.0$ & 346.17 & 150 & 316.5 & -27.1 & 0.167 & & & \\
\hline & 27 & 1 & $12.0-14.0$ & 357.63 & 150 & 1.9 & -0.6 & 0.222 & & & \\
\hline
\end{tabular}


Table 13. (Continued).

\begin{tabular}{|c|c|c|c|c|c|c|c|c|c|c|c|}
\hline \multirow[b]{2}{*}{ Hole } & \multirow[b]{2}{*}{ Core } & \multirow[b]{2}{*}{ Section } & \multirow[b]{2}{*}{ Interval $(\mathrm{cm})$} & \multirow{2}{*}{$\begin{array}{l}\text { Sub-bottom } \\
\text { Depth } \\
\text { (m) }\end{array}$} & AF Demag. & Relative & & Intensity & $\begin{array}{l}\text { Beddi } \\
\text { Orienta }\end{array}$ & & \\
\hline & & & & & Field (Oe) & Declination & Inclination & $\left(\times 10^{-6} \mathrm{emu} / \mathrm{cc}\right)$ & & Dip & Remarks \\
\hline 493 & 27 & 5 & $2.0-4.0$ & 363.53 & 150 & 347.6 & 60.8 & 0.210 & N 61E & $11 \mathrm{~S}$ & \\
\hline & 28 & 4 & $92.0-94.0$ & 372.43 & 150 & 192.8 & 29.4 & 0.139 & $77 \mathrm{E}$ & $27 \mathrm{~N}$ & "A \\
\hline & 29 & 2 & $41.0-43.0$ & 378.42 & 150 & 24.2 & 68.7 & 0.150 & $53 \mathrm{E}$ & $39 \mathrm{~N}$ & A \\
\hline & 29 & 5 & $3.0-5.0$ & 382.54 & 150 & 93.9 & 40.3 & 0.105 & $28 \mathrm{E}$ & $34 \mathrm{E}$ & \\
\hline & 30 & 1 & $30.0-32.0$ & 386.31 & 150 & 272.9 & 62.7 & 0.500 & $69 \mathrm{E}$ & $17 \mathrm{~S}$ & \\
\hline & 30 & 3 & $141.0-143.0$ & 390.42 & 150 & 172.0 & 51.5 & 0.543 & $19 \mathrm{~W}$ & $19 \mathrm{E}$ & \\
\hline & 30 & 5 & $78.0-80.0$ & 392.79 & 150 & 110.4 & 66.9 & 0.374 & $45 \mathrm{E}$ & $22 \mathrm{~S}$ & \\
\hline & 31 & 1 & $59.0-61.0$ & 396.10 & 150 & 337.7 & 24.4 & 0.148 & $45 \mathrm{E}$ & $22 \mathrm{~S}$ & \\
\hline & 31 & 4 & $120.0-122.0$ & 401.21 & 150 & 97.3 & 36.2 & 0.157 & $75 \mathrm{~W}$ & $11 \mathrm{~S}$ & \\
\hline & 32 & 1 & $31.0-33.0$ & 405.32 & 150 & 152.4 & 34.0 & 0.297 & $37 \mathrm{E}$ & $24 \mathrm{E}$ & \\
\hline & 32 & 3 & $75.0-77.0$ & 408.76 & 150 & 68.4 & 82.9 & 0.082 & $73 \mathrm{~W}$ & $22 \mathrm{~S}$ & \\
\hline & 33 & 1 & $140.0-142.0$ & 415.91 & 150 & 307.5 & 55.5 & 0.124 & $52 \mathrm{E}$ & $21 \mathrm{~S}$ & \\
\hline & 34 & 1 & $78.0-80.0$ & 424.79 & 150 & 88.6 & 47.4 & 0.016 & & & \\
\hline & 34 & 4 & $66.0-68.0$ & 429.17 & 150 & 249.0 & 46.0 & 0.281 & & & \\
\hline & 35 & 1 & $56.0-58.0$ & 434.07 & 150 & 48.7 & 31.4 & 0.331 & N $49 \mathrm{~W}$ & $13 \mathrm{~S}$ & \\
\hline & 35 & 4 & $30.0-32.0$ & 438.31 & 150 & 197.9 & 39.7 & 0.319 & $14 \mathrm{E}$ & $10 \mathrm{~W}$ & \\
\hline & 36 & 1 & $22.0-24.0$ & 443.23 & 150 & 137.1 & 73.0 & 0.080 & $22 \mathrm{~W}$ & $8 \mathrm{E}$ & "B" \\
\hline & 36 & 4 & $129.0-131.0$ & 448.80 & 150 & 85.5 & 14.2 & 0.279 & $59 \mathrm{~W}$ & $18 \mathrm{~N}$ & \\
\hline & 37 & 1 & $54.0-56.0$ & 453.05 & 150 & 234.5 & -53.9 & 0.008 & & & \\
\hline & 38 & 1 & $127.0-129.0$ & 463.28 & 150 & 355.1 & 41.5 & 0.232 & $\mathrm{~N} 5 \mathrm{E}$ & $24 \mathrm{~W}$ & "B” \\
\hline & 38 & 3 & $66.0-68.0$ & 465.67 & 150 & 160.9 & 20.9 & 0.037 & & & \\
\hline & 39 & 1 & $111.0-113.0$ & 472.62 & 150 & 63.9 & 35.1 & 0.019 & & & \\
\hline & 39 & 4 & $27.0-29.0$ & 476.28 & 150 & 71.3 & 33.8 & 0.015 & & & \\
\hline & 40 & 2 & $54.0-56.0$ & 483.05 & 150 & 340.6 & 53.4 & 0.005 & & & \\
\hline & 41 & 1 & $54.0-56.0$ & 491.05 & 150 & 51.0 & -4.6 & 0.275 & & & \\
\hline & 41 & 3 & $20.0-22.0$ & 493.71 & 150 & 216.6 & 77.3 & 0.150 & & & \\
\hline & 42 & 2 & $29.0-31.0$ & 501.80 & 150 & 146.3 & 46.5 & 0.256 & N 34E & $18 \mathrm{~W}$ & "B" \\
\hline & 42 & 4 & $87.0-89.0$ & 505.38 & 150 & 310.8 & 23.9 & 0.135 & $59 \mathrm{E}$ & $8 \mathrm{~W}$ & \\
\hline & 43 & 1 & $92.0-94.0$ & 510.43 & 150 & 53.9 & 22.7 & 0.603 & $73 W$ & $16 \mathrm{~S}$ & \\
\hline & 43 & 4 & $26.0-28.0$ & 514.27 & 150 & 266.6 & 37.2 & 0.411 & $87 \mathrm{~W}$ & $13 \mathrm{~S}$ & \\
\hline & 44 & 3 & $66.0-68.0$ & 522.67 & 150 & 319.6 & 12.8 & 0.586 & & & \\
\hline & 44 & 5 & $14.0-16.0$ & 525.15 & 150 & 352.2 & 17.1 & 0.580 & & & \\
\hline & 45 & 2 & $89.0-91.0$ & 530.90 & 1: & 30.6 & 17.8 & 0.334 & $\mathrm{~N} 84 \mathrm{~W}$ & $19 \mathrm{~S}$ & \\
\hline & 45 & 3 & $136.0-138.0$ & 532.87 & 150 & 207.4 & 34.2 & 0.472 & $23 \mathrm{E}$ & $18 \mathrm{E}$ & \\
\hline & 46 & 1 & $46.0-48.0$ & 538.47 & 150 & 4.9 & 39.6 & 0.294 & $53 \mathrm{~W}$ & $16 \mathrm{~S}$ & \\
\hline & 46 & 3 & $77.0-79.0$ & 541.78 & 150 & 299.3 & 61.4 & 0.295 & $74 \mathrm{~W}$ & $11 \mathrm{~S}$ & \\
\hline & 47 & 1 & $48.0-50.0$ & 547.99 & 150 & 70.4 & 34.8 & 0.404 & $62 \mathrm{E}$ & $16 \mathrm{~S}$ & \\
\hline & 47 & 3 & $100.0-102.0$ & 551.51 & 150 & 314.5 & 81.5 & 0.126 & $22 \mathrm{E}$ & $28 \mathrm{E}$ & \\
\hline & 48 & 1 & $81.0-83.0$ & 557.82 & 150 & 99.4 & 71.4 & 0.277 & $43 \mathrm{E}$ & 33E & \\
\hline & 48 & 3 & $24.0-26.0$ & 560.25 & 150 & 235.5 & 79.6 & 0.147 & $77 \mathrm{~W}$ & $23 \mathrm{~S}$ & \\
\hline & 49 & 1 & $102.0-104.0$ & 567.53 & 150 & 38.8 & 30.3 & 0.586 & $38 \mathrm{~W}$ & $7 \mathrm{~S}$ & \\
\hline & 49 & 4 & $35.0-37.0$ & 571.36 & 150 & 196.0 & 40.8 & 0.356 & $88 \mathrm{~W}$ & $24 \mathrm{~S}$ & \\
\hline & 49 & 6 & $119.0-121.0$ & 575.20 & 150 & 135.8 & 32.7 & 0.189 & $43 W$ & $13 \mathrm{~S}$ & \\
\hline & 50 & 2 & $146.0-148.0$ & 578.97 & 150 & 31.7 & 69.3 & 0.125 & $43 W$ & $20 \mathrm{~S}$ & \\
\hline & 50 & 4 & $64.0-66.0$ & 581.15 & 150 & 64.2 & 48.7 & 0.073 & $87 \mathrm{E}$ & $26 \mathrm{~S}$ & \\
\hline & 51 & 1 & $98.0-100.0$ & 586.49 & 150 & 288.3 & 3.7 & 0.021 & & & \\
\hline & 54 & 3 & $64.0-66.0$ & 617.65 & 150 & 137.5 & 29.4 & 0.070 & N 10E & $31 \mathrm{E}$ & \\
\hline $493 \mathrm{~A}$ & 1 & 2 & $11.0-13.0$ & 1.62 & 150 & 296.1 & 51.5 & 2.706 & & & \\
\hline & 2 & 1 & $23.0-25.0$ & 2.74 & 150 & 306.0 & 47.7 & 2.380 & & & \\
\hline & 2 & 2 & $31.0-32.0$ & 4.32 & 150 & 74.6 & 45.3 & 6.073 & & & \\
\hline & 2 & 3 & $64.0-66.0$ & 6.15 & 150 & 161.5 & 41.9 & 1.370 & & & \\
\hline 493B & 1 & 4 & $30.0-32.0$ & 16.81 & 150 & 265.0 & 32.8 & 0.537 & & & \\
\hline & 2 & 1 & $15.0-17.0$ & 21.66 & 150 & 151.9 & -5.7 & 0.775 & & & \\
\hline & 2 & 2 & $65.0-67.0$ & 23.66 & 150 & 155.9 & 41.7 & 0.852 & & & \\
\hline & 2 & 5 & $87.0-89.0$ & 28.38 & 150 & 211.9 & -11.5 & 0.286 & & & \\
\hline & 3 & 3 & $42.0-44.0$ & 34.43 & 150 & 181.0 & -3.5 & 0.193 & & & \\
\hline & 3 & 4 & $20.0-22.0$ & 35.71 & 150 & 145.9 & 26.7 & 0.362 & & & \\
\hline & 3 & 5 & $58.0-60.0$ & 37.59 & 150 & 320.6 & 18.7 & 0.451 & & & \\
\hline & 3 & 6 & $43.0-45.0$ & 38.94 & 150 & 214.8 & 2.6 & 0.228 & & & \\
\hline & 4 & 6 & $144.0-146.0$ & 49.45 & 150 & 157.6 & -10.6 & 0.077 & & & \\
\hline & 5 & 1 & $42.0-44.0$ & 50.43 & 150 & 111.7 & 43.5 & 0.098 & & & \\
\hline & 5 & 2 & $12.0-14.0$ & 51.63 & 150 & 67.0 & 25.0 & 0.129 & & & \\
\hline & 6 & 2 & $36.0-38.0$ & 61.37 & 150 & 87.0 & 46.8 & 0.079 & & & \\
\hline & 6 & 3 & $52.0-54.0$ & 63.03 & 150 & 157.1 & -0.7 & 0.176 & & & \\
\hline & 6 & 4 & $24.0-26.0$ & 64.25 & 150 & 341.9 & -21.4 & 0.039 & & & \\
\hline & 7 & 1 & $59.0-61.0$ & 69.60 & 150 & 214.8 & 52.7 & 0.141 & & & \\
\hline & 7 & 2 & $52.0-54.0$ & 71.03 & 150 & 314.4 & -8.1 & 0.040 & & & \\
\hline & 7 & 3 & $71.0-73.0$ & 72.72 & 150 & 353.9 & 45.7 & 0.027 & & & \\
\hline & 8 & 1 & $81.0-83.0$ & 79.32 & 150 & 357.5 & -33.4 & 0.034 & & & \\
\hline & 8 & 2 & $16.0-18.0$ & 80.17 & 150 & 355.9 & -53.0 & 0.139 & & & \\
\hline & 9 & 1 & $143.0-145.0$ & 89.44 & 150 & 96.4 & -31.3 & 0.097 & & & \\
\hline & 10 & 1 & $65.0-67.0$ & 98.16 & 150 & 137.1 & -1.9 & 0.140 & & & \\
\hline & 11 & 2 & $6.0-8.0$ & 108.57 & 150 & 211.6 & 9.9 & 1.397 & & & \\
\hline & 11 & 3 & $12.0-14.0$ & 110.13 & 150 & 140.0 & -4.2 & 0.121 & & & \\
\hline & 11 & 3 & $144.0-146.0$ & 111.45 & 150 & 277.6 & -63.1 & 0.149 & & & \\
\hline
\end{tabular}


The intensity on the outer rise and in the lower part of lower slope (Sites 487 and 488) is on the order of $10^{-5}$ $\mathrm{emu} / \mathrm{cc}$, which is one order stronger than in the middle and upper parts of lower slope (Sites 491 and 492), as follows:

\begin{tabular}{ccccc}
\hline & $\begin{array}{c}\text { Average } \\
\text { Intensity of } \\
\text { Remanent } \\
\text { Magnetization } \\
\text { after 150-Oe } \\
\text { AF Demag. } \\
\text { Site }\end{array}$ & $\begin{array}{c}\text { No. of } \\
\text { Samples }\end{array}$ & $\begin{array}{c}\text { Sedimentation } \\
\text { (m/m.y.) }\end{array}$ & $\begin{array}{c}\text { Depth } \\
\text { (m) }\end{array}$ \\
\hline 492 & $10^{-6.2 \pm 0.8}$ & 8 & 14.8 & 1935 \\
491 & $10^{-6.2 \pm 0.8}$ & 5 & 31.9 & 2883 \\
488 & $10^{-5.0 \pm 0.7}$ & 17 & 374 & 4254 \\
487 & $10^{-5.2 \pm 0.4}$ & 21 & $19-420$ & $3500-4764$ \\
\hline
\end{tabular}

These data indicate the existence of a boundary (which I will call "magnetization boundary") among the sediments with different intensities of remanent magnetization. On the continental side, the boundary is located between Sites 488 and 491 (2883-4254 m water depth). On the ocean side, because the sediments at Site 487 , on the outer rise, have a stronger magnetization intensity and because the water depth is increasing from 3500 to 4764 meters with the Cocos Plate motion, the boundary is located above $\mathbf{3 5 0 0}$ meters. The boundary is nearly horizontal at a water depth slightly shallower than that of the outer rise and this boundary line intersects the constant sedimentation rate line as shown in Figure 19.

Magnetization intensity in sediments is controlled by the amount and grain size of magnetic minerals. Because there is no significant difference in grain size distribution of sediments among the lower slope sites, the effect of grain size on intensity may be ignored. Thus magnetization intensity is controlled mainly by the magnetic mineral content. The intersection of the magnetization boundary line and constant rate lines suggests that the magnetic minerals are separated by turbidity currents. The magnetic minerals are concentrated in the lower sediments below the magnetization boundary, which, as I have noted, is nearly horizontal and slightly shallower than the water depth of outer rise. Unless the relation of depth between the boundary and outer rise has changed in the past, the intensity of magnetization may provide a paleobathymetric indicator.

There are also noticeable changes in the remanent magnetization intensity in a sedimentary sequence from the lower slope area at Sites 491 and 492 (Figs. 14 and 15 ); in the upper section of the sedimentary sequence the intensity is on the order of $10^{-6} \mathrm{emu} / \mathrm{cc}$ and in the lower section $10^{-5} \mathrm{emu} / \mathrm{cc}$. The transition between the upper and lower sections is limited to a 10 -meter area. Because the values of intensity in the lower section are similar to those in sediments accumulated during the last 0.69 m.y. at Sites 488 and 487 , below the magnetization boundary water depth, I believe that the changes in intensity of remanent magnetization occurred when the site traveled across the magnetization boundary. This belief is supported by the fact that no such changes in intensity occur in the sites located below the water depth of the magnetization boundary (Figs. 10 and 11).

The sediments from the lower slope area may be classified (from bottom to top) into three facies: thick layers of sand, mud with thin sand layers, and mud. Subdepth and age of the boundaries of these facies and the magnetic intensity transitions are as follows:

\begin{tabular}{ccccc}
\hline \multicolumn{5}{c}{$\begin{array}{c}\text { Subdepth (m) and } \\
\text { Age (m.y.) of the } \\
\text { Boundaries }\end{array}$} \\
Site & $\begin{array}{c}\text { Distance } \\
\text { from Trench } \\
(\mathrm{km})\end{array}$ & $\begin{array}{c}\text { Mud/Mud } \\
\text { with Sand }\end{array}$ & $\begin{array}{c}\text { Mud with } \\
\text { Sand/Sand }\end{array}$ & $\begin{array}{c}\text { Magnetic } \\
\text { Intensity } \\
\text { Transition }\end{array}$ \\
\hline 492 & 22.8 & $129.5(6.0)$ & $247(8.6)$ & $228(8.1)$ \\
491 & 16.7 & $76(2.6)$ & $256(5.0)$ & $75(2.6)$ \\
488 & 6.6 & $105(0.3)$ & $410(0.9)$ & $-(-)$ \\
\hline
\end{tabular}

The three facies are considered to represent the relative distance or relative height from the turbidite axis, the coarser-grained facies corresponding to locations closer to the turbidite axis. The Middle America Trench, which presently contains turbiditic sands, as at Site 486, must have done so as far back as $9 \mathrm{Ma}$, because the same kind of sand with the same magnetic properties (Type T) from 8.6 Ma was recovered from the uppermost part of the lower slope at Site 492. The general facies change from sand to mud in the lower slope means that the height of the lower slope surface relative to the trench bottom has increased with time. Age of the boundaries between the facies increases with the distance of the site from the trench (Fig. 20). Although the age of the magnetic intensity transition also increases with the distance from the trench, the gradient of age against distance is steeper than that of the facies boundaries, and the magnetic intensity transition is located in different facies at different sites. At Site 492 the transition occurs in the lower part, which is mud with thin sand layers; at Site 491 it is just above the upper boundary, which is mud with thin sand layers; and Site 488 has not yet reached the transition in spite of accumulating mud (Fig. 20). This change in relation between facies and the intensity transition indicates that the trench is relatively shallower with increasing age. At Site 492, the magnetic intensity transition is at a horizon close to the thick sand layer. This indicates that the depth of the trench relative to the outer rise was not great when these thick sand layers accumulated.

\section{ORIENTATION ANALYSIS OF BEDDING PLANE AND FAULT PLANE}

Positions of strata and faults are fundamental to geologic structure, and determining them is important to a reconstruction of the tectonic evolution of the area. Dip of bedding plane has never been measured directly in the holes drilled by Glomar Challenger, because the diameter of the bore holes is too small for the ordinary dip meters used in oil wells. During Leg 66 we attempted to determine the orientation of bedding and fault planes by means of paleomagnetic direction. 


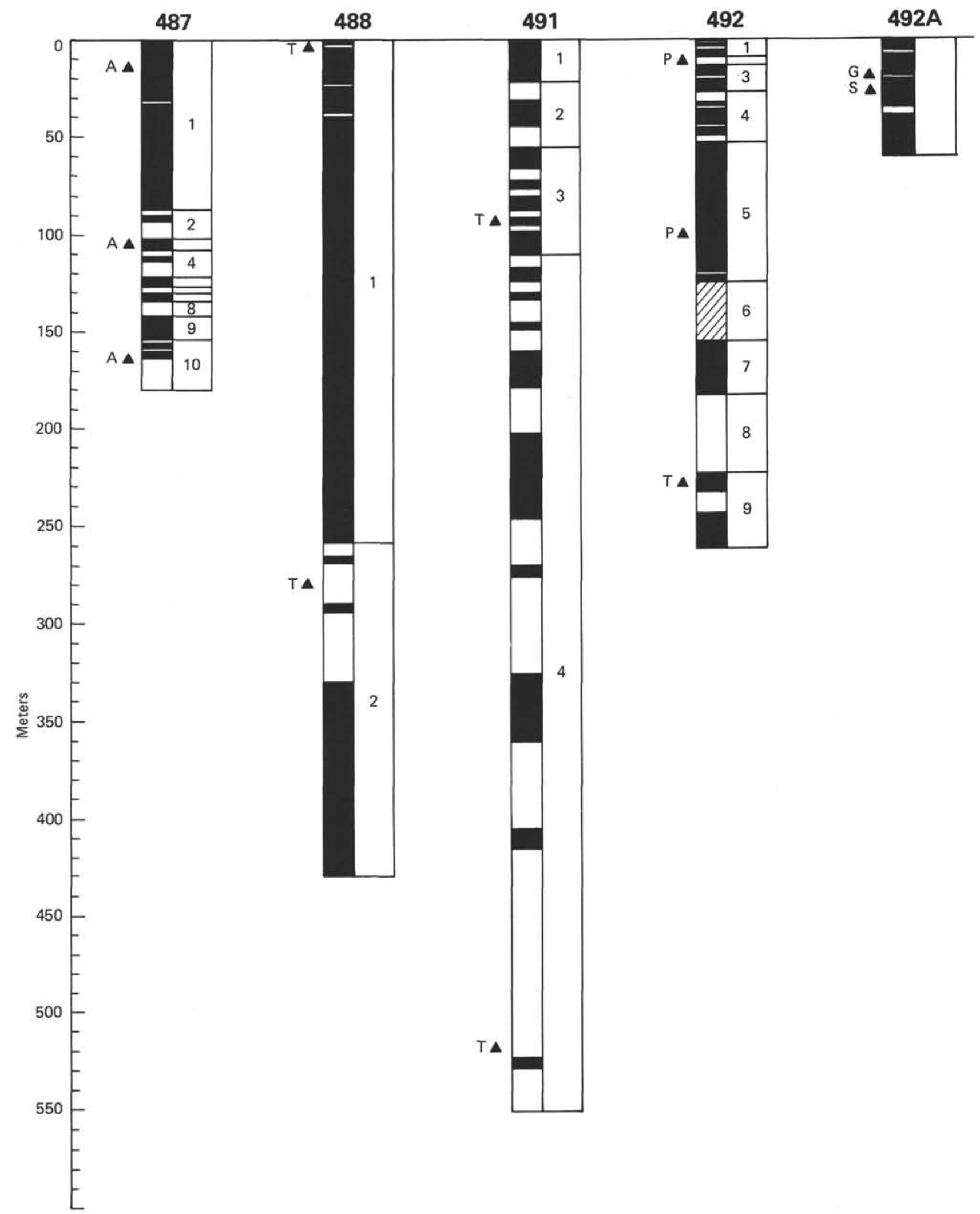

Figure 18. Magnetostratigraphic correlation of Leg 66 holes. ( $\boldsymbol{\Delta}=$ horizons of samples for stepwise AF demagnetization test [Fig. 2], black $=$ normal polarity, white $=$ reversed polarity.) 


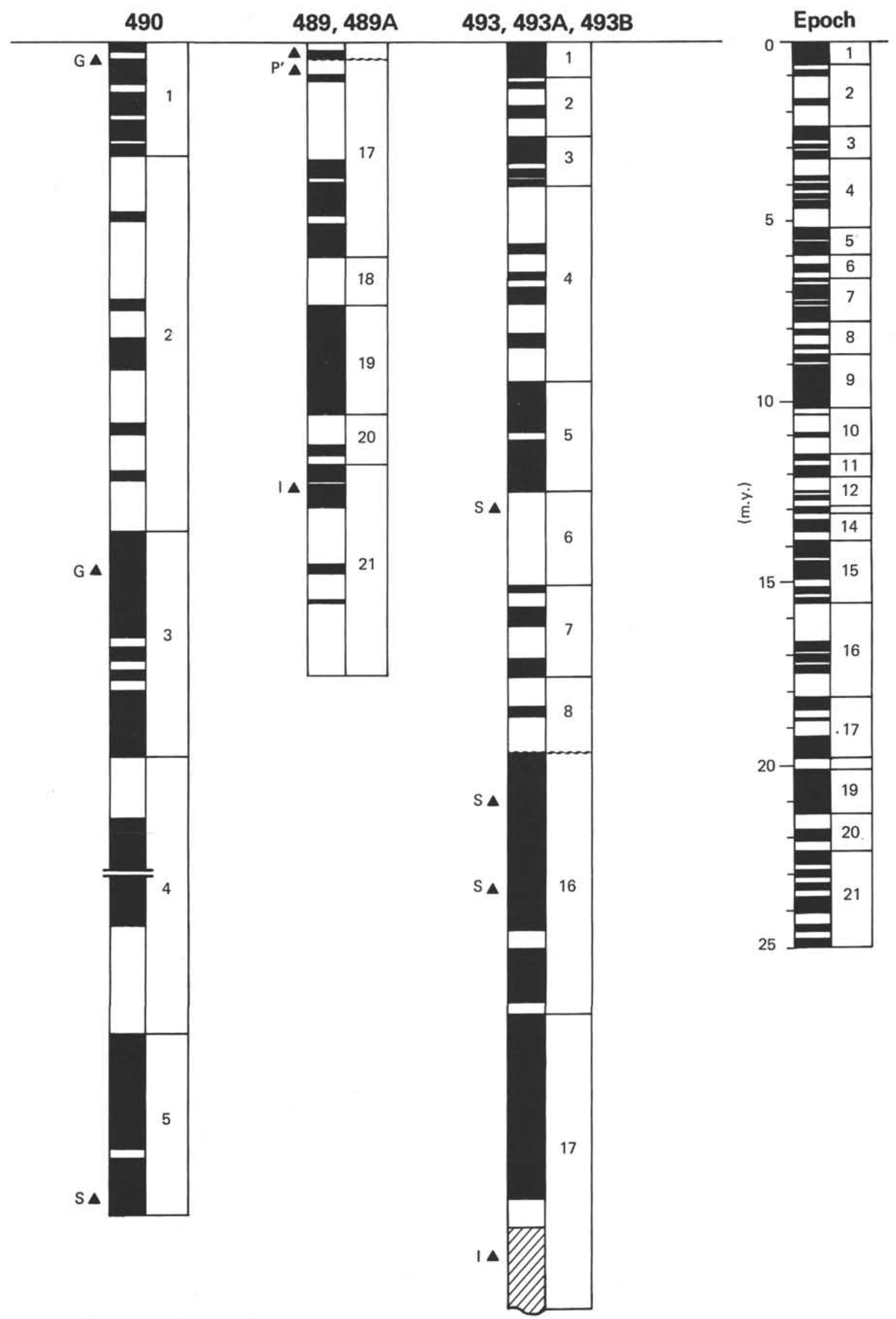

Figure 18. (Continued). 

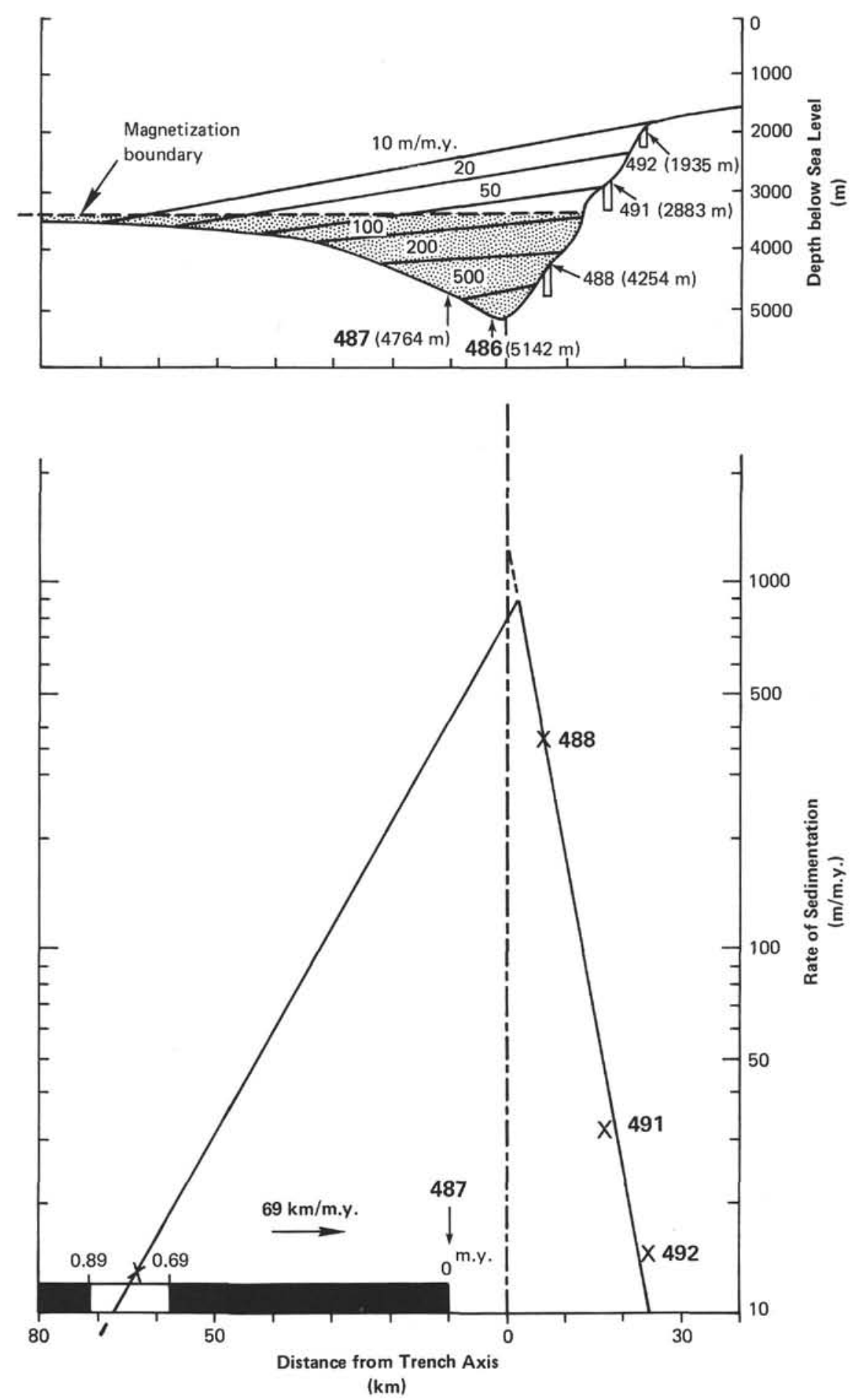

Figure 19. Rate of sedimentation during the last 0.69 m.y., Middle America Trench area. (Top graph): relation between rate of sedimentation and submarine topography; (bottom graph): relation between rate of sedimentation and distance from trench axis. (Broken line indicates magnetic boundary. In dotted area below the boundary, sediments have a magnetic intensity of approximately $10^{-5} \mathrm{emu} / \mathrm{cc}$.)

The principle is essentially the same as using a magnetic compass in the field. The only difference being the focus on past instead of present geomagnetic field. We can measure the declination of remanent magnetization after correction for dip of bedding plane and dip direction of bedding against the core tube. Orientation is possible with the following assumptions: (1) The declination of geomagnetic field was $0^{\circ}$ (due north) during normal polarity and $180^{\circ}$ (due south) during reversed polarity; (2) geomagnetic polarity can be determined with the inclination of remanent magnetization; (3) drilling axis is vertical; and (4) axis of folds are not 


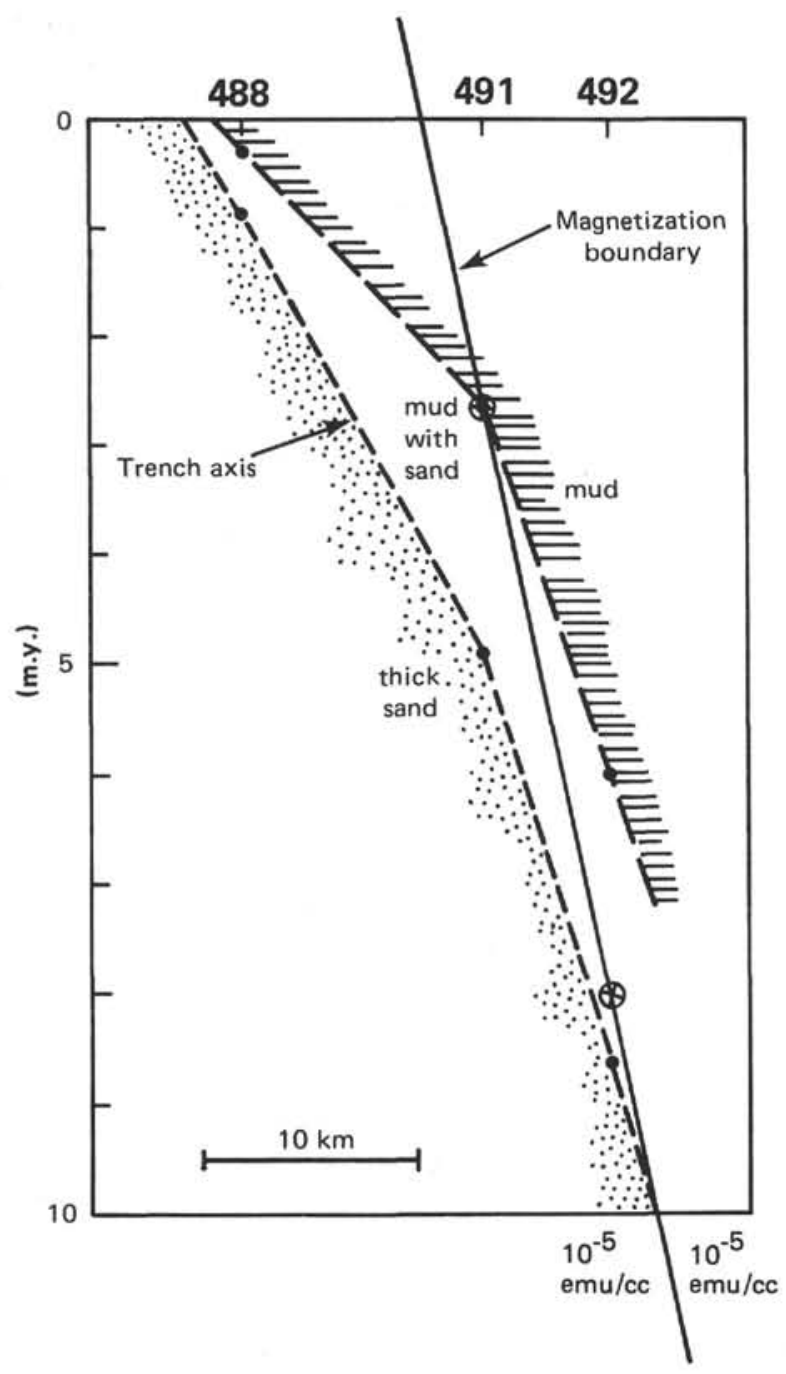

Figure 20. Ages of lithofacies boundaries and magnetization boundary, lower slope area.

plunging (i.e., horizontal). In the low latitude area, the deviation of declination of the present geomagnetic field is less than $20^{\circ}$. The polarity of the ancient geomagnetic field can be estimated by an inclination of remanent magnetization larger than $10^{\circ}$. The deviation of drilling axis measured during Leg 66 was within $3^{\circ}$ of the vertical.

\section{Bedding Orientation in the Lower Slope}

Inclined beds occurred below 350 meters subdepth in the lower part of the Site 488 lower slope, below 100 meters subdepth in the middle part of the Site 491 lower slope, and below 110 meters subdepth in the upper part of the Site 492 lower slope. Orientation of bedding plane was determined at 60 horizons.

At Site 488, the dips determined at three horizons agree with each other $\left(20^{\circ}-35^{\circ}\right.$ east-northeast) (Fig. 21C and Table 8). The east dip in an upslope direction is consistent with seismic reflection data (Shipley et al., 1980).

In Site 491 sediments below 100 meters subdepth, the dips of 44 bedding planes are oriented; they dip from $4^{\circ}$ to $64^{\circ}$ in a generally north-northeast direction, which is

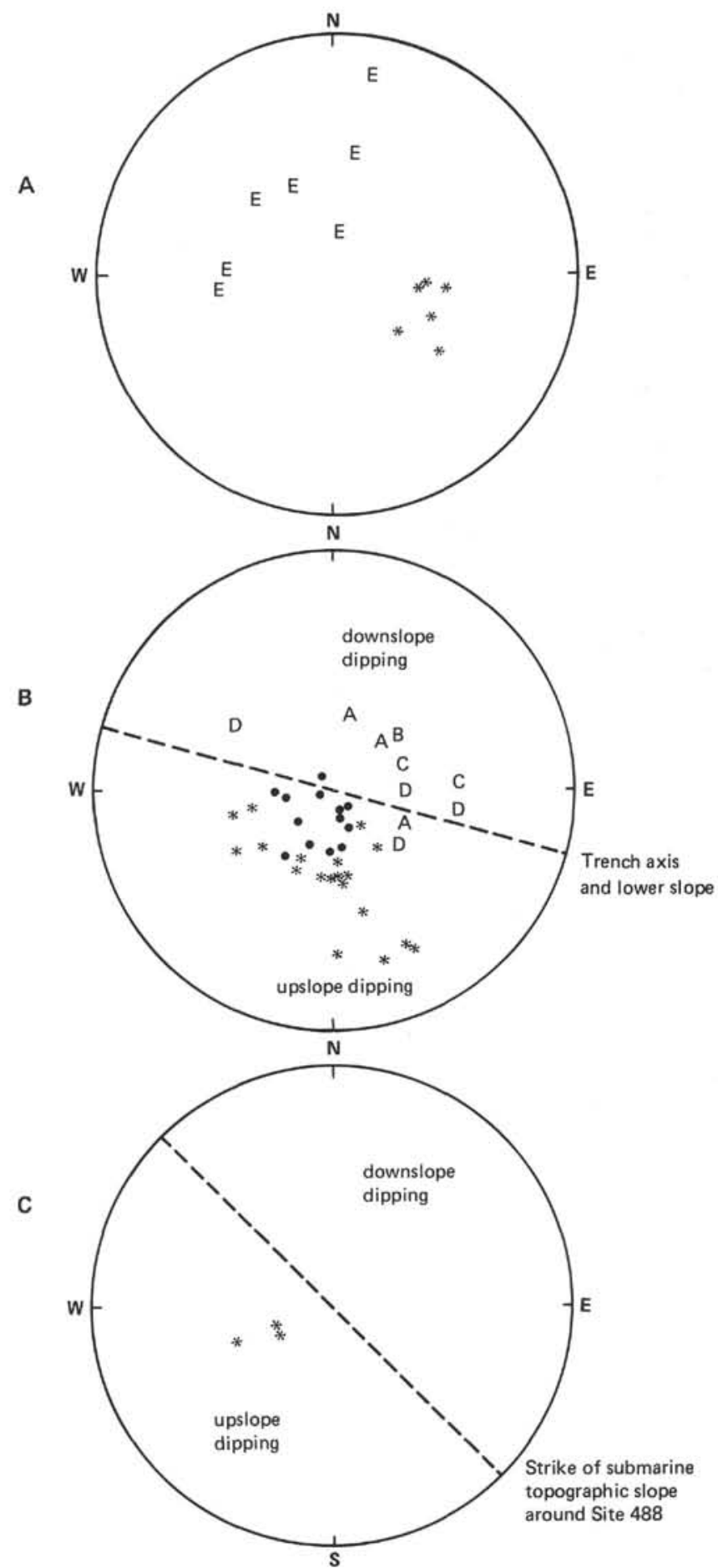

Figure 21. Bedding directions in the lower slope. Pole of bedding plane is projected on lower hemisphere of the stereo net. A, Site 492; B, Site 491; C, Site 488. (For an explanation of A, B, C, D, and $\mathrm{E}$ see text, Fig. 23, and Table 11. $\bullet$ = bedding direction below $415 \mathrm{~m}$ sub-bottom at Site 491 .)

opposite to the direction of submarine topographic slope (Fig. 21B and Table 11). In five limited intervals the sediments dip southwestward, and the dip angle changes. The interval from 120 to 135 meters subdepth (A in Fig. 21B) is a transition between the upper hori- 
zontal and the lower inclined beds. In the interval from 160 to 170 meters (B in Fig. 21B), the upper $30^{\circ}-40^{\circ}$ dipping beds grade into lower horizontal beds. The interval from 250 to 285 meters (C in Fig. 21B) has steep dips $\left(60^{\circ}\right)$ in the upper part and lower, gentle dips $\left(15^{\circ}-30^{\circ}\right)$ in the lower part. Below a subdepth of 285 meters (D, in Fig. 21B) the southwestern dip attains a maximum of $45^{\circ}$ at 345 meters and is $41^{\circ}$ from 400 to 425 meters, where a brecciated zone with poor recovery occurs. The general strike of both bedding planes is $\mathrm{N} 60^{\circ} \mathrm{W}$, parallel to that of lower slope surface and trench axis (Fig. 22).

Sediment layers at Site 492 below 110 meters subdepth dip from $14^{\circ}$ to $74^{\circ}$ and are partly overturned. Dips were measured at 13 horizons. The layers strike $\mathrm{N} 40^{\circ} \mathrm{E}$, perpendicular to the submarine ridge to the north of this site (Fig. 22). The dip directions are northwest and southeast, as shown in Figure 21A and listed in Table 12. Southeasterly dips were limited to the interval from 160 to 231 meters subdepth (E in Fig. 21A). With regard to the dip direction, this interval from 160 to 230 meters forms the middle part of the sediments recovered at Site 492. The lower segment of the upper part, between 125 and 160 meters subdepth, was brecciated by tectonic disturbance, and no paleomagnetic samples could be collected. The middle part has steeper dips than the others, and the steepest $\operatorname{dip}\left(74^{\circ}\right)$ is observed at 214 meters subdepth.

In the lower slope area, the horizon with downslope dip are limited to intervals associated with dip angle variation and tectonic brecciation. This implies that upslope dip direction is the normal attitude of the bedding planes and that downslope direction is a result of tectonic deformation. The alternating occurrence of upslope and downslope dips can be explained as parts of an anticline in which axial planes are inclined upslope, possibly as a result of thrusting, as illustrated in Figure 23. Seismic reflection data revealed the same type of thrusting and related deformation beneath the lowest part of the lower slope (Shipley et al., 1980). This deformation is part of the accretionary process caused by subduction of the oceanic plate along the continental margin. Displacement on this thrust must be small, because the magnetobiostratigraphic succession is undisturbed; we found neither disordered biostratigraphic markers nor disordered magnetostratigraphic sequences in the lower slope area.

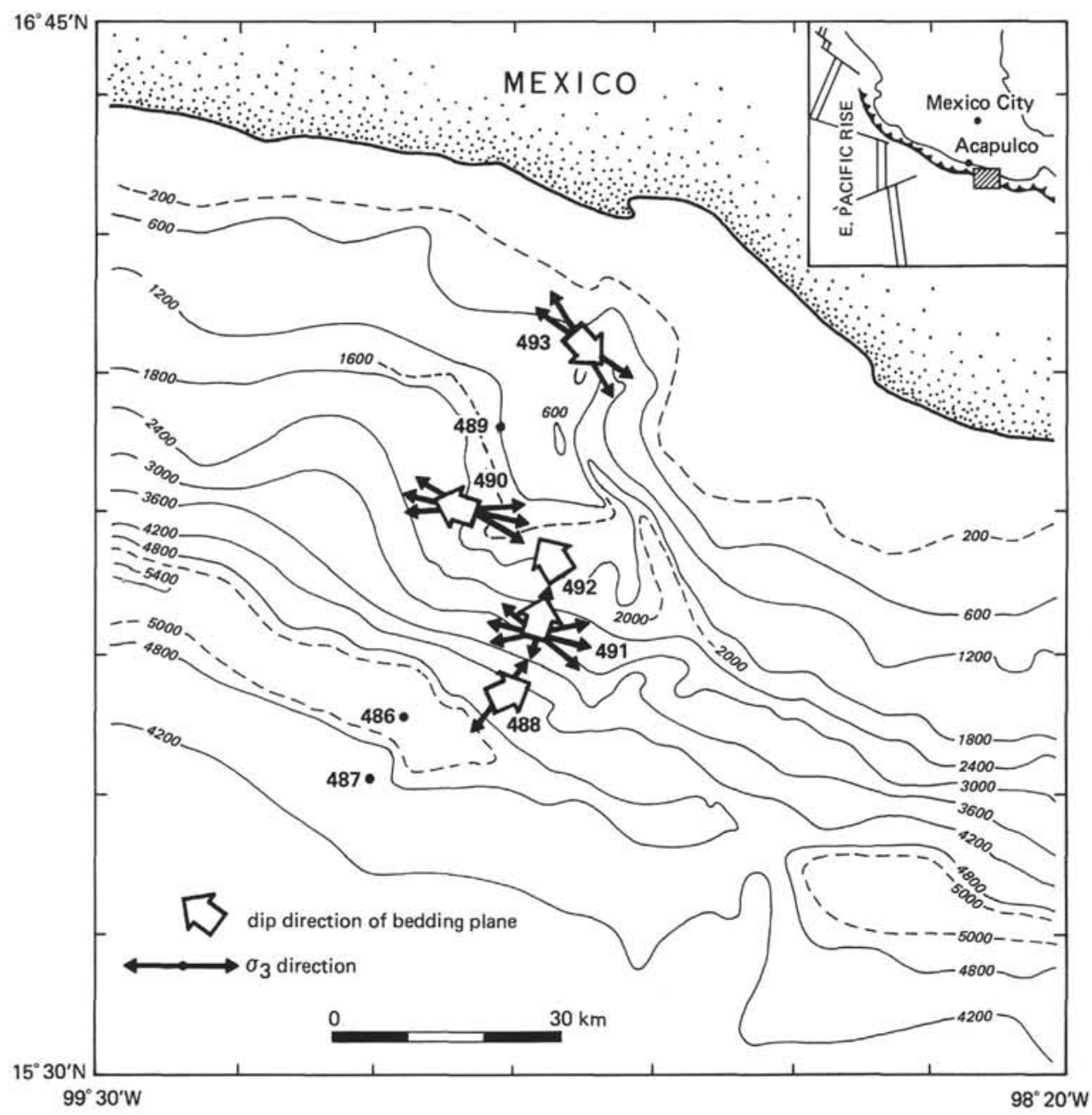

Figure 22. Dipping direction of bedding plane and direction of minimum compressional (or tensional) axis of stress field in Leg 66 area. 

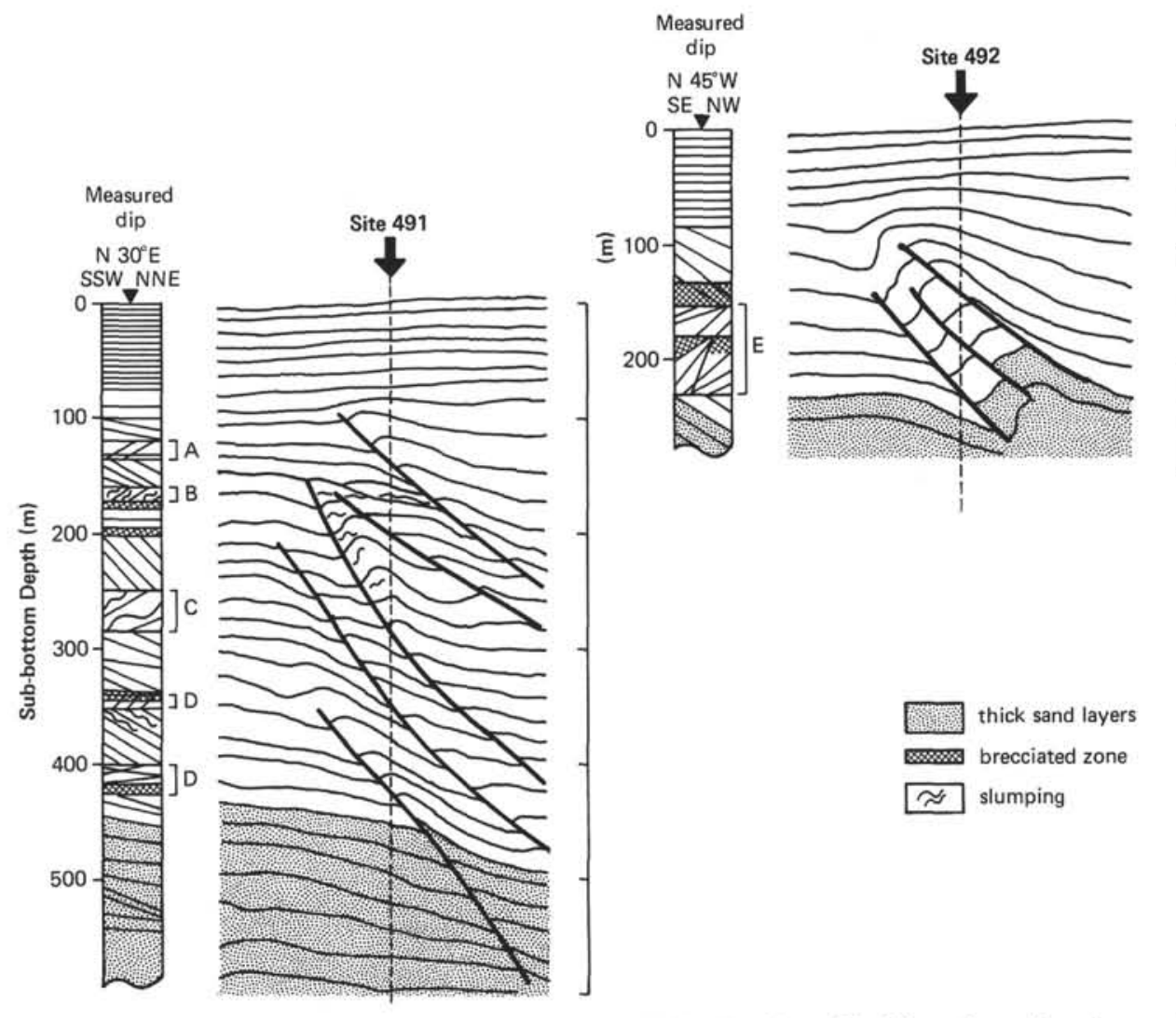

Figure 23. Variations with sub-bottom depth in dip and dip direction of bedding plane, slumping, and tectonic brecciation, Sites 491 and 492 , lower slope.

\section{Bedding Orientation in the Upper Slope}

Forty inclined beds were oriented in the outer part of the upper slope at Site 490, where sediments below 345 meters subdepth ranged in dip from $10^{\circ}$ to $81^{\circ}$. Dip directions of the bedding planes are shown in Figure 24B and Table 10. Most of the dips are westward; a few are northward. Mean and standard deviation of the dip directions are $\mathrm{N} 80^{\circ} \pm 25^{\circ} \mathrm{W}$. This direction corresponds to that of the topographic slope in the area of Site 490 . Bedding dips below 350 meters gradually increase with depth. Between 400 and 430 meters subdepth, sediments dip $10^{\circ}$ to $75^{\circ}$ westward and are cut by slickensided normal faults and oblique slip faults with a brecciated zone. Below this fault zone, the bedding dips gradually decrease with increase of depth. This change indicates that the normal faults caused the steep bedding dips (Fig. 25).

We measured the dips of 37 inclined beds in the inner part of the upper slope at Site 493 (Table 13). The sedimentary sequence of this site comprises the upper part of the upper Miocene to the present, overlying the lower part of the lower Miocene with an unconformity at 360 meters subdepth. The upper part is almost horizontal except for the possibly slumped beds at 278 and 286 meters subdepth. The slumped beds strike $\mathrm{N} 20^{\circ} \mathrm{E}$ parallel to submarine ridge to the east of this site (Figure $24 \mathrm{~A}$ ), suggesting that the uplift of the submarine ridge and related slumping occurred in the late Miocene, Epoch 6. The dip angle of the lower part ranges from $0^{\circ}$ to $39^{\circ}$ in a generally southeast direction parallel to but steeper than the submarine topographic slope. A northwestward dip was observed in two limited intervals from 370 to 380 meters (A in Fig. 24A) and from 435 to 507 meters (B in Fig. 24A) subdepth.

Tectonic features revealed in the upper slope are mostly normal faults dipping in a downslope direction, accompanied by drag folds in contrast with thrusts dipping in an upslope direction in the lower slope. The difference in tectonic configuration indicates the difference in tectonic forces between the two areas.

\section{Orientation of Fault Planes and Stress Fields}

Fault planes can be oriented in the same manner as bedding planes. If we find a conjugate set of faults, an estimation of stress field is possible using the fault plane orientation and fault displacement. The fault planes and stress fields were oriented at six horizons at Sites 488 and 491 on the lower slope and at five horizons of Sites 490 and 493 on the upper slope.

Many artificial fractures had been produced by drilling and handling, as mentioned earlier and noted by Lundberg and Moore (this volume). Such artificial fractures were eliminated for this study by using the nature of the fracture surface and systematic orientation with sawn surface. 

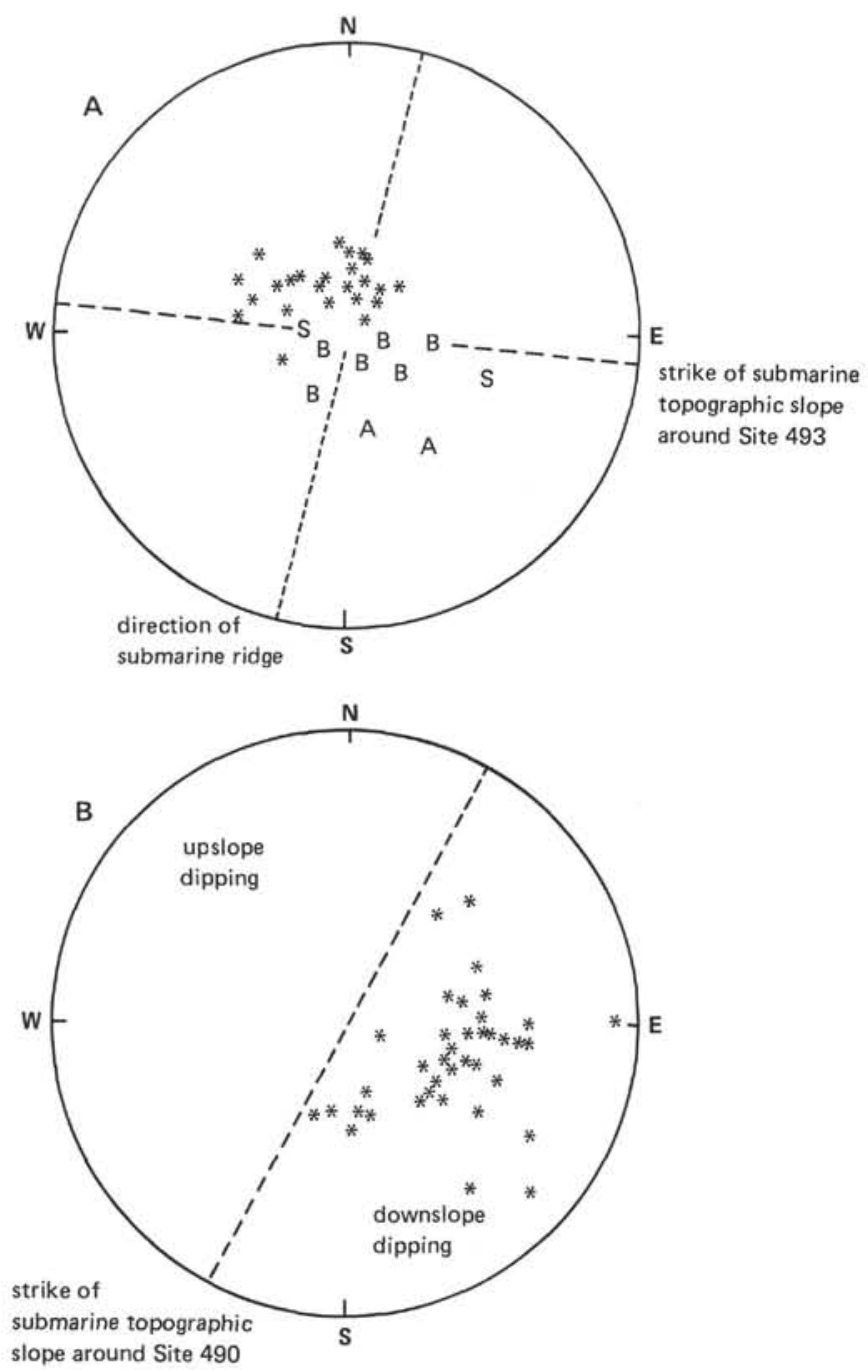

Figure 24. Bedding direction of upper slope. Pole of bedding plane is projected on lower hemisphere of stereo net. A, Site 493; B, Site 490. (For an explanation of A, B, and S see text and Table 13.)

\section{Lower Slope}

The stress field is determined at 383 meters subdepth at Site 488 and at five horizons in the interval from 516 to 524 meters subdepth at Site 491 (Table 14). At five of the six horizons, the stress fields have a nearly vertical axis of maximum compressional stress corresponding to the direction of gravity and overburden pressure. At 441.00 meters subdepth at Site 491 , the stress field has a maximum compressional axis plunging at $38^{\circ}$, suggesting that the horizontal compressional stress was comparable to the vertical compressional stress.

The determined stress fields may be divided into two groups, using the horizontal stress condition: One has a minimum compressional (or tensional) axis subparallel to trench axis; the other has a minimum compressional axis perpendicular to the trench axis. The stress perpendicular to the trench axis is compressional or tensional in different places within a single hole. The two states may exist within a 1-meter interval-for example, at 523.13 meters and 523.89 meters subdepth at Site 491 .
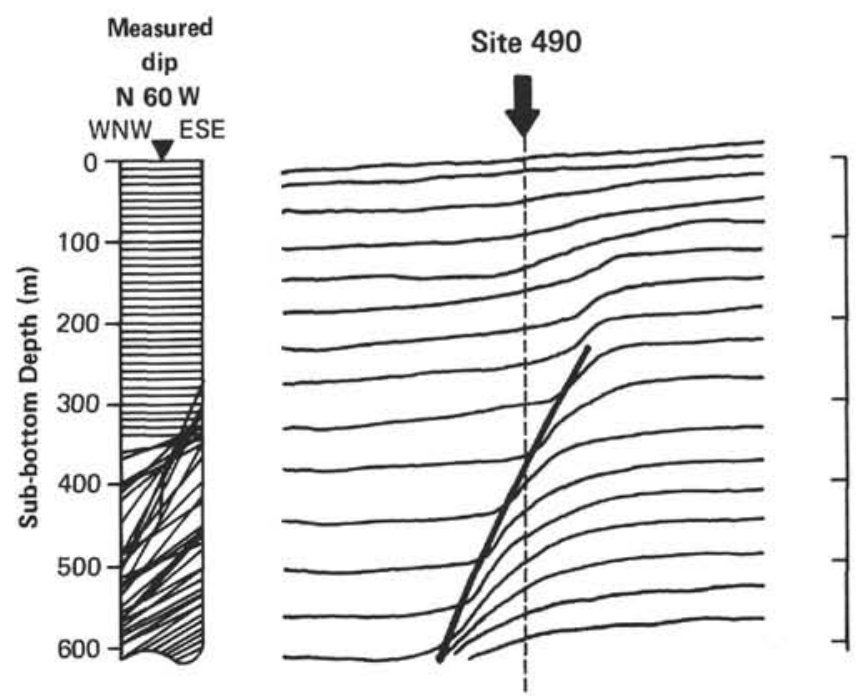

Figure 25. Variations with sub-bottom depth in dip and dip direction of bedding plane, Site 490 , upper slope.

The difference is probably associated with drag folding and thrusting at shallow subdepth.

\section{Upper Slope}

Many faults with slickensided surfaces were observed in the lower part of the sediments at Site 490, ranging in subdepth from 400 to 430 meters. Three sets of conjugate faults were oriented and stress fields estimated (Table 15). The maximum compressional axis is almost vertical and the minimum compressional axis is horizontal in an east-west direction. The direction of the minimum compressional axis is concordant with the dip direction of bedding plane (Fig. 22). The steep dip of bedding plane in this interval could have been caused by a drag fold associated with a dipping normal fault, which was formed in the east-west minimum compressional stress field. The westward slope of submarine topography can be explained as a result of this tectonic movement (Fig. 25).

At Site 493, several conjugate fault sets and fracture zones were observed in the lower part of the cored section between 560 and 580 meters subdepth. Two stress fields were determined from the conjugate sets (Table 15). The minimum compressional axis is horizontal in a northwest-southeast direction, which agrees with the predominant dip directions of bedding planes (Fig. 22).

The stress field in the upper slope is uniform with the maximum compressional axis vertical, the intermediate axis perpendicular to the trench axis, and the minimum compressional axis parallel to the trench axis. This means that the horizontal compressional stress is smaller than the vertical compressional stress, corresponding to the overburden, and the normal faults trend perpendicular to the trench axis (parallel to the horizontal compressional axis) on the upper slope.

\section{CONCLUSIONS}

The paleomagnetic studies of sediments and basement rocks from the Middle America Trench off Mex- 
Table 14. List of orientation of conjugate fault planes and stress field, lower slope.

\begin{tabular}{|c|c|c|c|c|c|c|}
\hline & & $\begin{array}{l}\text { Sub-bottom } \\
\text { Depth }\end{array}$ & Orientation of & & Stress Field & \\
\hline Hole & Core/Section & & Conjugate Fault Planes & $\sigma_{1}$ & $\sigma_{2}$ & $\sigma_{3}$ \\
\hline \multirow[t]{5}{*}{491} & $49-3,50 \mathrm{~cm}$ & 441.00 & $\begin{array}{l}\text { N } 50 \mathrm{E} 59 \mathrm{E} \\
\mathrm{N} 3 \mathrm{~W} 48 \mathrm{E}\end{array}$ & N63W38D & S88E48D & $\mathrm{S} 17 \mathrm{~W} 12 \mathrm{D}$ \\
\hline & $57-3,31 \mathrm{~cm}$ & 516.81 & $\begin{array}{l}\text { N 71E 44N } \\
\text { N 9E 56E } \\
\text { N 4E 40W }\end{array}$ & S46W60D & N33E30D & S53E5D \\
\hline & $57-3,146 \mathrm{~cm}$ & 517.96 & $\left\{\begin{array}{llll}\mathrm{N} & 61 \mathrm{~W} & 37 \mathrm{E} \\
\mathrm{N} & 7 \mathrm{~W} & 28 \mathrm{E}\end{array}\right.$ & S37E77D & N1IW10D & S79W5D \\
\hline & $58-1,13 \mathrm{~cm}$ & 523.13 & 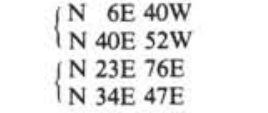 & N6E75D & S22W13D & S69E3D \\
\hline & $58-1,89 \mathrm{~cm}$ & 523.89 & 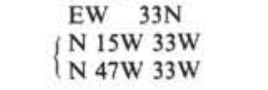 & S69E72D & N52W19D & S27W1D \\
\hline 488 & $42-2,16 \mathrm{~cm}$ & 382.66 & $\begin{array}{l}\text { N } 54 \mathrm{~W} 68 \mathrm{~N} \\
\text { N } 50 \mathrm{~W} 61 \mathrm{~S}\end{array}$ & S53E74D & N48W15D & N42E3D \\
\hline
\end{tabular}

Note: $\sigma_{1}=$ maximum compressional axis, $\sigma_{2}=$ intermediate axis, $\sigma_{3}=$ minimum compressional or tensional axis, $\{=$ curved fault plane.

Table 15. List of orientation of conjugate fault planes and stress field, upper slope.

\begin{tabular}{|c|c|c|c|c|c|c|}
\hline \multirow[b]{2}{*}{ Site } & \multirow[b]{2}{*}{ Core/Section } & \multirow{2}{*}{$\begin{array}{l}\text { Sub-bottom } \\
\text { Depth } \\
\text { (m) }\end{array}$} & \multirow{2}{*}{$\begin{array}{c}\text { Orientation of } \\
\text { Conjugate Fault Planes }\end{array}$} & \multicolumn{3}{|c|}{ Stress Field } \\
\hline & & & & $\sigma_{1}$ & $\sigma_{2}$ & $\sigma_{3}$ \\
\hline \multirow[t]{3}{*}{493} & $48-1,80 \mathrm{~cm}$ & 557.80 & $\begin{array}{l}\text { N } 67 \mathrm{E} 27 \mathrm{~N} \\
\mathrm{~N} 18 \mathrm{E} 58 \mathrm{E}\end{array}$ & S77W64D & N30E18D & S54E17D \\
\hline & $48-1,90 \mathrm{~cm}$ & 557.90 & $\begin{array}{l}N \text { 48E 75N } \\
N \text { 70E 66S } \\
N \text { SE 71W }\end{array}$ & N64E61D & S45W28D & N32W5D \\
\hline & $44-2,125 \mathrm{~cm}$ & 401.25 & $\begin{array}{l}\text { (N52W69D) } \\
\text { N 10E 52EE } \\
\text { (N87E54D) } \\
\text { N 5E 73W }\end{array}$ & S38E72D & NIEI4D & S88W12D \\
\hline 490 & $47-1,67 \mathrm{~cm}$ & 423.17 & 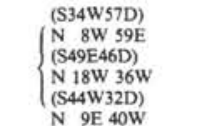 & N8W62D & S22W $25 \mathrm{D}$ & S89W8D \\
\hline & & & $\begin{array}{l}\text { (S41W23D) } \\
\text { N 38E 60E } \\
\text { (SSES2D) }\end{array}$ & N4W71D & S28W16D & S65E10D \\
\hline
\end{tabular}

Note: $\sigma_{1}=$ maximum compressional axis, $\sigma_{2}=$ intermediate axis, $\sigma_{3}=$ minimum compressional or tensional axis $\{=$ curved fault plane, ()$=$ direction of slickenside.

ico during Leg 66 reveal several characteric magnetic properties. The remanent magnetization of sediment samples can be divided into seven types on the basis of reaction to stepwise AF demagnetization. The normalreverse tests and inclination analysis indicate that the most of the remanent magnetization are reliable for paleomagnetic investigations after 150-Oe AF demagnetization.

Basalts recovered from the outer rise at Site 487 have characteristics typical of ocean basalt containing maghemitizated titanomagnetite grains and possessing stable remanent magnetization; titanium content in the magnetite is remarkably low, however. Intensity of remanent magnetization in metamorphic and plutonic rocks recovered from the upper slope area at Sites 489 and 493 is too weak to produce the observed magnetic anomalies over the upper slope area.

Magnetostratigraphically the sedimentary sequences range in age from Recent to Early Miocene and have been classified into Epochs 1 through 21, which permits a quantitative estimate of sedimentation rate by correlation with an established geomagnetic time scale. The rate of sedimentation in the area along the Middle
America Trench decreases with distance from the trench. The evolution of the sedimentation rate, sedimentary facies, and changes in magnetic mineral content indicate that the initiation of subduction and accretion under the lower slope area occurred about $10 \mathrm{Ma}$.

Orientations of bedding and fault planes are determined by paleomagnetic direction. On the lower slope, the bedding planes dip landward (upslope). On the upper slope, the bedding planes dip downslope. Calculated stress field from the conjugate fault directions are consistent with the direction of plate convergence, the minimum compressional axis or tensional axis parallel to the Middle America Trench.

\section{ACKNOWLEDGMENTS}

I am grateful to Hisao Nakagawa of Tohoku University, Kazuo Kobayashi of Tohyo University, Tsunemasa Saito of Yamagata University, and Asahiko Taira of Kochi University for helpful discussions and constructive criticism. I also thank Isao Hino of Tohoku University for preparing the polished sections and thin sections of basement rocks for optical observation and Masato Koyama of Shizuoka University for assistance in shore-based laboratory measurements.

\section{REFERENCES}

Akimoto, S., 1962. J. Phys. Soc. Jpn., 17(B-1):706.

Ishihara, S., 1977. The magnetite-series and ilmenite-series granitic rocks. Mining Geol., 27:293-305.

Johnson, H. P., 1979. Magnetization of the oceanic crust. Rev. Geophys. Space Phys., 17:215-226.

Minster, J. B., and Jordan, T. H., 1978. Present-day plate motions. J. Geophys. Res., 83:5331-5354.

Niitsuma, N., 1977. Remanent magnetization of slumped marine sedimentary rocks. Rock Magn. Paleogeophys., 4:44-52.

Ryan, W. B. F., Cita, M. B., Rowson, M. D., et al., 1974. A paleomagnetic assignment to Neogene stage boundaries and the development of isochronous datum planes between the Mediterranean, the Pacific and Indian oceans in order to investigate the response of the world ocean of the Mediterranean "salinity crisis." Riv. Ital. Pal., 80:631-638.

Shipley, T. H., McMillen, K. J., Watkins, J. S., et al., 1980. Continental margin of Guerrero and Oaxaca, Mexico. Mar. Geol., $35: 65-82$.

Yaskawa, K., Nakajima, T., Kawai, N., et al., 1973. Palaeomagnetism of a core from Lake Biwa (1). J. Geomagn. Geolelectr., $25: 447-474$. 


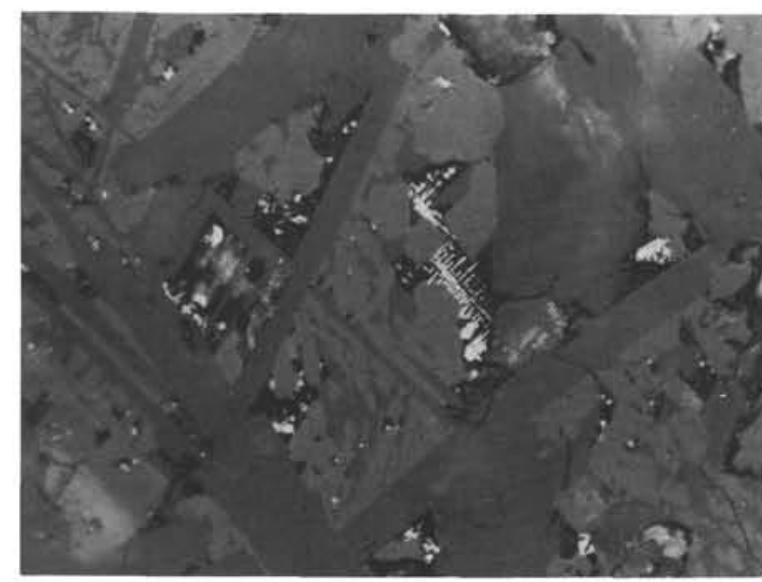

1

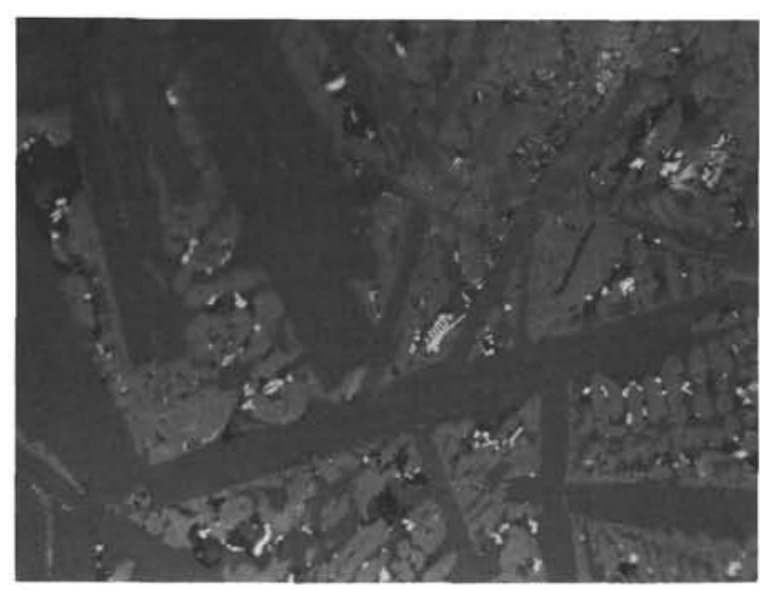

2

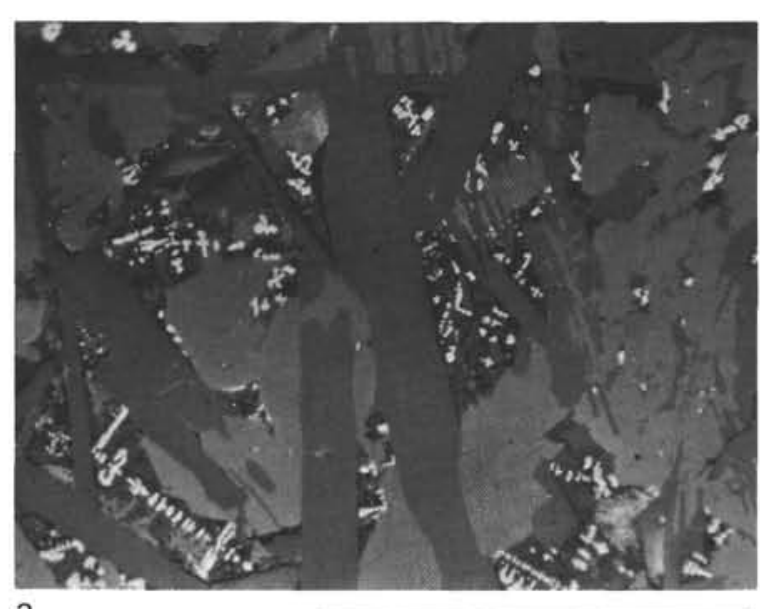

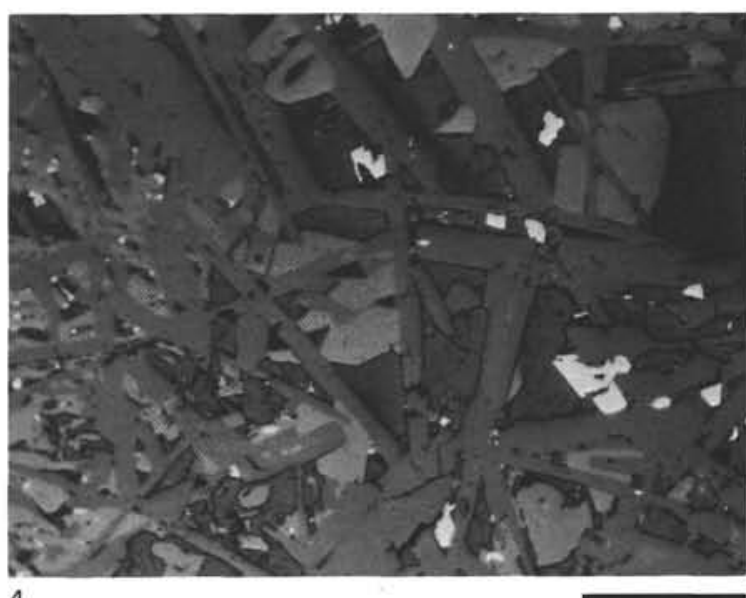

4

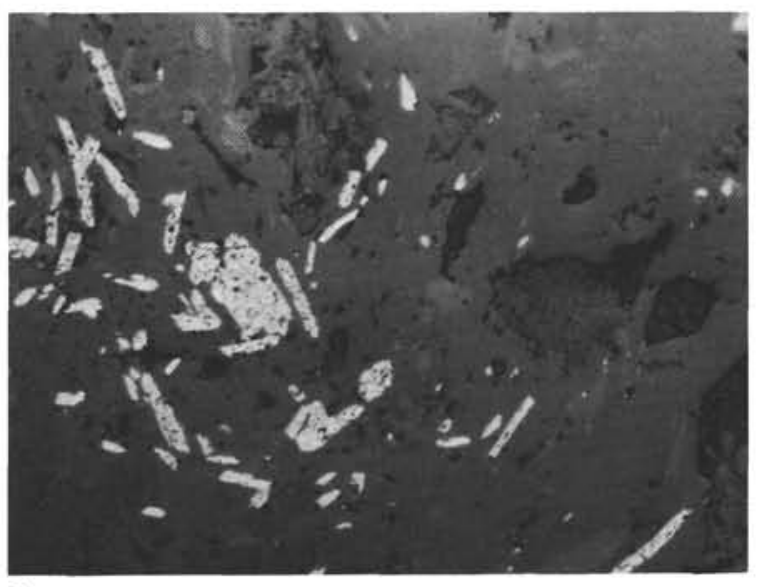

5

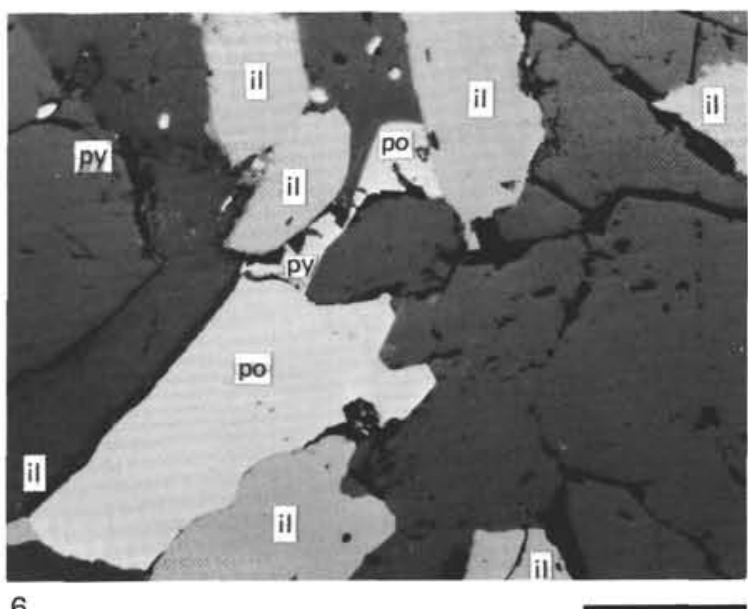

6

Plate 1. Reflective micrographs of basement rocks in the outer rise and upper slope of the Middle America Trench area off Mexico (scale bar $=100$ $\mu \mathrm{m})$. 1. Skeletal maghemitizated magnetite in abyssal basalt, Section 487-20-1 (Piece 2, $172.10 \mathrm{~m}$ sub-bottom). 2. Skeletal maghemitizated magnetite in ocean basalt, Section 487-20-1 (Piece 13, $172.94 \mathrm{~m}$ sub-bottom). 3. Skeletal maghemitizated magnetite in ocean basalt, Section 487-20-1 (Piece 17, $173.19 \mathrm{~m}$ in sub-bottom). 4. Cubic and skeletal maghemitizated magnetite in ocean basalt, Section 487-20-1 (Piece 17, $173.19 \mathrm{~m}$ in sub-bottom). 5. Lath-shaped rutile in metamorphic rock, Section 489A-34-1 (Piece 6, $318.06 \mathrm{~m}$ in sub-bottom). 6. Ilmenite (il), pyrrhotite (po), and pyrite (py) with granular shape in plutonic rock, Section 493-59-2 (Piece 9, 658.75 m sub-bottom). 